\author{
UNIVERSIDADE DE SÃO PAULO \\ INSTITUTO DE PSICOLOGIA \\ DEPARTAMENTO DE NEUROCIÊNCIAS E COMPORTAMENTO
}

SANDRA MARIA ALVARENGA ANTI POMPEU

\title{
Elaboração e aplicação
}

do teste de divisão de atenção em tarefas funcionais

SÃO PAULO 


\section{Elaboração e aplicação}

\section{do teste de divisão de atenção em tarefas funcionais}

Dissertação apresentada ao Instituto de Psicologia da Universidade de São Paulo para obtenção do título de Mestre em Psicologia.

Área de concentração:

Neurociências e Comportamento

Orientadora:

Profa. Dra. Maria Elisa Pimentel Piemonte

SÃO PAULO 
Autorizo a reprodução e divulgação total ou parcial deste trabalho, por qualquer meio convencional ou eletrônico, para fins de pesquisa, desde que citada a fonte.

Catalogação da publicação

Serviço de Biblioteca e Documentação

Instituto de Psicologia da Universidade de São Paulo 
Nome: POMPEU, Sandra Maria Alvarenga Anti

Título: Elaboração e aplicação do teste de divisão de atenção em tarefas funcionais

Dissertação apresentada ao Instituto de Psicologia da Universidade de São Paulo para obtenção do título de Mestre em Psicologia.

Aprovado em:

Banca Examinadora

Prof. Dr. Instituição:

Julgamento: Assinatura:

Prof. Dr. Instituição:

Julgamento: Assinatura:

Prof. Dr. Instituição:

Julgamento: Assinatura:

Prof. Dr. Instituição:

Julgamento: Assinatura: 


\section{AGRADECIMENTOS}

A Profa. Dra. Maria Elisa, que acompanho e admiro desde a graduação, pela orientação e confiança.

A toda minha família, pelo constante incentivo, apoio e suporte.

Ao meu marido José Eduardo Pompeu, meu maior incentivador, companheiro e exemplo profissional.

A minha filha Bianca, que tantas vezes dormiu ao meu lado enquanto eu trabalhava no computador sem nunca reclamar.

A todos meus colegas de trabalho, em especial a Alessandra Palazzin pela amizade e conforto nos momentos mais difíceis.

A todos os participantes deste estudo. 


\section{RESUMO}

POMPEU, S.M.A.A. (2013). Elaboração e Aplicação do Teste de Divisão de Atenção em Tarefas Funcionais. Dissertação de Mestrado, Instituto de Psicologia, Universidade de São Paulo, São Paulo.

O objetivo do presente estudo foi elaborar um teste de divisão de atenção envolvendo tarefas funcionais da marcha, controle postural estático e dinâmico e controle manual e aplicar este teste em adultos jovens, idosos e indivíduos com DP em estágio iniciais e moderados de evolução da doença. Trata-se de um estudo transversal realizado na Associação Brasil Parkinson, São Paulo. Participaram do estudo 20 adultos jovens, 17 idosos e 47 indivíduos com diagnóstico de DP, 16 no estágio I na escala de estadiamento de Hoehn Yahr, 15 no estágio II e 16 no estágio III. O desempenho dos 84 participantes foi verificado durante a execução de quatro tarefas denominadas de funcionais: marcha, controle postural dinâmico, controle postural estático e uma de controle manual. Também foi analisado o desempenho de oito tarefas específicas, quatro de características motoras e quatro cognitivas. As doze tarefas, funcionais e específicas, foram avaliadas quando executadas isoladamente (condição chamada de tarefa simples (TS), e também em dupla tarefa, quando uma tarefa funcional foi executada simultaneamente a uma tarefa específica motora (dupla tarefa motora (DTM) e também associada a uma tarefa específica cognitiva (dupla tarefa cognitiva (DTC). Nas condições de dupla tarefa o desempenho de ambas as tarefas foi mensurado. A análise estatística foi realizada por meio de ANOVA de medidas repetidas e pós hoc teste de Tukey para a verificação de possíveis diferenças de desempenho entre jovens e idosos, idosos e pacientes com DP, e entre pacientes nos diferentes estágios da DP. Na comparação entre jovens e idosos, as quatro tarefas funcionais propostas mostraram-se sensíveis para identificar as diferenças associadas ao processo de envelhecimento, em especial a marcha e a tarefa de controle manual. Já entre idosos e indivíduos com DP, a tarefa mais sensível para identificar diferenças foi a de controle manual, onde os indivíduos com DP apresentaram desempenho inferior em todas as condições. Na comparação entre os indivíduos com DP no estágio I, II e III a menos sensível foi a de controle manual, que não identificou prejuízos entre os estágios iniciais da doença (I e II). Com intuito de verificar o impacto global da associação de tarefas, foi analisada a 
soma dos prejuízos da divisão da atenção para a tarefa funcional e a tarefa específica motora e cognitiva, chamado de custo total motor e custo total cognitivo. Observamos diferentes padrões de resultados: a combinação entre a tarefa de controle postural estático e uma tarefa motora foi a condição mais sensível para identificar as alterações do processo de envelhecimento na habilidade de dividir a atenção, entre idosos e indivíduos com DP nenhuma das condições foi capaz de identificar diferenças e entre os estágios da DP, o custo da divisão da atenção entre a tarefa de controle postural estático e uma tarefa cognitiva foi a condição mais sensível. Conclui-se que o teste de avaliação em divisão de atenção proposta mostrou ser um instrumento de boa aplicabilidade, baixo custo e sensível para a identificação de alterações decorrentes do processo de envelhecimento, prejuízos associados à DP e sua progressão.

Palavras Chave: atenção, desempenho motor, idosos, doença de Parkinson. 


\begin{abstract}
POMPEU, SMAA. (2013). Preparation and application of attention division test in functional tasks. Dissertação de Mestrado, Instituto de Psicologia, Universidade de São Paulo, São Paulo.
\end{abstract}

The aim of this study was to develop a testing division of tasks involving attention functional gait, postural control static and dynamic control manual and apply this test in young adults, seniors and individuals with PD in early and moderate stage of the disease. This is a cross-sectional study in Associação Brasil Parkinson, São Paulo. Study participants were 20 young adults, 17 seniors and 47 individuals diagnosed with PD, 16 in stage I in the scale of Hoehn Yahr staging, 15 in stage II, 16 stage III. The performance of 84 participants was observed during the execution of four functional tasks named: gait, postural control, dynamic, static postural control and manual control. We also analyzed the performance of eight specific tasks, four motor and four cognitive characteristics. The twelve tasks, and specific functional, were evaluated when performed alone (called simple task (ST), and also in dual task, when a functional task was performed simultaneously with a specific motor task (dual motor task (DMT) and also associated with a specific cognitive task (dual cognitive task (DCT). Under the conditions of dual task performance of both tasks was measured. Statistical analysis was performed using repeated measures ANOVA and post hoc Tukey test for checking possible performance differences between young and old, elderly and PD patients, and between patients in different stages of PD. Comparing young and old, the four functional tasks proposals were sensitive to identify differences associated with aging, particularly walking and manual control task. Among elderly and individuals with PD, the most sensitive task was to identify differences in manual control, where individuals with PD showed poorer performance in all conditions. Comparing individuals with DP in stage I, II and III was the least sensitive to manual control, which did not identify losses from the early stages of the disease (I and II). Aiming to verify the impact of the global association task, we analyzed the sum of losses of the division of attention to the task and the task specific functional motor and cognitive, called the total cost of motor and cognitive total cost. observed different patterns of results: the combination of static postural control task and a motor task was the most sensitive condition to identify the 
changes of aging on the ability to divide attention among elderly individuals with PD and none of the conditions was able to identify and differences between stages of PD, the cost of the division of attention between the task of static postural control and a cognitive task was the most sensitive condition. As conclusion that the assessment test in proposed division of attention shown to be an instrument of good applicability, inexpensive and sensitive for identifying changes resulting from the aging process, and losses associated with DP its progression.

Keywords: attention, aging, Parkinson's disease. 


\section{LISTA DE FIGURAS}

Figura-1 Contador Manual Mecânico 60

Figura-2 Contador Manual Digital 61

Figura-3 Tarefa Específica Motora Utilizando um Step 62

Figura-4 Desempenho de Marcha Comparando Idosos e Jovens 78

Figura-5 Desempenho do Controle Postural Dinâmico Comparando Idosos e Jovens

Figura-6 Desempenho do Controle Manual Comparando Idosos e Jovens 81

Figura-7 Desempenho do Controle Postural Estático Comparando Idosos e Jovens.

Figura-8 Desempenho de Marcha Comparando Indivíduos com DP e Idosos... 85

Figura-9 Desempenho do Controle Postural Dinâmico Comparando Indivíduos com DP e Idosos 86

Figura-10 Desempenho do Controle Manual Comparando Indivíduos com DP e Idosos 87

Figura-11 Desempenho do Controle Postural Estático Comparando Indivíduos com DP e Idosos

Figura-12 Desempenho de Marcha em Indivíduos com DP 91

Figura-13 Desempenho do Controle Postural Dinâmico em Indivíduos com DP 93

Figura-14 Desempenho do Controle Manual em Indivíduos com DP 94

Figura-15 Desempenho do Controle Postural Estático em Indivíduos com DP ......95 Figura-16 Custo total das Duplas Tarefas Motoras Comparando Idosos e Jovens _.99 Figura-17 Custo Total das Duplas Tarefas Cognitivas Comparando Idosos e Jovens 
Figura-18 Custo Total das Duplas Tarefas Motoras Comparando Indivíduos com DP e Idosos 103

Figura-19 Custo Total das Duplas Tarefas Cognitivas Comparando Indivíduos com DP e Idosos 104

Figura-20 Custo Total das Duplas Tarefas Motoras Comparando os Diferentes Estágios da DP 107 Figura-21 Custo Total das Duplas Tarefas Cognitivas Comparando Diferentes Estágios da DP 109 


\section{LISTA DE TABELAS}

Tabela-1. Estudos examinando a DT na marcha de indivíduos idosos e indivíduos com DP

Tabela-2. Estudos examinando a DT no controle postural de idosos e indivíduos com DP

Tabela-3. Estudos examinando a DT na função manual de idosos e indivíduos com DP 48

Tabela-4. Tarefas funcionais 58

Tabela-5. Tarefas específicas motoras 63

Tabela-6. Tarefas específicas cognitivas 66

Tabela-7. Combinações de tarefas funcionais e específicas motoras e cognitivas 69

Tabela-8. Medida de desempenho das tarefas funcionais 72

Tabela-9. Medidas de desempenho das tarefas específicas motoras 72

Tabela-10. Medidas de desempenho das tarefas específicas cognitivas 73

Tabela-11. Dados Demográficos e Características dos Pacientes 76 


\section{LISTA DE ABREVIATURAS}

ANOVA

C Manual

CP Dinâmico

CP Estático

Desv Pad

DP

DP-I

DP-II

DP-III

DT

DTC

DTM

FE

GDS-15

HY

ID

JV

MEEM

TS
Análise de

Controle Manual

Controle Postural Dinâmico

Controle Postural Estático

Desvio Padrão

Doença de Parkinson

Doença de Parkinson Estágio I

Doença de Parkinson Estágio II

Doença deParkinson Estágio III

Dupla Tarefa

Dupla Tarefa Cognitiva

Dupla Tarefa Motora

Função Executiva

Escala de Depressão Geriátrica - 15

Hoenh Yahr

Idosos

Jovens

Mini-Exame do Estado Mental

Tarefa Simples 


\section{SUMÁRIO}

1. INTRODUÇÃO

2. REVISÃO DE LITERATURA 20

2.1 A função executiva 20

$2.2 \mathrm{O}$ controle da atenção $\quad 24$

2.3 A dupla tarefa

2.3.1 Custos gerados pela DT 28

2.3.3 O desempenho da DT em indivíduos idosos _ 32

2.3.4 O desempenho da DT em pacientes com doença de Parkinson _ _ 34

2.4 A importância da avaliação em DT na prática da fisioterapia $\ldots \ldots \ldots \ldots . . . . . . . . . . . . . . . . .39$

3 OBJETIVOS

3.1 Objetivo geral

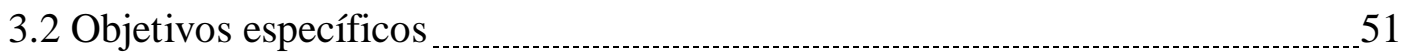

4 MATERIAIS E MÉTODOS 52

4.1 Tipo de estudo

4.2 Casuística $\quad 52$

4.2.1 Critérios de inclusão

4.2.2 Critérios de exclusão

4.3 Local

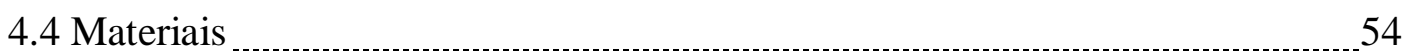

4.5 Procedimentos 54

4.5.1 Tarefas funcionais 55

4.5.1.1 Tarefa de marcha 55 
4.5.1.2 Tarefa de controle postural dinâmico

4.5.1.3 Tarefa de controle manual

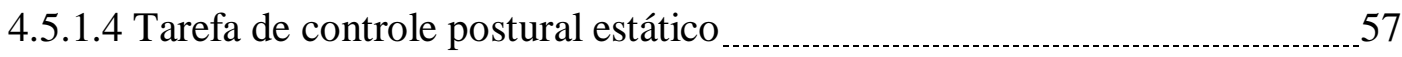

4.5.2 Tarefas específicas _._. 58

4.5.2.1 Tarefas específicas motoras 59

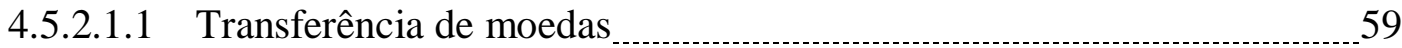

4.5.2.1.2 Pressionar um contador manual mecânico $\quad 59$

4.5.2.1.3 Pressionar um contador manual digital _ 60

4.5.2.1.4 Step 61

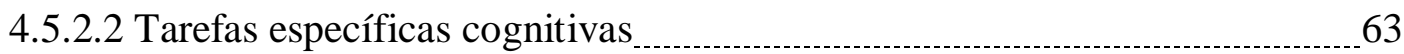

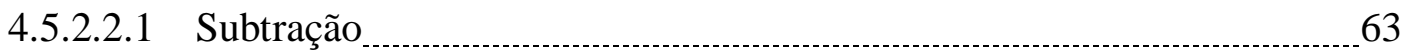

4.5.2.2.2 Fluência verbal

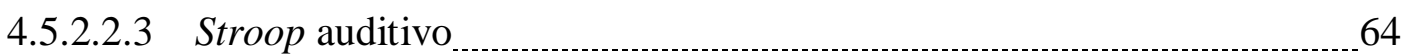

4.5.2.2.4 Stroop auditivo modificado $\quad 65$

4.5.2.3 Avaliação em condição de Tarefa Simples

4.5.2.4 Avaliação em condição de Dupla Tarefa

4.6 Análise de resultados

5 RESULTADOS 75

5.1 Dados demográficos e características dos indivíduos _... 75

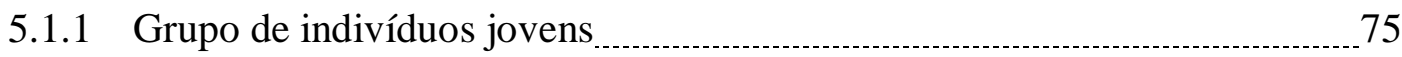

5.1.2 Grupo de idosos 75

5.1.3 Grupo de indivíduos com DP 75

$5.2 \quad$ Aplicabilidade do teste 76

5.3 Análise da sensibilidade das tarefas funcionais propostas _....................... 77

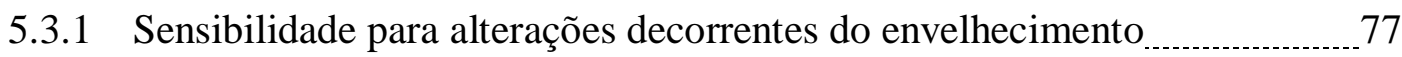


5.3.2 Sensibilidade para alterações decorrentes da DP

5.3.3 Sensibilidade para alterações decorrentes da progressão da DP 90

5.4 Análise da sensibilidade das condições propostas 97

5.4.1 Análise da sensibilidade das condições propostas para as alterações decorrentes do envelhecimento 98

5.4.2 Análise da sensibilidade das condições propostas para as alterações associadas à DP 102

5.4.3 Análise da sensibilidade das condições propostas para as alterações associadas à progressão da DP 106

6 DISCUSSÃO 111

7 CONCLUSÃO 116

REFERÊNCIAS 117

ANEXOS 125 


\section{INTRODUÇÃO}

A alta complexidade de comportamentos que o ser humano é capaz de desempenhar é especialmente associada a operações envolvendo a função executiva (FE). A FE refere-se a uma variedade de processos envolvidos no planejamento, monitoramento e produção de comportamentos complexos orientados para um objetivo, por meio da formulação de planos de ação eficientes, essenciais para a adaptação à vida cotidiana (FRASER; LI; PENHUNE, 2010; BAKOS et al, 2008; VAN IERSEL et al., 2008; COPPIN et al., 2006; SZAMEITAT et al., 2002).

Um importante papel da FE diz respeito a seu envolvimento com operações que disponibilizam, deslocam e distribuem adequadamente recursos atentivos. Conceitualmente, atenção é um mecanismo que possibilita ao indivíduo processar informações ou ações relevantes de forma mais intensa, rápida e precisa enquanto "ignora" outras entradas irrelevantes (YOGEV; HAUSDORFF; GILADI, 2008; MCDOWD, 2007; ROCHESTER et al., 2004).

Uma situação complexa que envolve a manipulação da atenção e consequentemente da FE é a execução de duas tarefas concorrentes, denominada como desempenho simultâneo ou dupla tarefa (DT). A condição de DT é considerada um comportamento motor complexo, pois depende da habilidade de dividir a atenção entre mais de uma tarefa ao mesmo tempo, indicando um alto poder de processamento do sistema nervoso. Neste contexto, a FE agiria coordenando a "distribuição" da atenção para o desempenho de diferentes tarefas, permitindo com que ocorra a divisão da atenção entre elas quando necessário e minimizando a interferência gerada (MCCULLOCH et al. 2010; MCKINLAY et al., 2009; YOGEV; HAUSDORFF; GILADI, 2008; NEWMAN; KELLER; JUST, 2007; BLOEM et al., 2001).

O estudo de situações de DT vem aumentado nos últimos anos, já que várias atividades frequentes e rotineiras exigem a habilidade do indivíduo em dividir a atenção, o que constitui um pré-requisito para uma vida funcional, independente e segura. Dificuldades no desempenho de DT são associadas a alto risco de queda e limitação funcional, especialmente para a população idosa e para pacientes com doenças neurológicas. Academicamente, o paradigma da DT permite a análise dos processos e 
estruturas encefálicas envolvidos na aquisição da automaticidade e na manipulação de recursos atentivos (MCCULLOCH, 2007; YOGEV et al., 2005;)

O processo de envelhecimento fisiológico é associado a severo declínio da FE, incluindo prejuízos na flexibilidade mental, atenção e dificuldades no gerenciamento de situações de DT. Alguns autores discutem que o envelhecimento induz a deficiências na flexibilização da alocação de recursos atentivos em resposta a demandas dinâmicas, resultando em severas limitações funcionais além de alto risco de queda nestas condições (FRASER; LI; PENHUNE, 2010; PRAKASH et al., 2009; BAKOS et, al., 2008; BOCK, 2008; COPPIN et al., 2006; HUXHOLD et al., 2006).

Quando o processo de envelhecimento é alterado pela presença de doenças que afetam o sistema nervoso, as deficiências de desempenho em DT podem se acentuar. A Doença de Parkinson (DP) caracterizada por prejuízos motores e cognitivos decorrentes da depleção de dopamina nos circuitos internos dos núcleos da base é uma das doenças que mais afetam o desempenho nessa condição.

Diversos estudos mostram evidências da perda de desempenho de pacientes com DP em situações de DT, na marcha (GILADI; HAUSDORFF, 2009; BAKER; ROCHESTER; NIEUWBOER, 2007; DUBOST et al., 2006; CANNING et al., 2005; GALLETY; BRAUER, 2005; ROCHESTER et al., 2005; YOGEV et al., 2005; CAMPBELL, 2003; O’SHEA; MORRIS; IANSEK, 2002; PLOTNIK, 2010), no equilíbrio (HOLMES et al., 2010; LAJOIE; GALLAGHER, 2004; MARCHESE et al., 2003; ASHBURN, 2001; MORRIS et al., 2000), em atividades manuais (PRADLAM et al., 2010; PROUD; MORRIS, 2010; WU; HALLET, 2008; BROWN e JAHANSHAHI, 1998; HORSTINK et al, 1990; BENECKE et al 1986;) e na mobilidade funcional (KELLY, 2012; ROCHESTER, 2008; COPPIN, 2006). As hipóteses citadas nestes estudos para a dificuldade em desempenhar a DT em pacientes com DP apontam para deficiência da função executiva, redução de recursos atentivos disponíveis (ROCHESTER et al. 2004; BOUND et al, 2000; YOGEV, 2008), dificuldade em deslocar estes recursos entre diferentes tarefas (ZGALJARDIC et.al, 2003; ZGALJARDIC et.al, 2006; ROCHESTER et al. 2004; BOND e MORRIS, 2000) e em orientar a atenção entre estímulos aprendidos e estímulos novos, além do declínio do controle automático dos movimentos o que exige um maior controle cortical até mesmo em atividades simples (ROCHESTER et al. 2004; BOUND et al, 2000; YOGEV et al, 2008). 
Apesar dos diversos estudos sobre o assunto em idosos e pacientes com DP, a forma de avaliação em DT é bastante heterogênea. Fatores importantes como a padronização das tarefas concorrentes, a duração do teste, o controle do desempenho não só da tarefa motora, como também da concorrente, frequentemente são ignorados.

Ainda não há proposta de uma forma padronizada para a avaliação do desempenho em condições de DT. Isso dificulta a comparação de estudos sobre a caracterização do perfil, possíveis déficits e sua progressão nestes pacientes, prejudicando também a comparação entre os efeitos de diferentes formas de intervenções, farmacológica, cirúrgica ou fisioterápica. Além disso, a ausência de protocolos padronizados e exequíveis dificultam que a avaliação dessa habilidade seja incorporada na pratica clinica.

Particularmente para a prática da fisioterapia, cujo objetivo final é atingir a máxima capacidade funcional do paciente, a avaliação em DT é fundamental, pois permite a análise de ações de forma integrada ao seu contexto e propósito, como (1) a identificação de diferentes perfis de deficiências entre os indivíduos, (2) a fundamentação necessária para a elaboração de estratégias terapêuticas específicas e, (3) a análise dos efeitos dessas novas abordagens sobre essa deficiência, bem como a comparação entre diferentes abordagens.

Assim, objetivo deste estudo foi elaborar e testar um teste de divisão de atenção em adultos jovens, idosos e pacientes com DP em estágios iniciais e moderados de evolução da doença.

Para a elaboração do teste, os seguintes pontos foram levantados: (1) a viabilidade de aplicação clínica, o que permitiria que o teste fosse utilizado por pesquisadores e clínicos, (2) a avaliação da marcha, do controle postural estático e dinâmico e do controle manual, o que possibilitaria a comparação dos efeitos da divisão de atenção sobre diferentes tarefas no mesmo individuo e entre populações, (3) o efeito da adição de diferentes tarefas motoras e cognitivas, o que permitiria a comparação dos custos decorrentes da divisão de atenção entre tarefas da mesma natureza ou não, (4) a padronização do tempo de duração dos testes, o que minimizaria a influência de outros fatores, como a memória operacional, no desempenho em DT, (5) a padronização do 
registro do desempenho de todas as tarefas envolvidas, testadas de forma isolada ou em DT, o que permitiria a quantificação uniforme do desempenho.

Após a elaboração, a sua aplicabilidade foi testada em três diferentes populações, incluindo adultos jovens, idosos e idosos com DP em estágios iniciais e moderados, o que permitiu verificar a sensibilidade do teste para as perdas associadas ao processo de envelhecimento, para a DP e sua progressão.

Nossa hipótese é que o teste seja exequível, sensível ao processo de envelhecimento, à DP e sua progressão.

Confirmada essa hipótese, o trabalho contribuirá tanto para a área de pesquisa sobre os mecanismos envolvidos no gerenciamento de duas tarefas simultâneas e os perfis de comprometimento dessa habilidade em diferentes populações, e para a área clinica, onde permitira a avaliação dessa habilidade de forma rápida e barata, e a análise dos efeitos de diferentes abordagens terapêuticas sobre a mesma. 


\section{REVISÃO DE LITERATURA}

\subsection{A função executiva}

O cotidiano de um indivíduo requer a habilidade de administrar várias atividades diárias visando um objetivo final, como por exemplo, acordar toda manhã, vestir-se, alimentar-se e ir trabalhar com intuito de adquirir recursos financeiros. Porém no caminho, situações inesperadas podem ocorrer fazendo com que indivíduo reformule seu planejamento inicial e tenha que resolver da melhor maneira possível estas situações de conflito. Comportamentos como estes permitem a interação com o mundo de uma forma concreta e objetiva, através da formulação de planos de ação adequados a situação atual que também sejam flexíveis e adaptativos, para moldar- e assegurar o sucesso das ações em andamento. Estas operações são denominadas em conjunto como funções executivas (FE) (FRASER; LI; PENHUNE, 2010; BAKOS et al., 2008; VAN IERSEL et al., 2008).

A FE refere-se, portanto a uma variedade de processos cognitivos que usam e modificam informações de várias regiões corticais para planejar, modular e produzir comportamentos orientados para um objetivo, além de controlar a disponibilidade e flexibilidade de recursos atentivos. Estes processos são indispensáveis para a execução de atividades de vida diária de forma independente e efetiva (MCKINLAY et al., 2009; YOGEV; HAUSDORFF; GILADI, 2008).

Segundo Yogev, Hausdorff e Giladi (2008), a FE engloba vários componentes, entre eles a volição, definida como a capacidade de executar um comportamento intencional e a formulação de objetivos para o início de uma atividade; o planejamento, ou seja, a identificação e organização dos passos necessários para alcançar um objetivo através da formulação de um plano de ação baseado em experiências prévias que possa ser moldado à situação atual e a análise de alternativas; monitoramento da resposta, que possibilita ao indivíduo comparar a ação em curso com o plano interno planejado,que além de facilitar a detecção de erros, possibilita 
ajustes no comportamento e a tomada de novas decisões; controle atentivo e duplatarefa, que refere-se à habilidade de alocar a atenção entre tarefas executadas simultaneamente.

Estes componentes da FE estão profundamente imbricados no comportamento do ser humano, uma vez que a vida real requer a todo o momento o processamento executivo para distinção de objetivos, soluções, início e término de tarefas nem sempre bem definidos.

Do ponto de vista anatômico, acredita-se que o lobo frontal, mais especificamente o córtex pré-frontal dorsolateral (CPFDL) é uma importante área relacionada a aspectos cognitivos da FE. Esta região apresenta extensas comunicações com praticamente todas as áreas corticais e subcorticais, incluindo os núcleos da base, cerebelo e núcleos do tronco encefálico. (DRAG et al., 2009; YOGEV, HAUSDORFF e GILADI, 2008; OWEN, 2004).

Portanto, apesar da FE não ser definida anatomicamente, o lobo frontal é uma das regiões mais importantes, porém não a única, envolvida com o processamento destas informações e operações. Esta noção embasa o caráter integrativo dos processos relacionados com a FE, compreendendo uma rede abrangente de conexões cerebrais (STUSS; ALEXANDER, 2000).

Prakash et al. (2009) investigaram as regiões cerebrais relacionadas ao controle atentivo durante o Stroop Test. Neste teste o sujeito analisado deve dizer a cor com a qual as palavras estão escritas, porém estas palavras são nomes de cores. Portanto existem situações congruentes (a palavra amarelo escrito em amarelo) e incongruentes (a palavra amarelo escrita em verde, por exemplo). As situações incongruentes provocam uma interferência na nomeação da cor, denominado de efeito Stroop, constituindo um teste muito utilizado para o rastreio da função cognitiva e controle atentivo. Os autores utilizaram ressonância magnética funcional para investigar as áreas cerebrais ativas durante a execução desta tarefa, observando que adultos jovens apresentaram um aumento do recrutamento de córtex pré-frontal e parietal superior nas condições incongruentes. Estes achados foram interpretados como um maior recrutamento de áreas cerebrais, especialmente do CPFDL, envolvidos na flexibilidade no deslocamento de recursos atentivos em situações de conflito, resultando em 
amplificação da ação de neurônios de áreas relacionadas ao processamento da cor e supressão de representações neuronais especializadas na identificação de palavras.

Szameitat et al. (2002) discutem que a FE capacita o ser humano a desempenhar comportamentos complexos, inclusive quando informações contraditórias ou distratoras devem ser processadas para que certo objetivo seja alcançado. Estes autores utilizaram as imagens de ressonância magnética funcional para determinar as áreas cerebrais envolvidas em comportamentos complexos envolvendo a $\mathrm{FE}$, utilizando para isto o paradigma da dupla tarefa (DT) envolvendo uma tarefa de tempo de reação. Houve aumento de ativação do CPFDL e córtex parietal superior, o que refletiria a necessidade da FE para coordenar a interferência gerada pela execução de tarefas simultâneas.

Outra importante operação relacionada a FE refere-se à memória operacional (MO) ou de trabalho; ela é descrita como um arquivamento temporário de informação on-line, utilizada para a resolução de diversas tarefas cognitivas. Acredita-se que as áreas pré-frontais armazenam temporariamente informações acessadas de outros sítios neurais, sendo mantidas neste local enquanto forem relevantes para guiar um comportamento prospectivo (HELENE; XAVIER, 2003; FUSTER, 1999).

O entendimento do que é e como atua a FE no comportamento é muito relevante para a prática fisioterápica, uma vez que incorporar um trabalho direcionado à melhora da FE dentro de uma sessão de terapia convencional pode maximizar a aquisição de habilidades. Isto pode incluir o monitoramento dos resultados de suas próprias ações, o desenvolvimento da resolução de problemas, auxiliando o paciente a detectar um problema em potencial e corrigi-lo adequadamente (STUDER , 2007). 


\subsection{O controle da atenção}

Como já citado anteriormente, a FE relaciona-se estreitamente com diversas operações envolvendo a atenção, já que um comportamento orientado para um objetivo requer a seleção de informações relevantes através da alocação de recursos. Um dos papéis da FE é de coordenar a "distribuição" da atenção para o desempenho de diferentes tarefas, permitindo com que ocorra a sua divisão entre tarefas quando necessário.(MCCULLOCH et al., 2010).

Conceitualmente, atenção é um mecanismo que possibilita ao indivíduo processar informações, pensamentos ou ações relevantes enquanto "ignora" outras entradas irrelevantes. É um termo que abrange uma série de processos relacionados à forma com a qual o organismo recebe um estímulo e como ele será processado. Também estaria relacionada com a habilidade de direcionar recursos cognitivos e seletivamente processar determinada informação de forma mais intensa, rápida e precisa (YOGEV; HAUSDORFF; GILADI, 2008; MCDOWD, 2007; ROCHESTER et al, 2004).

Segundo Yogev, Hausdorff e Giladi (2008) e McCulloch et al., (2010) a atenção pode ser descrita de acordo com seu envolvimento e a necessidade das tarefa, incluindo o foco ou seleção, sustentação, divisão e alternância. A atenção seletiva, também chamada de concentração, é a capacidade de focar-se em uma informação relevante para processamento consciente enquanto informações distraidoras são suprimidas. Já a atenção sustentada refere-se a capacidade de manter a atenção em uma tarefa ao passar do tempo. A divisão da atenção é a habilidade de executar mais de uma tarefa ao mesmo tempo, enquanto alternância é o rápido deslocamento da atenção de uma tarefa para outra.

Situações que requerem a habilidade de realizar tarefas complexas que demandam a divisão da atenção em mais de um foco são desafiadoras não só para idosos, mas também para indivíduos jovens saudáveis. A divisão de atenção indica uma situação em que o indivíduo processa mais de um tipo de informação ou realiza mais de uma ação no tempo (NEWMAN; KELLER; JUST, 2007; BLOEM et al, 2001). 
Existem três modelos sugeridos para explicar o motivo da dificuldade em tarefas de divisão de atenção: o primeiro é o de capacidade limitada de compartilhamento, ou seja, a atenção tem uma capacidade limitada em dividir seus recursos entre tarefas concorrentes de acordo com a complexidade, familiaridade e importância das ações envolvidas. De acordo com este modelo, diversas informações podem ser processadas simultaneamente caso não necessite de recursos atentivos além daqueles disponíveis. Quando os recursos disponíveis são excedidos, existem duas possíveis consequências: o desempenho simultâneo será prejudicado ou até impedido as tarefas são realizadas sequencialmente com a priorização de cada uma de forma alternada (MCDOWD, 2007).

Já a teoria do bottleneck afirma que certas operações mentais, como o processo de escolha e seleção de uma ação ou estímulo para determinada tarefa, necessitam dos mesmos mecanismos centrais de forma sequencial, o que acarretaria em um "afunilamento" em determinado momento; portanto enquanto uma resposta está sendo selecionada, o processamento de uma segunda ficaria dificultada. O terceiro modelo é chamado de "cross-talk", onde ao contrário da teoria anterior, presume que na execução concorrente de atividades similares não haveria interferência, pois o uso do mesmo circuito aumentaria sua eficiência, com consequente menor necessidade do uso de recursos atentivos (WU; HALLET, 2009; SZAMEITAT, 2002; PASHLER, 1994).

A divisão da atenção também pode ser influenciada por diversos fatores incluindo variabilidade individual, familiaridade com as duas tarefas, fadiga, ansiedade, idade e experiência na condição verificada (MCDOWD, 2007).

Ainda não há um consenso que explique melhor o processamento de informações e os mecanismos da interferência observada na DT, porém estas teorias são bastante debatidas em pesquisas sobre ações em DT (YOGEV et al., 2008). 


\subsection{A Dupla tarefa}

A execução eficiente de atividades cotidianas compreende a capacidade de realizar simultaneamente mais de uma tarefa, o que constitui um pré-requisito para uma vida funcional, independente e segura. Várias atividades frequentes e rotineiras exigem a habilidade do indivíduo em dividir a atenção, como caminhar e ao mesmo tempo procurar um objeto no bolso ou manter uma conversa no telefone celular.

Situações como esta, onde duas tarefas ocorrem concomitantemente, são denominadas de dupla tarefa (DT). Dificuldades no desempenho de DT são associadas a alto risco de queda e limitação funcional, especialmente para a população idosa e para pacientes com doenças neurológicas, razão pela qual o entendimento destas situações é de extrema importância na prática clínica do fisioterapeuta. Academicamente, o paradigma da DT permite a análise dos processos e estruturas encefálicas envolvidas na aquisição da automaticidade e na manipulação de recursos atentivos (MCCULLOCH, 2007; YOGEV et al., 2005)

Diferentes tipos de combinações de DT são possíveis:duas tarefas motoras, cognitivas ou podem incluir uma tarefa cognitiva e outra motora. Além disso, nas tarefas motoras, as tarefas podem envolver efetores completamente diferentes, por exemplo, pode haver a associação de uma ação manual com uma oculomotora, manual e verbal entre outras possibilidades (PASHLER, 1994).

Portanto, no paradigma ou metodologia da DT é realizado o estudo do desempenho de duas tarefas realizadas simultaneamente; uma das duas tarefas é definida como primária enquanto a outra é denominada secundária. Neste método, inicialmente o desempenho da tarefa primária e secundária são avaliados separadamente, isto é, em situação de tarefa simples (TS). Na DT, o desempenho da tarefa primária deve ser mantido no valor baseline enquanto verifica-se o desempenho da tarefa secundária: se o desempenho da tarefa secundária é reduzido em DT, isto pode refletir uma alta demanda atentiva direcionada à tarefa primária, sugerindo insuficiente capacidade de reservas atentivos para a realização das duas tarefas concorrentes (MCCULLOCH, 2007; NEWMAN; KELLER; JUST, 2007). 
A perda de desempenho na condição de DT em relação à TS é denominada de custo da DT, refletindo alta demanda atentivo para uma das tarefas ou para ambas. O custo da DT no desempenho da tarefa primária, na secundária ou em ambas, pode ser expresso, por exemplo, pela diminuição no número de movimentos executados em determinado tempo, aumento no número de erros até a incapacidade de completar as tarefas (MCCULLOCH, 2007).

Vários autores não têm aderido aos procedimentos experimentais descritos acima, pois o desempenho de uma ou de ambas as tarefas podem variar quando comparadas a condição de TS; esta seria uma forma de avaliar a DT de uma maneira mais próxima da realidade, pois os indivíduos frequentemente combinam tarefas necessárias para atividades corriqueiras e podem priorizar uma em relação à outra baseada na demanda.

Por exemplo, em uma situação de instabilidade postural, se o indivíduo estiver conversando no celular sobre um assunto de extrema importância pode desviar sua atenção para este processo cognitivo em detrimento do controle postural. Becic et al (2010) discutem uma destas situações citando o ato de dirigir e falar ao celular simultaneamente; os indivíduos geralmente destinam maior atenção para a direção, porém se uma importante negociação é discutida através do telefone celular, pode ocorrer o deslocamento do foco atentivo para esta conversa e consequente prejuízos para o dirigir, com possíveis efeitos catastróficos.

Desta forma durante a análise de duas tarefas concorrentes designar uma como primária e outra como secundária não demonstraria o que acontece em situações naturais, isto é, há uma grande relevância funcional em entender a forma na qual o indivíduo reconhece uma situação como a mais importante e direciona seus recursos atentivos a ela. 


\subsubsection{Custos gerados pela DT}

A interferência no desempenho gerada pela execução da DT é bastante citada em diferentes populações e condições.

Um estudo analisou o desempenho de jovens saudáveis enquanto andavam e ao mesmo tempo executavam uma tarefa de memorização de sequências de três, cinco e sete números e posterior verbalização deste conteúdo memorizado. Observou-se redução da velocidade e aumento da variabilidade de parâmetros como o tempo na fase de balanço e apoio nas condições de DT de maior complexidade, especialmente na verbalização de sequências compostas por sete números. Os autores argumentaram que a tarefa cognitiva associada a uma demanda articulatória gerada pela verbalização e à demanda motora da marcha causam custos ao desempenho mesmo em jovens saudáveis, provavelmente por criar uma condição de "tripla tarefa" que excede a quantidade de recursos atentivos disponíveis (ARMIERI et al., 2009), ou seja , mesmo em indivíduos com sistema nervoso íntegro os custos relacionados a DT podem ocorrer.

Além disso, já discutido anteriormente, a presença de déficits de FE, na divisão da atenção e do processamento de informações contribuem ainda mais para as limitações observadas nas situações de DT. A DT segundo Gothe, Kliegl e Oberauer (2007) é considerada uma das situações mais relacionadas ao conceito da função executiva. De acordo com esta visão, realizar duas ações simultâneas requer habilidades executivas para ordenar os recursos ou o tempo de processamento de duas tarefas além de programar as etapas para minimizar a interferência. Portanto, segundo os autores, o contraste de tarefas realizadas individualmente com situações de DT pode ser uma forma de estudar isoladamente a função executiva do indivíduo testado.

Na mesma linha de argumentação, Szameitat et al. (2002) definem que a FE é necessária para coordenar o processamento de diferentes fluxos de informações concorrentes; portanto a investigação do desempenho em DT demonstra como o cérebro realiza comportamentos complexos.

Portanto, indivíduos que apresentam primariamente déficits de FE e atenção podem apresentar grandes dificuldades para realizar ações em DT. Um estudo foi 
conduzido para analisar se pacientes com lesões cerebrais adquiridas apresentavam maior dificuldade do que indivíduos sadios no desempenho de uma tarefa de equilíbrio em DT. Os participantes permaneciam sobre uma plataforma de força enquanto concomitantemente executavam cinco diferentes tarefas cognitivas com diferentes graus de dificuldade. O grupo experimental mostrou maior oscilação do centro de pressão em todas as condições analisadas, devido à diminuição da capacidade atentiva e aumento da distratibilidade gerada pela perda do foco de atenção, além da priorização das tarefas cognitivas em detrimento da estabilidade postural, uma vez que a performance das tarefas cognitivas não foi afetada pela DT (BRAUER et al., 2004).

Deficiências sensório- motoras geradas por uma doença neurológica primária podem interferir diretamente no desempenho da DT. Mulder et al. (2002) argumentam que após lesão do sistema nervoso, atos motores anteriormente simples e automáticos passam a depender de alta demanda atentiva para sua execução; como há uma capacidade limitada de processamento neural disponível, o desempenho simultâneo de um ato motor e uma tarefa cognitiva, por exemplo, sobrecarregaram este sistema gerando custos na condição de DT.

Teorias sobre o desempenho em DT sugerem que os custos resultariam de uma limitação estrutural dos mecanismos de processamento, que permitiriam o processamento de apenas uma tarefa por vez, constituindo assim um bottleneck quando existem ações concorrentes. Tarefas simultâneas podem ser realizadas concomitantemente sem custos se houver uma capacidade de processamento adequado, porém se esta capacidade for excedida uma ou ambas as tarefas serão prejudicadas, e o sistema terá que priorizar apenas uma delas (MCCULOCH, 2007; BRAUER, 2004).

No caso de duas ações competirem pelos mecanismos de processamento, a interferência é atenuada através de maior direcionamento da FE para esta operação. A FE atuaria através da coordenação do processamento de informações, no caso de interferência, adaptando o as estratégias de processamento, envolvendo a inibição e ativação de representações neuronais relacionadas às tarefas e deslocando a atenção entre elas (SZAMEITAT, 2002; PASHLER, 1994).

Outros fatores que podem influenciar no surgimento dos custos associados à DT é a capacidade limitada em desempenhar duas tarefas simultâneas devido a insuficiente 
capacidade atentiva e dificuldades em alocar a atenção entre duas ou mais tarefas, operações associadas a FE. Quanto maior a complexidade da tarefa maior a necessidade destas operações, o que pode resultar em maior interferência (HUXHOLD et al., 2006; GAZZANIGA; IVRY; MANGUM, 2002; WOLLACOTT; SHUMWAY-COOK, 2002).

O grau de automaticidade das ações envolvidas na DT também é um fator importante, uma vez que ações automáticas não requerem demanda atentiva para sua realização (YOGEV et al, 2008). Para a compreensão da razão pela quais atividades consideradas automáticas dependem de menos controle atentivo, é interessante a discussão do substrato anátomo fisiológico que envolve os processos de aprendizado e o armazenamento de informações.

Sequências de movimento ainda não automatizadas ativam extensivamente o córtex pré-frontal dorsal e área cingulada anterior (área 32), regiões associadas ao engajamento da atenção em diversos processos da aprendizagem motora, como a preparação e recordação dos movimentos necessários para a execução, monitoração de resultados, tomada de decisões (LEHERECY et al, 2005; HIKOSAKA et al, 2002; PASSINGHAM et al, 1997).

Por outro lado, ações rotineiras, executadas com frequência, bem aprendidas, designadas como automáticas estariam envolvidas com a atividade de áreas corticais sensório-motoras mais posteriores e putâmem. Portanto, quando uma determinada tarefa torna-se automática, áreas encefálicas mais posteriores são responsáveis em monitorar seu desempenho, liberando as áreas frontais para o engajamento em novas atividades. Portanto, indivíduos capazes de realizar determinadas ações com um nível alto de automaticidade tem a capacidade de executar outra ação concorrente com o mínimo de interferência (JUEPTNER et al., 1997a; JUEPTNER et al., 1997b).

Quando duas ações são executadas ao mesmo tempo, uma é executada de maneira subconsciente através do suporte dos núcleos da base (NB), enquanto a outra é controlada pelo córtex frontal, região que fica "disponível” para a execução de tarefa novas ou menos aprendidas, que necessitam de direcionamento da atenção para sua execução de forma eficaz. Devido à perda no funcionamento adequado dos NB, a habilidade em executar movimentos sem a atenção fica comprometida (BOND; MORN'S, 2000). 
Portanto, nesta visão, atividades que necessitam de maior controle cortical, deixariam menos "espaço" para a execução de outra tarefa dependendo de atenção. O’Shea, Morris e Ianske (2002) discutem que ações envolvendo membros superiores dependem mais de áreas corticais, pois necessitam de feedback somatossensorial e visual constante do que a marcha, que é regulada por áreas menos "nobres", filogeneticamente mais antigas, como tronco encefálico, medula e cerebelo, 'necessitando de um menor controle por parte do córtex por constituir um movimento de características pré-programados.

Morris et al. (2000) relatam que o controle da marcha e principalmente dos membros superiores é mediado pelo córtex sensório-motor e áreas pré-motoras, enquanto que o equilíbrio dependeria de circuitos medulares, tronco encefálico, cerebelo, córtex sensorial e estriado. Desta forma, quanto maior a necessidade de processamento cortical, pior seria o desempenho da tarefa quando realizada simultaneamente a outra.

Porém, estudos vêm demonstrando que mesmo estes comportamentos básicos abrangendo a marcha e o equilíbrio necessitam de atenção para a sua execução dependendo de variáveis como idade, condições em que a tarefa é desempenhada e do nível de habilidade do indivíduo (YOGEV et al., 2008; COPPIN et al., 2006; YOGEV et al., 2005; WOLLACOTT; SHUMWAY-COOK, 2002).

Um artigo de revisão discute sobre a demanda atentiva necessária no controle postural e marcha sugere que mesmo adultos jovens consomem certa quantidade de atenção para o controle postural, porém ela é pequena e especialmente necessária quando o controle postural é exigido em uma demanda alta ou quando associado a uma tarefa secundária desafiadora (WOLLACOTT; SHUMWAY-COOK, 2002). 


\subsubsection{A priorização de uma tarefa em DT}

Outra possibilidade dentro do estudo da DT é a observação do desempenho após instruções feitas pelo examinador. Geralmente a orientação é para que os indivíduos prestem atenção em ambas as tarefas e tente realizá-las da melhor forma possível, mas também há a possibilidade do examinador orientar sobre qual tarefa deve ser priorizada, instruindo explicitamente para que o indivíduo direcione mais sua atenção para determinada ação. Esta estratégia permite a análise de diferentes padrões de priorização e flexibilidade mental.

Adultos jovens saudáveis não apresentam repercussões clínicas geradas pelo processo de priorização, porém o oposto ocorre em populações onde uma das tarefas da DT ou ambas demandam grande atenção para sua execução (KIZONY et al., 2010).

Yogev et al. (2010) discutem que idosos e pacientes com lesões neurológicas apresentam prejuízos na capacidade de priorizar determinadas tarefas, devido a perda de flexibilidade mental. Estes autores observaram o padrão de marcha e a execução de uma tarefa de fluência verbal em DT quando instruções explícitas sobre a priorização foram dadas a sujeitos adultos jovens e idosos. O comando para direcionar mais atenção à marcha na DT causou um aumento da velocidade de modo superior nos adultos jovens do que nos idosos, enquanto que o aumento da variabilidade, ou seja, menor estabilidade ocorreu apenas no grupo de idosos.

Estes dados sugerem que idosos apresentam uma redução da capacidade de priorizar e deslocar seus recursos atentivos entre diferentes tarefas, além de direcionar para a hipótese que em idosos a marcha é menos automática, portanto mais atenção deve ser devotada à ela mesmo condições normais.

Mcculloch et al. (2010) examinaram a relação entre equilíbrio, atenção e DT em indivíduos com lesão cerebral adquirida, correlacionando as pontuações obtidas em testes de equilíbrio e atenção ao desempenho em DT na marcha (marcha associada a uma tarefa de memorização de números). Os autores verificaram que as melhores pontuações em testes de atenção foram positivamente associadas a grandes custos em condição de DT. A hipótese foi que o protocolo utilizado permitiu que cada paciente 
priorizasse a marcha ou a tarefa cognitiva livremente, ocasionando uma grande variabilidade de resultados, de modo geral mostrou a priorização da marcha, que do ponto de vista adaptativo foi uma estratégia compensatória criada com intuito de maximizar a segurança e manutenção do equilíbrio à custa da perda de desempenho da tarefa concorrente. Isso demonstra como o processo de priorização é ativo e dependente de demandas individuais, ambientais e direcionadas a um objetivo.

\subsubsection{O desempenho da DT em indivíduos idosos}

Acredita-se que o processo de envelhecimento fisiológico é associado a severo declínio da FE, fato que pode estar relacionado ao surgimento de difusas lesões na substância branca que afetam circuitos fronto-basais. Testes neuropsicológicos específicos para a FE em idosos saudáveis mostram dados controversos, mas no geral apontam para prejuízos na resolução de problemas que envolvem a flexibilidade mental, atenção e consequentemente dificuldades no manejo de situações de DT (YOGEV et al., 2008; HUXHOLD et al., 2006).

Um estudo de Prakash et al. (2009) com objetivo de investigar as regiões corticais envolvidas no controle atentivo de adultos jovens e idosos utilizou o Stroop Test associado ao mapeamento por ressonância magnética funcional. Foi verificado que idosos mesmo em situações pouco desafiadoras (condições congruentes) apresentaram extenso recrutamento de áreas corticais, especialmente do córtex pré-frontal e parietal, quando comparados a adultos jovens. A consequência deste recrutamento excessivo é uma menor capacidade de processamento por estas regiões corticais quando há um aumento de demanda atentivo, sugerindo um decréscimo na eficiência e responsividade do córtex pré-frontal e parietal em situações cognitivas conflitantes.

Em contraste, adultos jovens mostram uma grande sensibilidade do CPFDL em tarefas de grande complexidade e em atividades que dependem de alto grau de processamento. Portanto, estes resultados evidenciam que o envelhecimento induz a 
déficits na flexibilidade da alocação de recursos atentivos em resposta a demandas dinâmicas.

Springer et al. (2006), Coppin et al. (2006) e Dubost (2006) analisaram parâmetros da marcha em idosos e adultos jovens em situação de DT com resultados semelhantes: Springer et al (2006) observaram diminuição na velocidade da marcha de todos os grupos em condição de DT, porém idosos com histórico de quedas apresentaram também alteração na variabilidade do tempo da fase de balanço além de prejuízos em testes de FE. Coppin et al. (2006) e Dubost (2006) também encontraram uma forte associação entre o status cognitivo de idosos e o desempenho destes em testes envolvendo DT.

Os autores discutem que há uma grande identificação entre déficits de FE e variabilidade da marcha. Os prejuízos de FE e atenção poderiam fazer com que idosos com histórico de quedas desviassem menos recursos atentivos para o controle postural e marcha, reduzindo assim sua capacidade de enfrentar e adaptar-se a mudanças ambientais, como obstáculos ou um solo molhado, predispondo-os a quedas.

A maior variabilidade no padrão de marcha devido ao desempenho simultâneo de atividades que demandam recursos atentivos é bem documentada em idosos, acarretando em aumento do número de hesitações, desvios laterais, variações do tamanho e largura do passo na marcha; Dubost et al. (2006) argumentam que estas alterações, principalmente a variabilidade do ritmo da marcha, ocorrem devido a perda de processos que comandam o padrão rítmico da marcha, controlado por áreas subcorticais. Portanto em idosos, andar e ao mesmo tempo executar uma tarefa cognitiva representa uma divisão de atenção, dependente da capacidade atentiva que envolve áreas corticais de alto processamento. Devido a isto, idosos perdem a automaticidade de movimentos antes considerados simples e rotineiros.

Fraser, Li e Penhune (2010) discutem que o declínio motor e cognitivo faz parte do processo de envelhecimento fisiológico, ao mesmo tempo em que se tornam mais interdependentes, ou seja, há maior necessidade de recursos cognitivos para a execução de tarefas motoras.

Estes autores avaliaram o desempenho de uma tarefa sequencial de dedos isoladamente e depois associada a duas situações de DT (associação a uma tarefa de 
julgamento de palavras e uma de subtração). Observou-se uma diferença significante na execução da DT em idosos quando comparados a adultos jovens, com maior interferência entre as tarefas. Os autores sugerem que em idosos a cognição "invade" o desempenho de tarefas antes predominante motoras, confirmando a perda do controle automático em idosos (FRASER; LI; PENHUNE, 2010).

O envelhecimento também reduz a eficácia dos sistemas sensorial e muscular envolvidos no controle postural, além de gerar um declínio na função do córtex parietal, relacionado com a representação interna do corpo. A perda destas funções associado a prejuízos cognitivos, incluindo déficits de memória processual e de atenção, comprometem o direcionamento de recursos atentivos para o controle postural em situações de (HUXHOLD et al., 2006).

A interpretação destes resultados proporcionam o melhor entendimento da interação da função cognitiva e comportamento motor em idosos, especialmente em condições de DT, acarretando severas limitações funcionais, além de alto risco de queda.

\subsubsection{Desempenho da DT em pacientes com Doença de Parkinson}

Além dos prejuízos em executar a DT observado em idosos, pacientes com doenças neurológicas também demonstram dificuldades em desempenhar tais atividades. Um dos pacientes mais estudados em situação de DT é aquele com DP, pois estes indivíduos apresentam características neuropatológicas distintas que justificam o interesse clínico e acadêmico pelo assunto.

A DP é uma doença degenerativa do sistema nervoso central, caracterizada por uma gama de sinais motores e não motores que acarretam em limitações e diversos graus de incapacidade funcional ao indivíduo acometido. A incidência aumenta com o avançar da idade, sendo estimada em 17,4 pessoas acometidas para cada 100.000 indivíduos entre 50 e 59 anos, números que aumentam para 93,1 pessoas com idade 
entre 70 e 79 anos. A idade média de início é 60 anos, com média de 15 anos de duração da doença do diagnóstico ao óbito (SAVICA; ROCCA e AHLSKOC, 2010; LEES; HARDY; REVESZ, 2009; YANAGISAWA, 2006).

A marca registrada da DP é a perda progressiva de neurônios dopaminérgicos localizados na substância negra pars compacta (SNc) mesencefálica, A SNc faz parte dos NB, que são um grupo de núcleos situados subcorticalmente com importantes interconexões funcionais. Estas estruturas formam uma rede neuronal complexa, organizada em paralelo com intuito de integrar a atividade de diferentes regiões corticais, mediando tanto funções motoras como não motoras do comportamento humano (WICHMANN; DOSTROVSKY, 2011; OBESO et al., 2002).

A DP é clinicamente caraterizada por sinais motores clássicos que incluem o tremor, rigidez, instabilidade postural e bradicinesia/ acinesia (SAVICA et al., 2010; LEES; HARDY,; REVESZ, 2009; JANKOVIC, 2008; LEENDERS; OERTEL, 2001; GELB; OLIVER e GILMAN, 1999).

Atualmente, várias pesquisas demonstram a grande importância dos NB em funções não motoras do comportamento humano, uma vez que lesões que acometem estas estruturas NB frequentemente associam-se a distúrbios não-motores como déficits cognitivos, psiquiátricos, autonômicos, sensoriais e do sono (SAVICA et al., 2010; RODRIGUEZ-OROZ et al., 2009; HIRAGA et al., 2009, HOU; LAI, 2007; ZGALJARDIC et al., 2003; GELB et al., 1999;).

Segundo Wylie et al (2009), circuitos fronto-basais são decisivos para o controle executivo da ação, incluindo a capacidade de suprimir respostas não desejadas em favor de respostas necessárias à demanda em curso. Presume-se que o CPFDL media a distribuição de recursos atentivos de acordo com a demanda de processamento. A escolha e a ativação de determinado comportamento ocorre através do deslocamento destes recursos, enquanto outros comportamentos concorrentes são inibidos. Isso faz com que do ponto de vista funcional, os NB estão em uma posição crucial no controle do movimento, atuando na decisão, seleção de planos motores específicos e na iniciação dos movimentos intencionais (DELONG; WICHMAN, 2009;; ZGALJARDIC et al., 2003;). 
Na DP, a perda de neurônios dopaminérgicos prejudica a conexão entre os NB e o lobo frontal, o que interrompe o fluxo normal de informações através destas vias e consequentemente afeta processos cognitivos dependentes destas áreas (DRAG et al., 2009; OWEN, 2004).

Cameron et al (2009) verificaram hipoativação do CPFDL e de outras áreas frontais durante tarefas de rastreio visual em pacientes com DP, fato que também justificaria os déficits no fluxo de informações nos circuitos fronto-basais destes indivíduos, relacionando a prejuízos de FE, particularmente no planejamento, manipulação e elaboração de estratégias envolvendo a memória operacional.

Os déficits de FE observados em pacientes com DP assemelham-se aos encontrados em pacientes com lesões de lobo frontal segundo Cameron et al. (2010).Em ambos os casos existem déficits em tarefas que requerem iniciação voluntária de uma resposta motora, controle executivo sobre ações vigentes e flexibilidade comportamental. Portanto, tarefas que requerem o início de uma resposta motora assim como um controle executivo sobre um comportamento são deficitárias em pacientes com DP.

Segundo Kelly et al. (2012) os prejuízos na mobilidade funcional de pacientes com DP são exacerbados em situações de DT. Vários estudos discutem sobre a perda de desempenho de pacientes com DP em situações de DT; alguns analisaram o desempenho da marcha como sendo a tarefa primária (PLOTNIK; GILADI; HAUSDORFF, 2009; BAKER; ROCHESTER; NIEUWBOER, 2007; CANNING et al., 2005; GALLETY; BRAUER, 2005; ROCHESTER et al., 2005; YOGEV et al, 2005; O’SHEA, MORRIS; IANSEK, 2002). Outros analisaram a estabilidade postural (HOLMES et al., 2010; MORRIS et al, 2000;) ou função manual (PRADLAM et al., 2010; WU; HALLET, 2008; BROWN; JAHANSHAHI, 1998; HORSTINK et al., 1990; BENECKE et al., 1986;) como tarefa primária. Os estudos variam sobre a natureza de tarefa secundária utilizada (motora ou cognitiva), sobre a forma de avaliação empregada, os estágios em que se encontravam os pacientes com DP avaliados e na existência de avaliação do desempenho da tarefa secundária.

Existem várias pesquisas que mostram a perda de desempenho em diversos parâmetros da marcha quando ela é considerada a tarefa primária, por exemplo, O’Shea, 
Morris e Iansek (2002) que observaram que pacientes com DP apresentaram diminuição da cadência e aumento do tempo em duplo apoio quando a marcha foi associada a uma tarefa motora e cognitiva. Rochester et al. (2005) verificaram diminuição da velocidade e do tamanho dos passos em pacientes com DP quando andavam e equilibravam uma bandeja com copos de água; Yogev et al. (2006) observaram maior assimetria de vários itens da marcha quando pacientes com DP andavam e realizavam subtrações concomitantemente.

Em relação à função de membros superiores, o estudo de Proud e Morris (2010) comparou o desempenho de pacientes com DP e sujeitos idosos sadios em uma tarefa de destreza manual associada à subtração, encontrando prejuízos no desempenho em ambos os grupos, porém de maneira mais proeminente no grupo experimental. Wu e Hallet (2008) alcançaram resultados semelhantes utilizando sequências de oposições de dedos da mão associada a uma tarefa de identificação visual, assim como Horstink et al. (1990) utilizando tarefas bimanuais concorrentes, uma mão deveria desenhar triângulos e apertar um bulbo de borracha com a outra.

Os resultados envolvendo DT no equilíbrio de pacientes com DP são mais controversos, pois artigos como o de Morris et al. (2000) verificaram prejuízos nos testes de equilíbrio em várias situações envolvendo a DT, enquanto Holmes et al. (2010) utilizando plataforma de força observaram diminuição das oscilações do centro de pressão enquanto pacientes com DP permaneciam na postura bípede realizando simultaneamente uma tarefa cognitiva.

Pacientes com DP dependem excessivamente de mecanismos corticais para a realização de movimentos devido à função deficitária dos NB. Essa dificuldade é observada especialmente quando executam tarefas simultâneas, sejam elas motoras, cognitivas ou quando é associada uma motora com uma cognitiva, indicando que esta alteração pode não relacionar-se a um problema puramente motor, ou seja, a DT em pacientes com DP afeta tanto o movimento como a cognição (PLOTNIK et al., 2010; PROUD; MORRIS, 2010; ROCHESTER et al., 2008; WU;HALLET, 2008; MARCHESE; BOVE, 2003).

Ao mesmo tempo em que ocorre a maior dependência de mecanismos mediados corticalmente para executar os movimentos, estes mecanismos também estão 
deficitários em indivíduos com DP. Bond e Morris (2000) associam a deficiência observada na DP à teoria de capacidade limitada de compartilhamento (capacitysharing). Pacientes com DP provavelmente possuem recursos centrais de processamento preservados, porém a lesão dos NB faz com que haja uma falha no deslocamento habitual da atenção.

Portanto, as possibilidades de usar estratégias alternativas com intuito de compensar as alterações dos NB através de circuitos corticais são também limitadas, já que para isso estes indivíduos necessitariam de funções cognitivas preservadas (YOGEV; HAUSDORFF; GILADI, 2008; YOGEV et al., 2005).

As hipóteses citadas nestes estudos para os custos da DT convergem para a já citada deficiência da FE, redução de recursos atentivos disponíveis, dificuldade em deslocar estes recursos entre diferentes tarefas, em orientar a atenção entre estímulos aprendidos e estímulos novos, além da perda da automaticidade gerando maior demanda cognitiva até mesmo em atividades simples (YOGEV et al., 2008; ZGALJARDIC et al., 2006; ROCHESTER et al., 2004; ZGALJARDIC et.al., 2003; BOUND et al., 2000).

As informações acumuladas sobre como pacientes com DP desempenham ações em DT refletem o comprometimento progressivo nas vias dopaminérgicas envolvendo os NB e suas conexões. Portanto a avaliação sistemática destas situações é de grande validade clínica, pois pode servir como marcadores da progressão da patologia.

Assim, a elaboração de um protocolo de avaliação em DT que seja sensível à evolução da doença é de interesse prático para os profissionais envolvidos no cuidado destes pacientes, uma vez que é uma forma prática e quantitativa de verificar tanto a evolução da doença como a resposta a terapias físicas e medicamentosas. 


\subsection{A importância da avaliação em DT na prática da fisioterapia}

A mobilidade e estabilidade necessárias para executar efetivamente atividades funcionais do dia a dia requerem a capacidade de realizar duas ou mais atividades motoras ou cognitivas simultaneamente, além da possibilidade de adaptar estas ações quando um evento não esperado ocorrer. A alta complexidade destas situações tão inerentes ao comportamento humano vem intrigando e expandindo a pesquisa envolvendo o paradigma da DT nos últimos anos (KELLY, et al., 2012; KIZONY et al., 2010).

A execução da DT é considerada uma função chave atribuída à $\mathrm{FE}$, envolvendo vários aspectos da atenção e sua manipulação, portanto o estudo de ações concorrentes possibilita a análise prática de aspectos cognitivos (AZOUVI et al., 2004). Segundo Koerts et al. (2011) os testes de papel para avaliação da FE são estruturados com regras rígidas, objetivos pré-determinados, sinalização do início e fim do comportamento testado; porém situações cotidianas que requerem o funcionamento executivo são pouco estruturadas, frequentemente sem soluções e objetivos claros; por estes motivos que análise da DT parece ser um instrumento que fornece pistas mais reais do status cognitivo e funcional individual.

$\mathrm{O}$ alto risco de queda relacionado à execução da DT durante a marcha e equilíbrio tem motivado a pesquisa referente a estratégias clínicas para a avaliação e tratamento destes déficits especialmente em indivíduos idosos e com doenças neurológicas, como a DP. A avaliação em condições de multitarefas demonstra ser um indicador mais sensível à déficits de equilíbrio e marcha do que avaliações em contexto de TS pois manipula a FE do indivíduo analisado (ZIJLSTRA et al., 2008; SPRINGER, 2006; SHUMWAY-COOK; BRAUER; WOLACOTT, 2000).

Na prática da fisioterapia, a avaliação em DT pode facilitar o reconhecimento de alterações por ser mais sensível do que a análise isolada da ação em grupos de pacientes com doenças neurológicas. Apesar de apresentar mecanismos ainda não totalmente compreendidos, a DT facilita a observação de informações que não são aparentes em exames de rotina além de permitir a análise do desempenho de atividades que necessitam de um alto grau de função cognitiva e que constituem a maior parcela das 
queixas de pacientes com comprometimento neurológico. Além disso, o conhecimento do comportamento de determinados grupos clínicos em DT facilita o estabelecimento e o desenvolvimento de um processo de reabilitação eficaz, uma vez possibilita o treinamento de estratégias mais seguras para cada grupo individualmente (MCCULLOCH et al., 2010; YOGEV et al., 2010;).

Devido a relevância deste assunto, a avaliação em DT precisa ser incluída na prática clínica de profissionais que trabalham com a reabilitação. Para que isto seja viável, esta avaliação deve ser prática e fidedigna, de fácil aplicação e baixo custo.

Apesar de existirem muitas pesquisas em DT, a forma de avaliação é bastante heterogênea, muitas vezes empregando para mensuração do desempenho medidas e aparatos laboratoriais, que são recursos pouco disponíveis no dia a dia. Os estudos variam quanto às atividades analisadas, os parâmetros, sujeitos, situações experimentais avaliadas, instruções quanto a priorização das tarefas entre outros, o que dificulta a análise e comparação de estudos. Outra questão importante é a ausência de dados sobre ambas as tarefas executadas em DT; alguns estudos não verificaram o desempenho da tarefa secundária cognitiva e/ou motora, o que pode gerar a falsa impressão de que a execução em DT não promoveu interferência.

As tabelas 1, 2 e 3 a seguir exemplificam a diversidade de estudos em DT abrangendo a análise do desempenho desta atividade em jovens, idosos e pacientes com DP. 


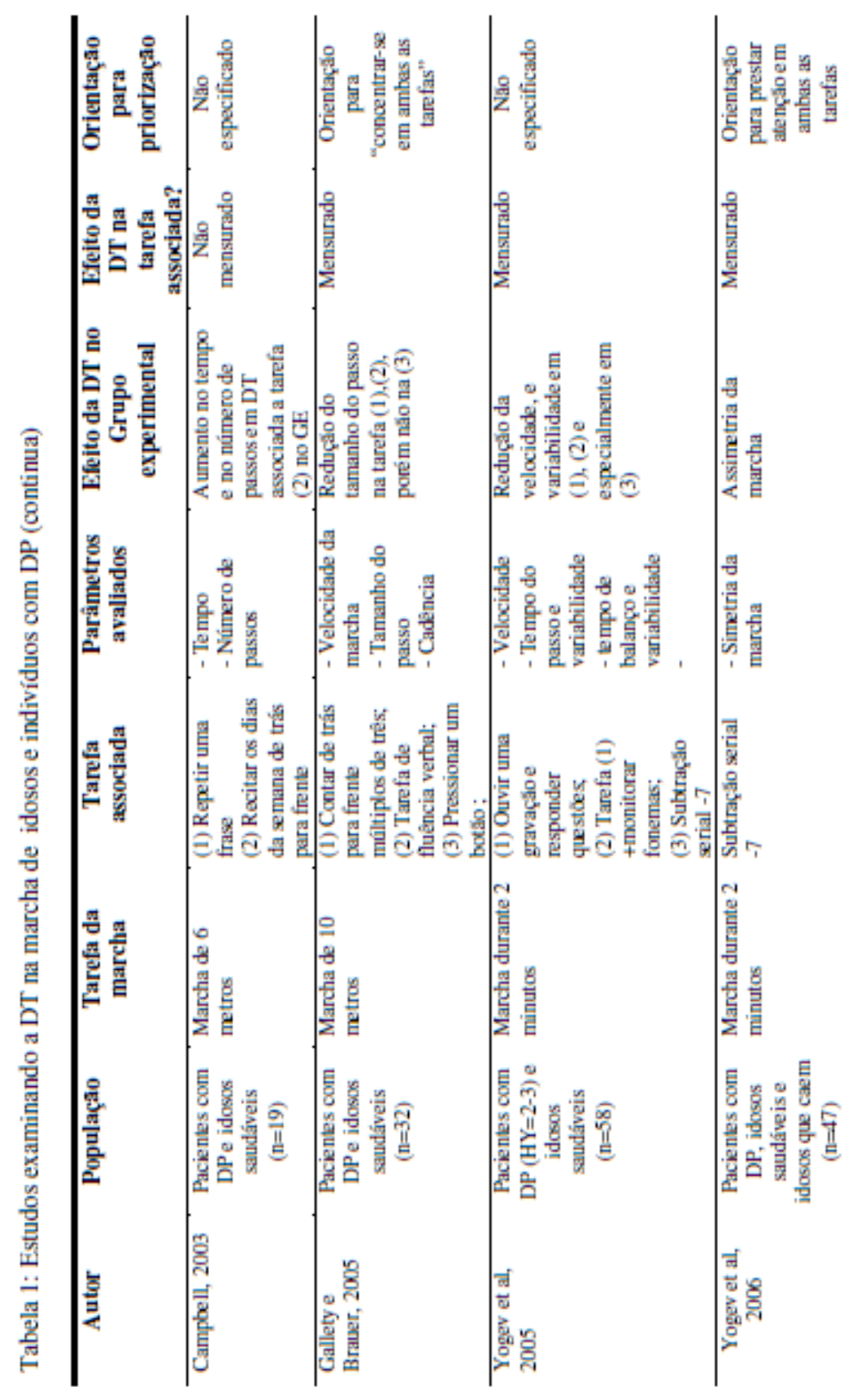




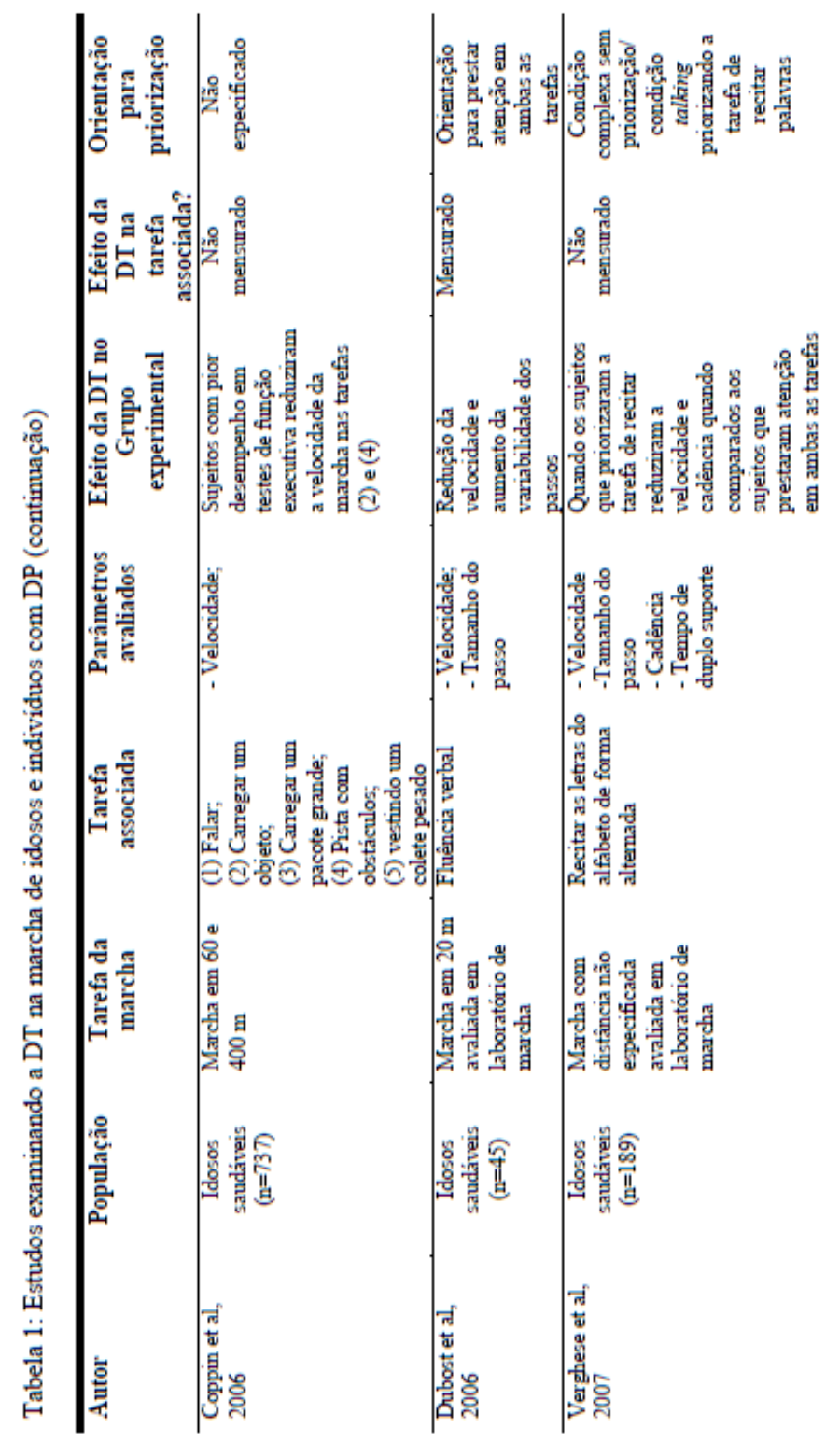




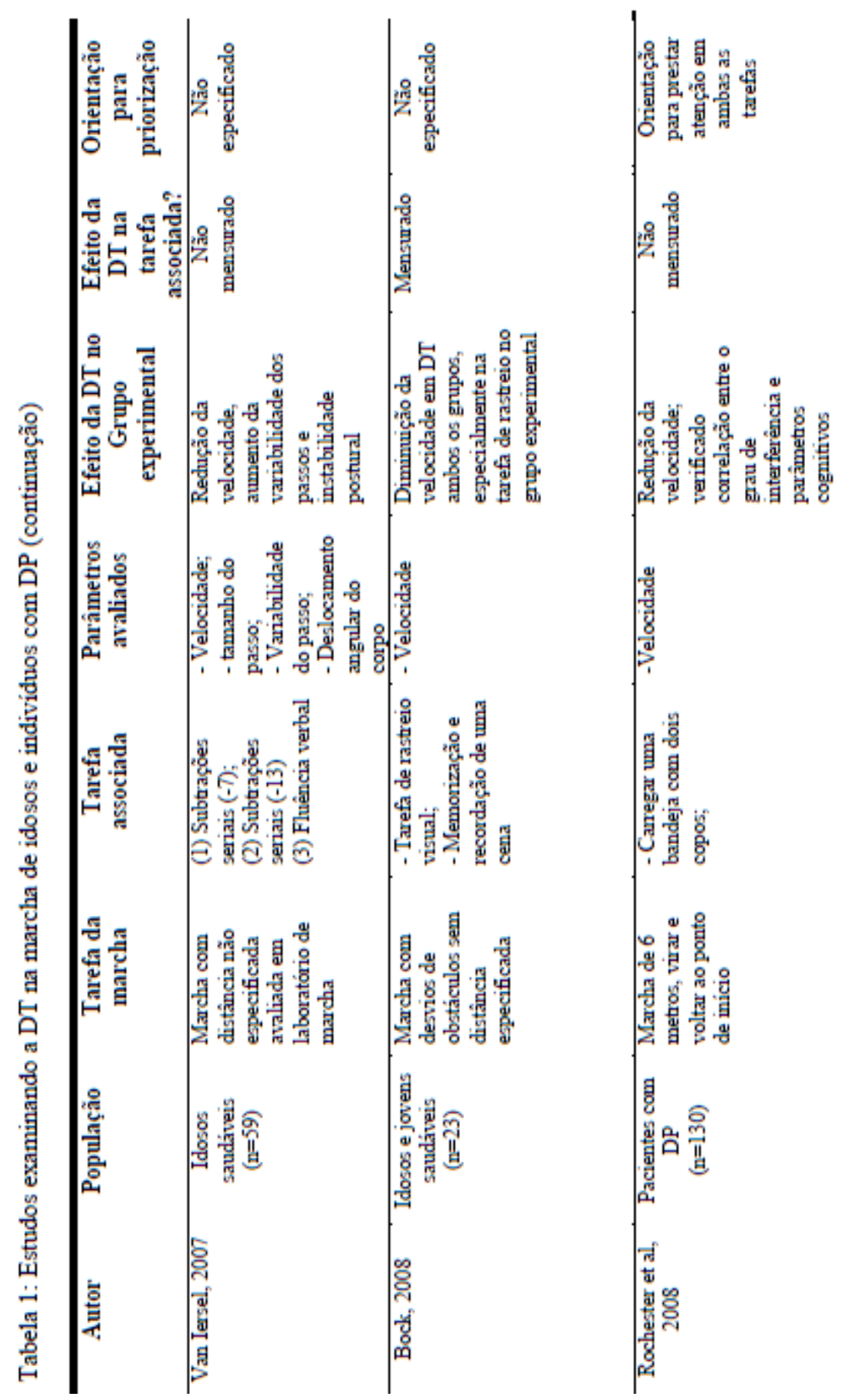




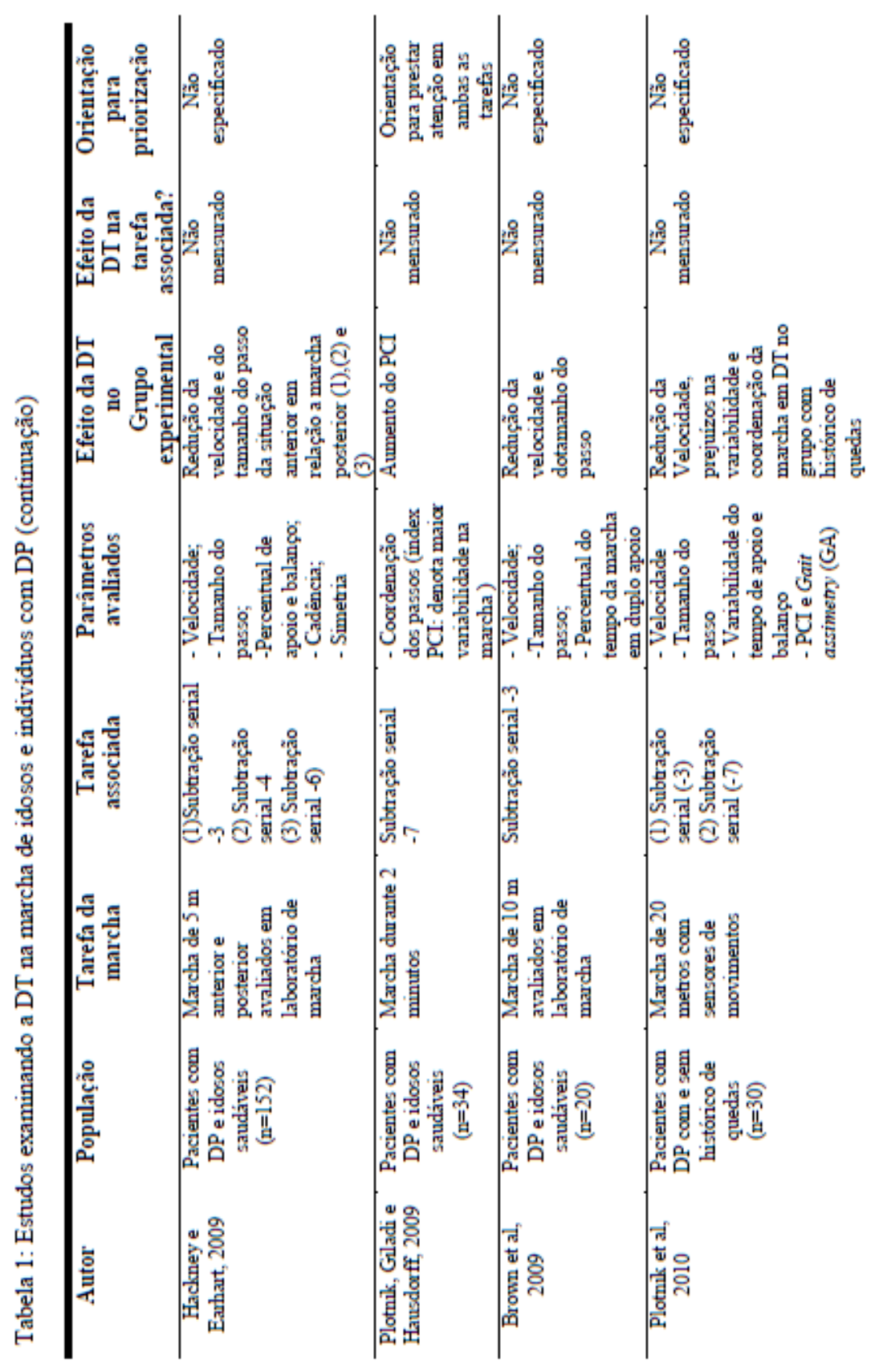



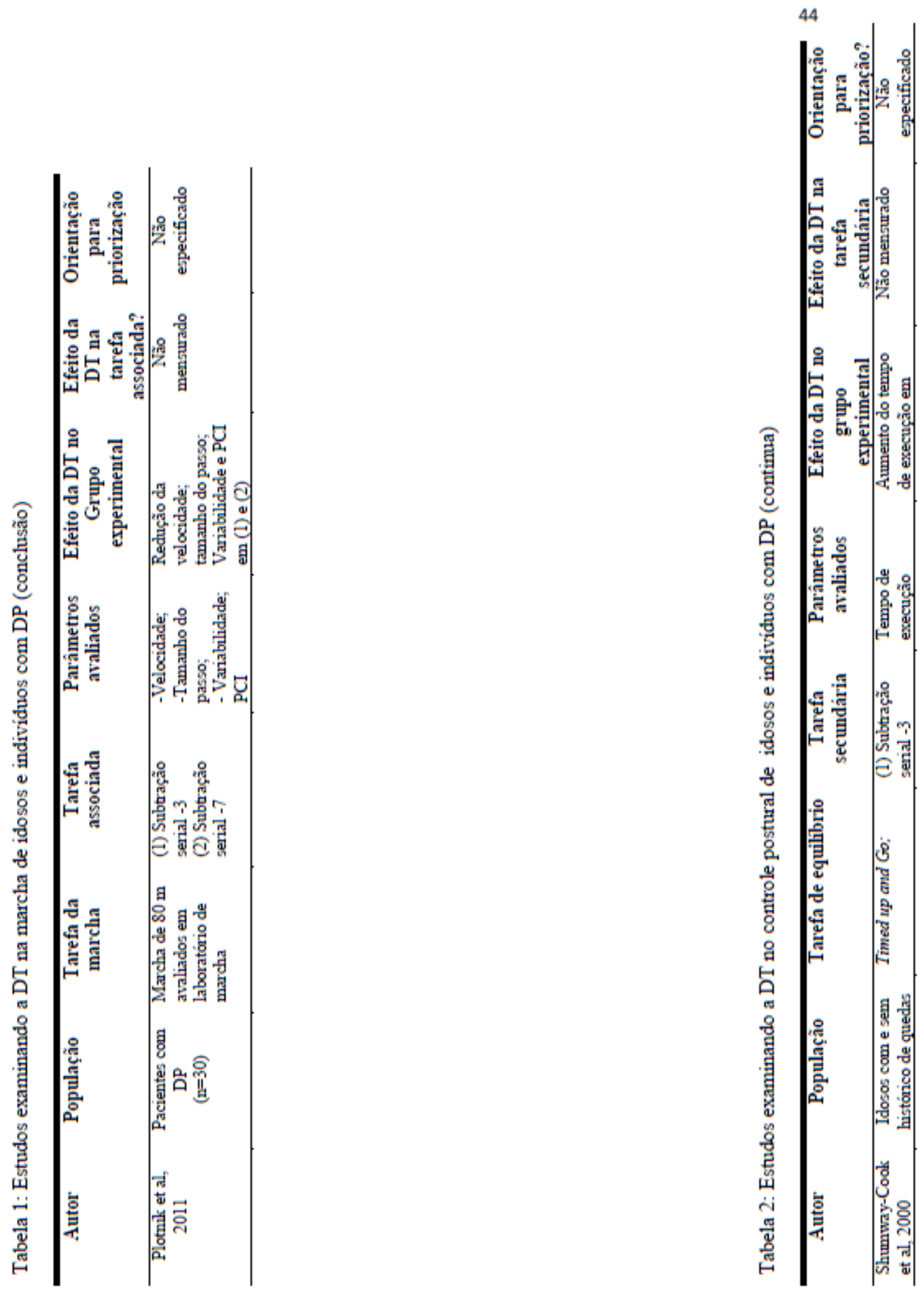


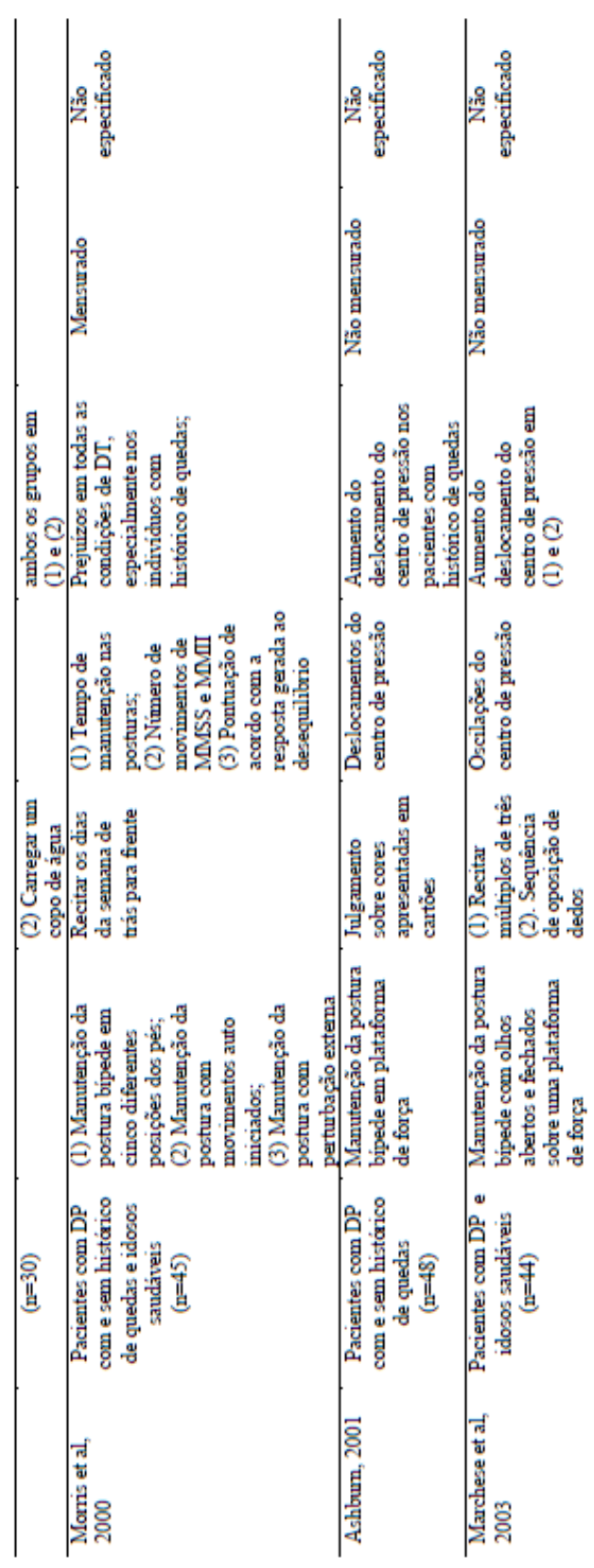



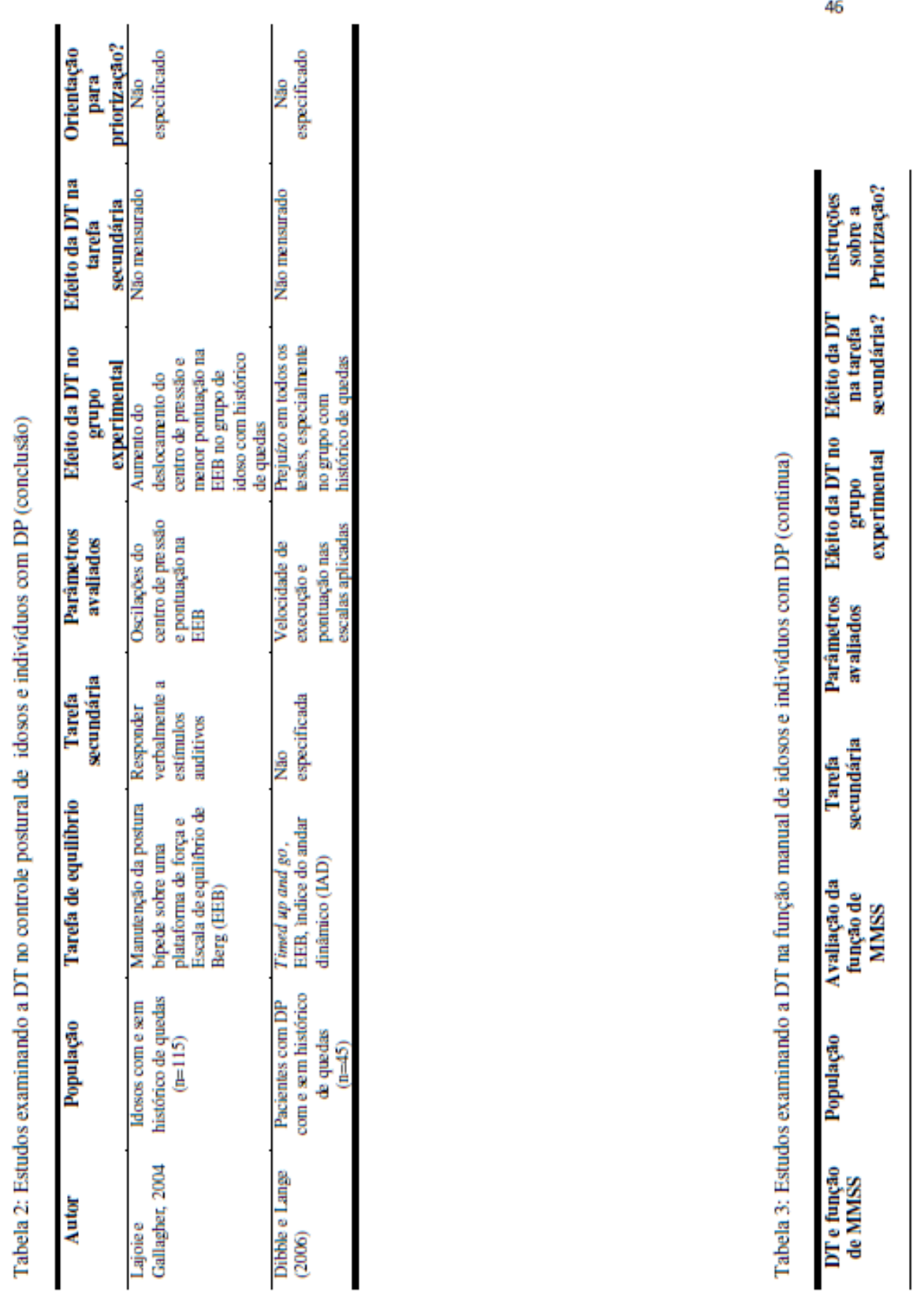


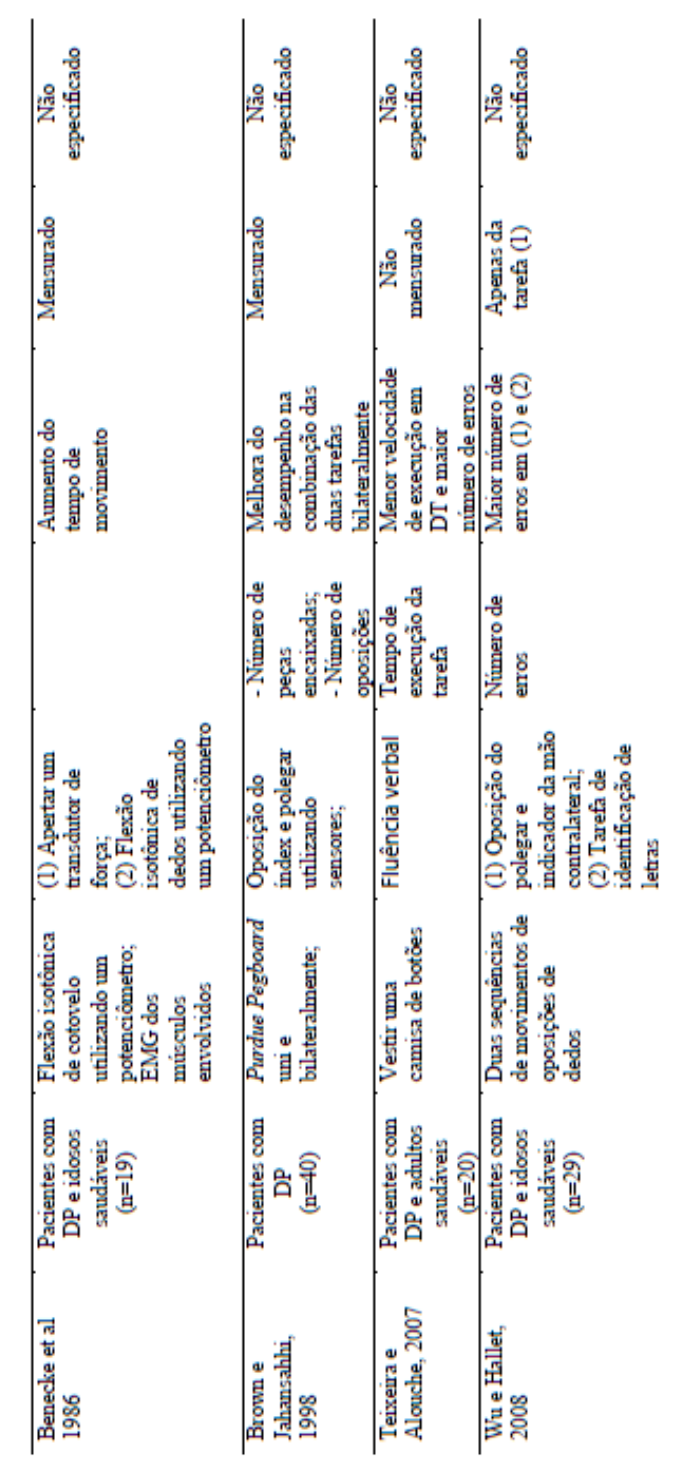




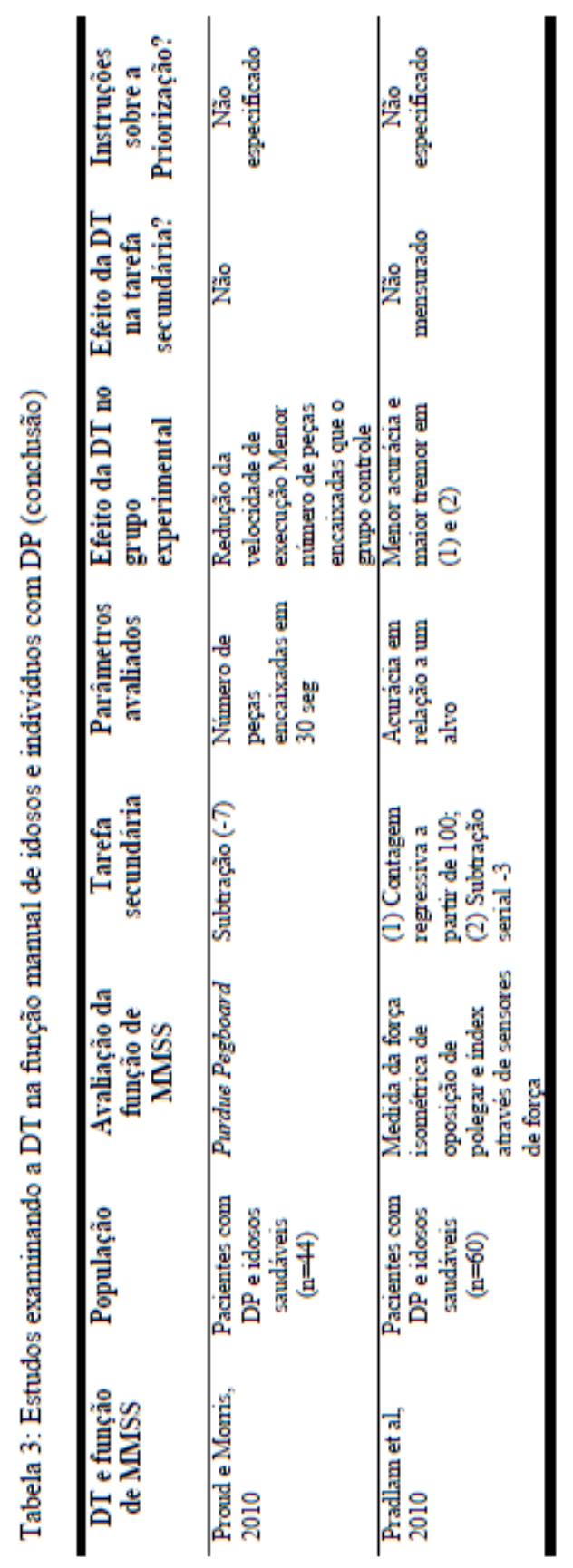


Como pode ser visualizado, a maior parte dos estudos de avaliação em DT analisa a marcha de diferentes grupos de indivíduos. Há uma grande heterogeneidade quanto os parâmetros de avaliação da marcha, (PLOTNIK et al., 2011; PLOTNIK et al., 2010; HACKNEY; BROWN et al., 2009; EARHART, 2009; VERGHESE et al., 2007; VAN IERSEL, 2007; DUBOST et al., 2006). Dos estudos citados, apenas quatro verificaram o desempenho da tarefa concorrente em DT (DUBOST et al., 2006; YOGEV et al., 2006; GALLETY; BRAUER, 2005; YOGEV et al., 2005) e seis relatam se houve instruções aos indivíduos participantes quanto a priorização de tarefas (PLOTNIK; GILADI; HAUSDORFF, 2009; ROCHESTER et al., 2008; VERGHESE et al., 2007; YOGEV et al, 2006; DUBOST et al, 2006;GALLETY; BRAUER, 2005 ). Esta heterogeneidade também pôde ser verificada nos estudos que discutiram sobre o controle postural e função manual em DT. 


\section{OBJETIVOS}

\subsection{Objetivo geral}

Desenvolver um teste de divisão de atenção envolvendo tarefas funcionais da marcha, controle postural estático e dinâmico e controle manual.

\subsection{Objetivos específicos}

- Aplicar o teste de divisão de atenção em adultos jovens, idosos e pacientes com DP em estágio iniciais e moderados de evolução da doença;

- Testar a sua aplicabilidade em adultos jovens, idosos e pacientes com DP em estágios iniciais e moderados de evolução da doença.

- Testar a sua sensibilidade para identificar alterações decorrentes do processo de envelhecimento, por meio da comparação entre adultos jovens e idosos,.

- Testar a sua sensibilidade para identificar alterações decorrentes da Doença de Parkinson, por meio da comparação entre idosos e pacientes com DP.

- Testar a sua sensibilidade para identificar alterações decorrentes da progressão da DP, por meio da comparação entre pacientes nos estágios iniciais e moderados da doença. 


\title{
4. MATERIAIS E MÉTODOS
}

\author{
4.1. Tipo de estudo
}

Trata-se de um estudo transversal

\subsection{Casuística}

Participaram deste estudo 46 pacientes com diagnóstico de DP (16 no estágio I na escala de estadiamento de Hoehn Yahr (HOEHN; YAHR, 1967), 15 no estágio II e 16 no estágio III, com idade entre 60 e 84 anos (média 69,36 e desvio padrão 7,74) de ambos os sexos (18 mulheres e 28 homens) com tratamento medicamentoso estável, recrutados da Associação Brasil Parkinson.

Também participaram 17 indivíduos idosos com idade entre 60 e 86 anos (média 71 e desvio padrão 8,66; nove homens e oito mulheres) acompanhantes de pacientes com DP que se encontravam na Associação Brasil Parkinson. Foram recrutados 20 adultos jovens com idade entre 20 e 39 (média de 25,56 e desvio padrão 6,17; 13 homens e sete mulheres) estudantes universitários da Universidade Paulista e Centro Universitário São Camilo que se dispuseram a ir à Associação Brasil Parkinson participar do estudo. 


\subsubsection{Critérios de inclusão}

Os critérios de inclusão comuns para os três grupos de indivíduos foram: (1) ausência de outras doenças neurológicas (além da DP), ortopédicas ou cárdiopulmonares diagnosticadas; (2) acuidade visual normal ou corrigida; (3) acuidade auditiva preservada.

Nos grupos de indivíduos idosos e com diagnóstico de DP foram acrescentados os seguintes critérios: (4) ausência de demência ou depressão determinada por pontuação superior a 23 no Mini Exame do Estado Mental (MEEM) (FOLSTEIN, et al., 1975) e (5) menor que seis na Escala de Depressão em Geriatria (GDS-15) (ALMEIDA; ALMEIDA, 1999).

Especificamente para os indivíduos com DP, (6) o diagnóstico de DP idiopática deveria ter sido feito por um neurologista, abrangendo indivíduos nos estágios I, II e III da escala de estadiamento de Hoehn Yahr (HY) (HOEHN \& YAHR, 1967); (7) tratamento estável com levodopa e/ou seus sinergistas;

Os indivíduos com DP avaliados frequentavam um programa de fisioterapia realizado uma vez por semana na Associação Brasil Parkinson.

Foi obtido o termo de consentimento de cada participante antes do início do estudo. O estudo foi aprovado pelo Comitê de Ética e Pesquisa da Universidade Paulista, para o uso de seres humanos em pesquisa (protocolo $\mathrm{n}^{\circ} 334 / 11$ CEP/ICS/UNIP).

\subsubsection{Critérios de exclusão}

Não participaram deste estudo indivíduos com (1) histórico de alcoolismo, desordens psiquiátricas, outras doenças neurológicas, ortopédicas ou cárdio-pulmonares diagnosticadas, (2) com alterações da acuidade visual ou auditiva não corrigida, (3) 
pontuação menor que 23 no MEEM, (4) pontuação maior que 6 na GDS-15, indivíduos com DP nos estágio IV e V na escala de HY, (5) que não apresentam tratamento medicamentoso estável.

\subsection{Local}

O estudo foi realizado na Associação Brasil Parkinson, localizado na Av. Bosque da Saúde, 1155, São Paulo, SP.

\subsection{Materiais}

Foram utilizados os seguintes materiais:

- um cronômetro digital (marca sw-2018 ${ }^{\circledR}$ );

- um contador manual mecânico de quatro dígitos

- um contador manual digital de quatro dígitos;

- cinco cartas de baralho comum;

- 20 moedas de plástico com diâmetro de 2,5 cm equivalentes a moedas de $\$ 1,00$;

- um step com as medidas 59x40x14;

- três aventais usados para procedimentos tamanho pequeno, médio e grande;

- uma fita métrica de 30 metros;

- duas mesas ;

- três cadeiras de diferentes tamanhos com encosto posterior;

- um rádio com tocador de CD (Philipps ${ }^{\circledR} \mathrm{AZ} 1137$ ),

- um CD com gravações do Teste Stroop auditivo e Stroop auditivo modificado;

- uma câmera digital (marca JVC Everio modelo GZ-MG630SU) com tripé 


\subsection{Procedimentos:}

- Elaboração do protocolo: Foram selecionadas com base na literatura e na experiência clínica de dois fisioterapeutas especialistas na área de neurologia e pesquisadores na área de neurociências, 12 tarefas, quatro denominadas funcionais e oito chamadas de específicas. As tarefas funcionais foram selecionadas por abrangerem ações envolvidas na rotina diária de todos os indivíduos.

Adiante segue a descrição da avaliação em condição de desempenho isolado ou tarefa simples (TS) das 12 tarefas funcionais e específicas.

\subsubsection{Tarefas funcionais}

As tarefas funcionais foram assim denominadas por refletirem atividades rotineiras, que fazem parte da vida cotidiana. As quatro tarefas analisadas foram tarefas referentes à marcha, controle postural estático, controle postural dinâmico e uma tarefa envolvendo o controle manual.

\subsubsection{Tarefa de marcha}

O parâmetro utilizado para avaliar o desempenho da marcha foi a distância percorrida no período de 30 segundos. Na avaliação da marcha em TS foi verificada a distância percorrida durante 30 segundos em um corredor de 30 metros, sendo orientando para que o indivíduo participante caminhasse com a maior velocidade e maior amplitude de passos possíveis.

Posição inicial do indivíduo: postura bípede 
Instrução para a tarefa: o comando dado era "quando eu falar já você irá caminhar com passos largos e com a maior velocidade possível". Indivíduos que faziam uso de aditamentos como a bengala foram avaliados fazendo uso deste suporte. Ao término dos 30 segundos, o avaliador que estava caminhando ao lado do indivíduo avaliado falava "pare" e colocava um marcador no chão ao lado do pé que estava posicionado mais à frente para a medição da distância percorrida.

\subsubsection{Tarefa de controle postural dinâmico}

$\mathrm{Na}$ tarefa de troca postural foi analisada a passagem da sedestação para bipedestação também durante 30 segundos. Foi utilizada uma cadeira sem braços com apoio posterior de altura adequada para cada indivíduo avaliado, isto é, o participante deveria manter-se sentado com os pés inteiramente apoiados no chão, formando um ângulo de $90^{\circ}$ na articulação do tornozelo, joelho e quadril. A cadeira era mantida com seu encosto apoiado na parede para evitar deslocamentos durante a execução da tarefa. Foram verificadas quantas vezes o indivíduo era capaz de levantar-se totalmente da cadeira, com extensão total de quadril e tronco, e depois sentar-se novamente durante 30 segundos.

Posição inicial do indivíduo: sedestação

Instrução para a tarefa: "quando eu falar já você irá passar de sentado para em pé o mais rapidamente possível, começando quando eu disser já”; a posição inicial era sentada, o examinador pedia que o participante realizasse uma repetição da troca postural antes da avaliação iniciar para melhor entendimento do movimento a ser realizado. O número de vezes que o paciente realizou esta transferência, isto é assumiu a postura bípede, foi verificada pelo avaliador. Quando o indivíduo avaliado apresentava dificuldade na troca postural uma cadeira foi posicionada anteriormente ao paciente para servir de apoio. 


\subsubsection{Controle manual}

Para verificação de uma função envolvendo os membros superiores os indivíduos participantes foram posicionados sentados em frente a uma mesa onde haviam cinco cartas que deveriam ser continuamente viradas e desviradas durante 30 segundos, utilizando a mão preferencial com a maior velocidade possível, enquanto a outra mão permanecia imóvel. A mão preferencial foi definida pelo participante após a orientação para que escolhesse a mão que "ele sentia como a mais ágil".

Posição inicial do indivíduo: sedestação (mantida durante todo o teste)

Instrução para a tarefa: "quando eu falar já você irá virar e desvirar continuamente estas cinco cartas, com a maior velocidade possível, até que eu fale para você parar". O examinador acompanhava a prova contando quantas cartas foram viradas no período estipulado.

\subsubsection{Tarefa de Controle postural estático}

Nesta tarefa o controle postural estático foi analisado através do tempo de manutenção do indivíduo na postura unipodal, sendo que foi estabelecido um tempo máximo de 30 segundos de teste. Foi solicitado que o sujeito permanecesse o maior tempo possível na postura, utilizando seu membro inferior preferencial no apoio.

Posição inicial do indivíduo: bipedestação.

Instrução para a tarefa: $\mathrm{O}$ membro preferencial era escolhido pelo participante após o examinador dar a seguinte orientação "quando eu falar já você irá ficar na posição de um pé só o maior tempo possível até que eu fale para você apoiar novamente o pé”; o tempo de manutenção na postura era cronometrado pelo examinador. O cronômetro era iniciado quando o indivíduo retirava um pé do chão e era parado quando ocorresse algum movimento brusco dos membros superiores ou o toque no solo do pé 
que estava suspenso. Cada indivíduo realizou uma primeira tentativa para o melhor entendimento da tarefa e logo em seguida o tempo foi cronometrado. O teste foi realizado com os indivíduos calçados. A tabela 1 resume as quatro tarefas funcionais avaliadas assim como o desempenho foi avaliado em cada uma delas.

Tabela-4. Tarefas funcionais

\section{TAREFAS Marcha - \\ FUNCIONAIS Distância percorrida em $30 \mathrm{seg}$}

Controle postural dinâmico -

Número de transferências de sedestação para bípede em 30 seg

Controle manual -

Número de cartas viradas em $30 \mathrm{seg}$

Controle postural estático -

Tempo de manutenção em apoio unipodal

\subsubsection{Tarefas específicas}

As tarefas específicas são oito atividades menos funcionais que as descritas anteriormente, sendo quatro definidas como motoras e quatro cognitivas. As tarefas específicas motoras foram assim denominadas, pois o principal determinante do sucesso do movimento é a própria qualidade do movimento; já nas tarefas cognitivas a ênfase foi à demanda cognitiva envolvida para a resolução da tarefa (SCHMIDT e WRISBERG, 2001). 
Todas as tarefas foram executadas durante o período de 30 segundos, nas mesmas condições das tarefas funcionais. Novamente, após a explicação da tarefa feita pelo examinador o paciente foi orientado a executar uma repetição de cada atividade para habituação com a atividade que deveria ser executada.

\subsubsection{Tarefas específicas motoras}

\subsection{Transferência de moedas:}

O indivíduo em inicialmente vestia um avental de tamanho apropriado fornecido pelo examinador (o tamanho apropriado era determinado quando os botões eram fechados e possibilitasse liberdade para a movimentação de membros superiores). Eram colocadas no bolso do lado da mão preferencial 20 moedas de plástico do tamanho de moedas de um real (aproximadamente 2,5 cm de diâmetro). $\mathrm{O}$ indivíduo era orientado a passar as moedas, uma por uma, usando a mão preferencial de um bolso para o outro, sendo que a outra mão poderia auxiliar apenas abrindo o bolso para facilitar o depósito das moedas.

\section{Posição inicial do indivíduo: bipedestação}

Instrução para a tarefa: "quando eu disser já você vai passar a maior quantidade de moedas de um bolso para o outro, o mais rápido possível até eu falar pare”.

Análise do desempenho: quantidade de moedas transferidas de um bolso para o outro em 30 segundos. 


\subsection{Pressionar um contador manual mecânico}

O indivíduo segurava em sua mão preferencial um contador manual, sendo solicitado para que ele apertasse a alavanca a maior quantidade de vezes possíveis. A quantidade de vezes que o paciente pressionava a pequena alavanca era visualizada no mostrador no contador manual.

Posição inicial: bipedestação

Instrução para a tarefa: "quando eu disser já você vai apertar o mais rapidamente possível esta alavanca até que eu fale pare"

Análise do desempenho: quantidade de vezes que o contador foi pressionado em 30 segundos. A figura 1 ilustra o contador manual mecânico utilizado no estudo.

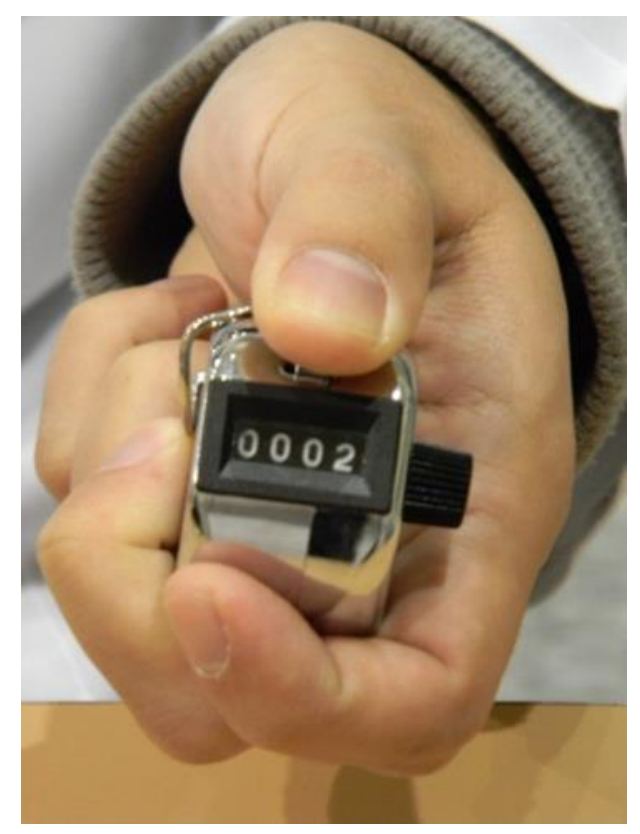

Figura-1. Contador manual mecânico 


\subsection{Pressionar um contador manual digital}

A tarefa proposta era similar a anterior, assim como a posição inicial, instrução para a tarefa e análise do desempenho; a única diferença era o formato do contador e a existência de um botão que deveria ser apertado. Foi optado por utilizar dois contadores visando evitar aprendizado. A figura 2 ilustra o contador manual digital utilizado no estudo.

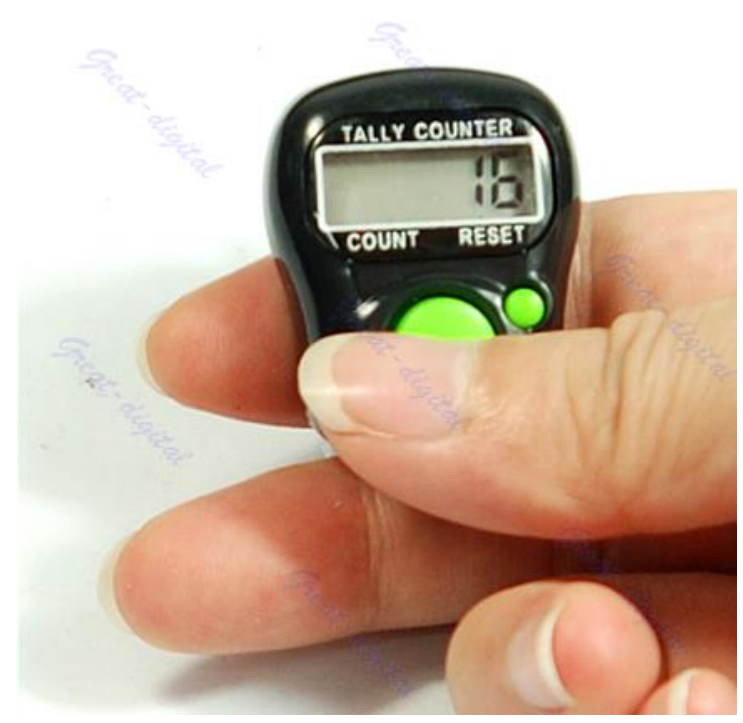

Figura-2. Contador manual digital

\subsection{Step}

Nesta atividade o participante permanecia sentado em uma cadeira e lateralmente ao seu membro inferior preferencial foi posicionado um step de $14 \mathrm{~cm}$ de altura. A tarefa consistia em retirar o pé do chão e tocar a sola o pé inteiro no step.

Posição inicial: sedestação (mantida durante toda a tarefa) 
Instrução para a tarefa: "quando eu disser já você vai bater o pé no chão e no step o mais rapidamente possível, eu vou contar quantas vezes você realiza este movimento até que eu fale pare".

Análise do desempenho: quantidade de vezes que o indivíduo tocou o pé no step no período de 30 segundos. A figura 3 ilustra a posição na qual permanecia o step para a realização da tarefa.

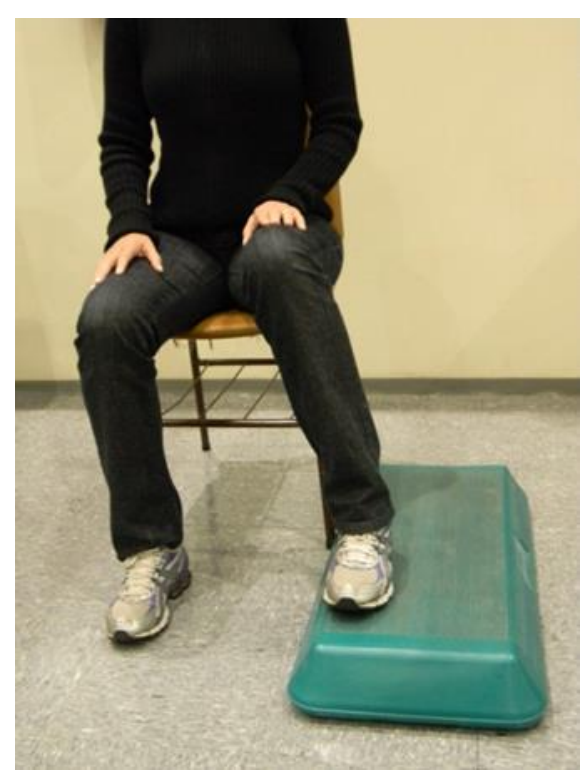

Figura-3. Tarefa específica motora utilizando um step. 
A seguir, as tarefas específicas motoras foram resumidas na tabela 5:

Tabela-5. Tarefas específicas motoras

\begin{tabular}{ll}
\hline TAREFAS & Transferência de moedas - \\
ESPECÍFICAS & Número de moedas transferidas em $30 \mathrm{seg}$ \\
MOTORAS & \\
\cline { 2 - 2 } & $\begin{array}{l}\text { Pressionar um contador manual mecânico - } \\
\text { Número de vezes que o contador foi pressionado em } 30 \mathrm{seg}\end{array}$ \\
& $\begin{array}{l}\text { Pressionar um contador manual digital - } \\
\text { Número de vezes que o contador foi pressionado em } 30 \mathrm{seg}\end{array}$ \\
& $\begin{array}{l}\text { Step - } \\
\text { Número de vezes que o participante tocava com o pé sobre o } \\
\text { step em } 30 \text { seg }\end{array}$ \\
&
\end{tabular}

4.5.2.2 Tarefas específicas cognitivas

\subsection{Subtração}

Os indivíduos realizavam operações mentais de subtração e respondiam em voz alta estas operações; número inicial para a subtração era 100, o resultado da primeira subtração era subtraído de sete e assim consecutivamente. $\mathrm{O}$ examinador, que permanecia ao lado do indivíduo participante e dizia "menos sete é..." para que o participante continuasse respondendo, independente do acerto ou não do cálculo.

Posição inicial: bipedestação 
Instrução para a tarefa: "quando eu disser já você irá fazer subtrações; eu vou dizer um número e eu quero que você diminua sete deste número e assim consecutivamente até que eu fale pare”.

Análise do desempenho: quantidade de operações corretas em 30 segundos.

\subsection{Fluência verbal}

Nesta atividade o indivíduo avaliado deveria falar a maior quantidade de nomes próprios com determinada letra escolhida pelo examinador; a letra escolhida era a letra M. Quando nomes iguais, porém de diferentes gêneros foram ditos (Márcio e Márcia, por exemplo) um deles não foi pontuado.

Posição inicial: bipedestação

Instrução para a tarefa: "quando eu disser já fale todos os nomes de pessoas que você conseguir lembrar, vale nome de mulher ou de homem, até que eu fale pare".

Análise do desempenho: quantidade de nomes foram ditos em 30 segundos. 


\subsection{Stroop auditivo}

Nesta tarefa o indivíduo ouvia uma gravação na qual uma voz masculina falava as palavras "alto" e "baixo" usando um tom de voz alto ou baixo em quatro diferentes combinações: a palavra "baixo" dita em tom de voz alto, a palavra "baixo" dita em tom de voz baixo; a palavra "alto" dita em tom de voz alto e finalmente a palavra "alto" dita em tom de voz baixo. A gravação ouvida pelo participante durava 30 segundos contendo a gravação de dez palavras, uma palavra dita a cada 3 segundos. Os indivíduos deveriam identificar e dizer logo após ouvir a gravação se o volume da voz era alto ou baixo, ignorando a palavra que era falada.

Posição inicial: sedestação

Instrução para a tarefa: "quando eu disser já você vai ouvir as palavras "alto" e "baixo" sendo faladas em um tom de voz alto ou baixo; você deve me responder, logo após a gravação, se o som da voz foi alto ou baixo, ignore a palavra que está sendo dita"

Análise do desempenho: quantidade de vezes o indivíduo acertou a discriminação das dez palavras.

\subsection{Stroop auditivo modificado}

Nesta tarefa o indivíduo ouvia uma gravação na qual uma voz masculina e uma voz feminina falavam as palavras "homem" e "mulher" em quatro diferentes combinações: a palavra "mulher" dita com voz de mulher, a palavra "mulher" dita com voz de homem; a palavra "homem" dita com voz de mulher e finalmente a palavra "homem" dita com voz de homem. A gravação ouvida pelo paciente durava 30 segundos contendo a gravação de dez palavras, uma palavra dita a cada 3 segundos. Os indivíduos deveriam identificar e dizer logo após ouvir a gravação se a voz era de uma mulher ou de um homem, ignorando a palavra que era falada. 
Posição inicial: sedestação

Instrução para a tarefa: "você vai ouvir duas pessoas falando as palavras "homem" e "mulher"; você deve me responder, logo após a gravação, se a voz é de uma mulher ou de um homem, ignore a palavra que está sendo dita”.

Análise do desempenho: quantidade de vezes o indivíduo acertou a discriminação das dez palavras.

A seguir, as tarefas específicas cognitivas foram resumidas na tabela 6:

Tabela-6. Tarefas específicas cognitivas:

\begin{tabular}{cl}
\hline TAREFAS & Subtração - \\
ESPECÍFICAS & Número de subtrações corretas em 30 seg \\
COGNITIVAS & \\
\hline
\end{tabular}

Fluência verbal -

Número de nomes próprios ditos em $30 \mathrm{seg}$

Stroop auditivo -

Número de acertos em 30 seg

\section{Stroop auditivo modificado -}

Número de acertos em $30 \mathrm{seg}$

- Aplicação do protocolo: O desempenho de todas as atividades, tanto das funcionais como das específicas motoras e cognitivas, foi avaliado isoladamente, situação denominada de tarefa simples (TS) e em associação, situação de dupla tarefa (DT). Na DT uma tarefa específica foi associada a uma tarefa específica motora e a uma específica cognitiva. 
Os participantes foram orientados a executar as tarefas propostas da melhor forma possível, isto é, não houve qualquer orientação por parte do examinador sobre a priorização de uma tarefa em relação à outra.

As tarefas foram filmadas pelo examinador para posterior verificação do desempenho das diferentes atividades. O protocolo foi aplicado individualmente, em um único dia, sempre pelo mesmo examinador no auditório da Associação Brasil Parkinson, um lugar silencioso e bem iluminado. O examinador permanecia ao lado dos indivíduos participantes durante todo o período da avaliação, fornecendo suporte externo se necessário. $\mathrm{O}$ examinador explicava detalhadamente cada atividade, logo após pedia para que o indivíduo realizasse uma repetição de cada tarefa para melhor entendimento e habituação da atividade proposta, porém não foi permitido mais que uma repetição para evitar fadiga e aprendizado.

\subsubsection{Avaliação em condição de TS}

$\mathrm{Na}$ avaliação em condição de TS o desempenho de todas as tarefas, tanto das funcionais como das específicas, foi analisado isoladamente, isto é, o indivíduo realizava apenas uma atividade.

4.5.4 Avaliação em Condições de dupla tarefa DT:

As 12 tarefas foram analisadas quanto ao seu desempenho também em condição de DT. As tarefas específicas e funcionais foram combinadas de tal forma que uma funcional fosse realizada simultaneamente a uma tarefa específica de característica motora e a uma específica de característica cognitiva. Os indivíduos participantes foram orientados a realizar ambas as tarefas com o mesmo empenho, sem priorizar uma das 
duas; o seguinte comando foi dado: "você vai realizar as duas tarefas ao mesmo tempo da melhor forma possível, tentando fazer as duas com a maior velocidade possível até que eu fale para você parar". Após esta orientação inicial nenhuma adicional foi feita durante a execução das atividades; caso o indivíduo cessasse a execução de uma das tarefas durante o teste não era feita nenhuma nova orientação ou incentivo.

A associação de uma tarefa funcional com uma tarefa específica motora foi denominada como dupla tarefa motora (DTM); quando a mesma tarefa funcional foi executada simultaneamente a uma tarefa específica de característica cognitiva foi chamada de dupla tarefa cognitiva (DTC). Portanto, a tarefa da marcha foi avaliada quando executada isoladamente em TS, em DTM e DTC.

As combinações das tarefas foram escolhidas pelo examinador com intuito de evitar limitação física à sua execução (por exemplo, associar a marcha com step). Durante a execução da DT ambas as tarefas foram avaliadas em seu desempenho, sendo que os indivíduos seguiram as mesmas orientações já descritas anteriormente para cada uma das 12 atividades. A tabela 7 a seguir mostra as combinações utilizadas neste estudo: 
Tabela-7. Combinações de tarefas funcionais e específicas motoras e cognitivas:
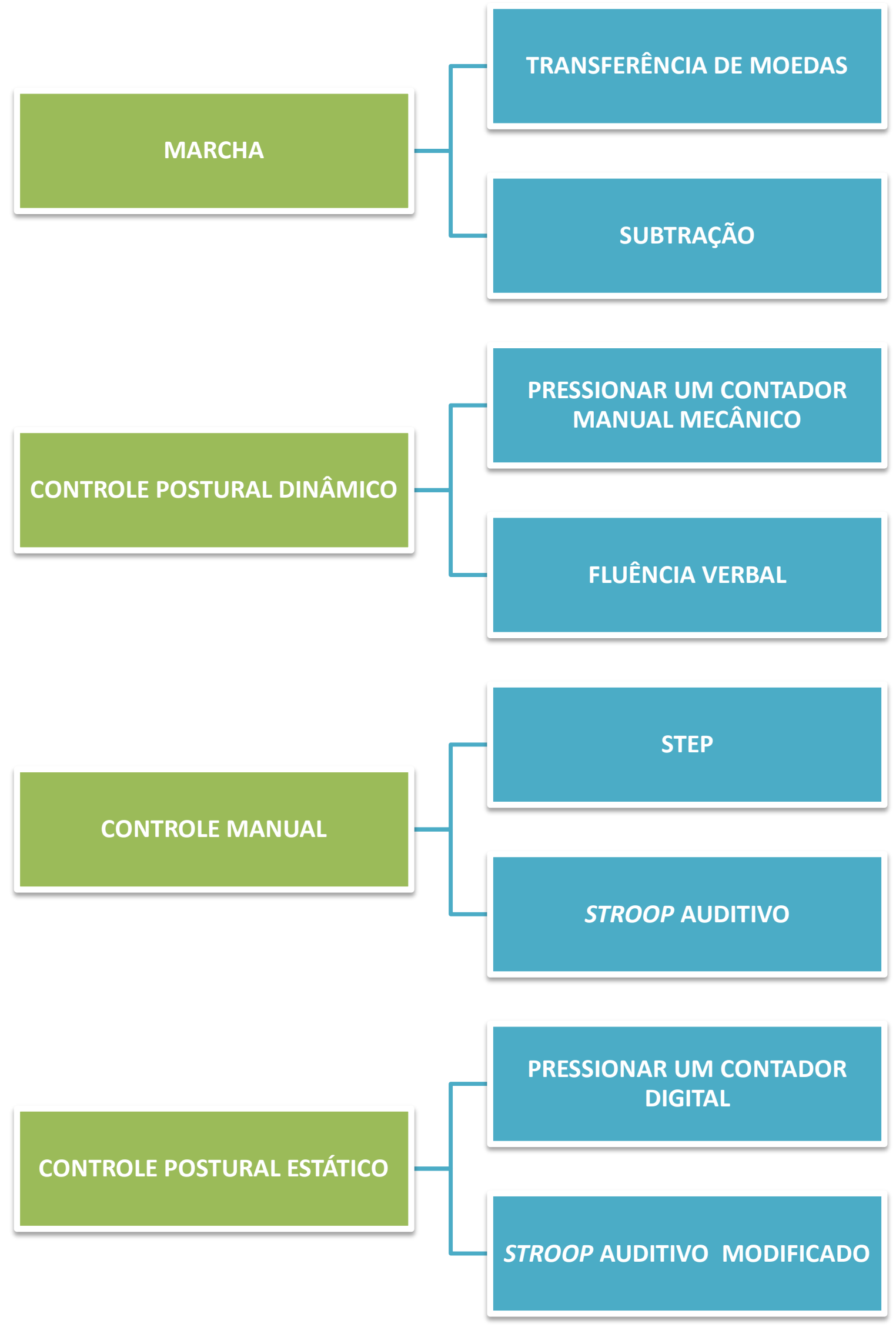
A marcha foi associada à transferência de moedas e a tarefa de subtração; na associação da marcha com a transferência de moedas, caso os indivíduos avaliados fizessem uso de bengala a tarefa era executada em todas as situações com este dispositivo, porém ao invés de transferir as moedas do bolso para o outro bolso era solicitado para que transferisse do bolso para a mão do examinador, que neste caso encontrava-se do lado contralateral do bolso de onde o indivíduo retirava as moedas. $\mathrm{Na}$ associação da tarefa de marcha com a subtração o examinador acompanhava o indivíduo participante enquanto este fazia os cálculos com a finalidade de anotar as respostas ditas.

$\mathrm{Na}$ tarefa de controle postural estático, a posição unipodal era mantida simultaneamente ao indivíduo pressionar o contador manual e depois enquanto realizava a tarefa de fluência verbal. $\mathrm{O}$ indivíduo participante era orientado a realizar as tarefas específicas apenas durante o tempo que conseguisse manter-se em unipodal.

As demais tarefas foram associadas, mantendo-se as mesmas orientações de execução da TS.

Foram definidas cinco estações (A, B, C, D e E) nas quais o participante circulava realizando as diferentes tarefas. As estações eram fixas, com intuito de facilitar a aplicação do protocolo e evitar a fadiga dos indivíduos, porém a ordem na qual o indivíduo iniciava nestas estações era aleatória, definida por sorteio ao início do teste. As estações eram compostas pelas seguintes tarefas:

- Estação A: marcha associada à tarefa de transferência de moedas; marcha em TS; marcha associada à tarefa de subtração.

- Estação B: Stroop auditivo modificado; Stroop auditivo modificado e tarefa de troca postural; step; tarefa de pressionar em contador manual digital.

- Estação C: posição unipodal e tarefa de pressionar um contador manual mecânico; Stroop auditivo; Stroop auditivo e tarefa de virar cartas; tarefa de transferência de moedas.

- Estação D: unipodal com tarefa de fluência verbal; tarefa de troca postural e tarefa de pressionar em contador manual digital; tarefa de virar cartas; tarefa de pressionar um contador mecânico.

- Estação E: tarefa de virar cartas e step; unipodal; tarefa de troca postural; tarefa de fluência verbal; subtração. 
Durante a aplicação dos testes nos indivíduos participantes, o tempo de duração do teste e a habilidade ou não de concluir o teste foram anotados pelo examinador. 


\subsection{Análise dos resultados}

Os dados demográficos e as características clínicas do grupo jovem, idoso, pacientes com DP nos estágios I, II e III da escala de Hoenh Yahr foram comparados por meio de Análise de variância de medidas repetidas (RM-ANOVA) one-way.

Para a análise da sensibilidade dos testes, o desempenho de todos os indivíduos foram analisados nas tarefas funcionais, tarefas específicas motoras e cognitivas; as tabelas abaixo descrevem as medidas de desempenho para cada uma das tarefas avaliadas:

Tabela-8: Medida de desempenho das tarefas funcionais

\section{TAREFA FUNCIONAL}

Marcha

Controle postural dinâmico

Controle postural estático

Controle manual

\section{MEDIDA DE DESEMPENHO}

Distância percorrida expressa em metros

$\mathrm{N}^{0}$ de trocas de sedestação para bipedestação

Tempo de manutenção em apoio unipodal

$\mathrm{N}^{\mathrm{o}}$ de cartas viradas

Abreviações: $\mathrm{N}^{\circ}$, Número.

Tabela 9: Medidas de desempenhos das tarefas específicas motoras

\begin{tabular}{lc}
\hline TAREFAS ESPECÍFICAS MOTORAS & MEDIDA DE DESEMPENHO \\
\hline Transferência de moedas & $\mathrm{N}^{\circ}$ de moedas transferidas \\
Pressionar um contador manual mecânico & $\mathrm{N}^{\mathrm{o}}$ de vezes que o contador foi pressionado \\
Pressionar um contador manual digital & $\mathrm{N}^{\mathrm{o}}$ de vezes que o contador foi pressionado \\
Step & $\mathrm{N}^{\mathrm{o}}$ de vezes que o pé tocava no step
\end{tabular}

Abreviações: $\mathrm{N}^{\mathrm{o}}$, Número. 
Tabela-10. Medidas de desempenho das tarefas específicas cognitivas.

\section{TAREFAS ESPECÍFICAS COGNITIVAS MEDIDA DE DESEMPENHO}

\begin{tabular}{lc}
\hline Subtração & $\mathrm{N}^{\mathrm{o}}$ de subtrações corretas \\
Fluência verbal & $\mathrm{N}^{\mathrm{o}}$ de nomes próprios \\
Stroop auditivo & $\mathrm{N}^{\mathrm{o}}$ de acertos em dez tentativas \\
Stroop auditivo modificado & $\mathrm{N}^{\mathrm{a}}$ de acertos em dez tentativas
\end{tabular}

Abreviações: $\mathrm{N}^{\circ}$, Número.

Foram realizadas 8 RM-ANOVA (2X3) utilizando o fator grupo e as três condições de teste (TS, DTM e DTC), sendo a última repetida (2x3 ANOVA). Deste modo, foram comparados os grupos idosos com jovens e idosos com DP e os respectivos desempenhos da TS com DTM, da TS com DTC e entre DTM e DTC, para as tarefas funcionais de marcha, controle postural estático, controle postural dinâmico e controle manual. Para os efeitos que alcançaram nível de significância, foi realizado o pos hoc teste de Tukey, para a verificação de eventuais diferenças entre os mesmos.

Foram realizadas quatro RM-ANOVA (3x3) utilizando o fator grupo e as três condições de teste (TS, DTM e DTC), sendo a última repetida (3x3 ANOVA). Deste modo, foram comparados os pacientes com DP no estágio I com estágio II, estágio I com estágio III e estágio II com estágio III e os respectivos desempenhos da TS com DTM, da TS com DTC e entre DTM e DTC, para as tarefas funcionais de marcha, controle postural estático, controle postural dinâmico e controle manual. Para os efeitos que alcançaram nível de significância, foi realizado o pos hoc teste de Tukey, para a verificação de eventuais diferenças entre os mesmos.

Para análise da sensibilidade das condições propostas, foi calculado o custo total motor e o custo total cognitivo para cada tarefa.

O custo motor na tarefa funcional representa a perda percentual de desempenho que houve após a introdução de uma tarefa concorrente. Também foi calculado o custo da tarefa específica motora, ou seja, a perda de desempenho na tarefa específica motora 
devido a execução simultânea com a tarefa funcional. $\mathrm{O}$ custo foi calculado segundo a fórmula TS - DTM/ TS x 100. Assim foi calculado o custo gerado pela DT em todas as tarefas avaliadas.

Portanto, o custo total da DTM foi a soma do custo da tarefa funcional e o custo da tarefa motora específica, enquanto que o custo total da DTC foi a soma custo da tarefa funcional e o custo da tarefa cognitiva específica.

Foram realizadas quatro RM-ANOVA $(2 \times 4)$ utilizando o fator grupo e o custo total da DTM e o custo total da DTC nas quatro tarefas avaliadas (marcha, controle postural estático, controle postural estático, controle manual). Deste modo foi comparado o custo total da DTM e DTC nos grupos jovens e idosos e idosos e pacientes com DP. Para os efeitos que alcançaram nível de significância, foi realizado o pos hoc teste de Tukey, para a verificação de eventuais diferenças entre os mesmos.

Foram realizadas duas RM-ANOVA $(3 \times 4)$ utilizando o fator o fator grupo e o custo total da DTM e o custo total das DTC nas quatro tarefas avaliadas (marcha, controle postural estático, controle postural estático, controle manual), comparando os custos dos pacientes com DP no estágio I com estágio II, estágio I com estágio III e estágio II com estágio III nas quatro tarefas funcionais. Para os efeitos que alcançaram nível de significância, foi realizado o pos hoc teste de Tukey, para a verificação de eventuais diferenças entre os mesmos.

O nível de significância adotado neste estudo foi de 0,05 . 


\section{RESULTADOS}

\subsection{Dados demográficos e características dos indivíduos}

\subsubsection{Grupo de indivíduos jovens}

A média de idade do grupo formado pelos indivíduos jovens foi de 25,56 (6,17). Neste grupo não foi aplicado o MEEM, já que o grupo era composto por estudantes universitários ou a GDS-15.

\subsubsection{Grupo de idosos}

A média de idade dos idosos foi de 69,36 $(7,74)$, a pontuação média do MEEM foi 27,31 (2,55) e da GDS-15 4,92 (2,52).

\subsubsection{Grupo de indivíduos com DP}

A média de idade dos indivíduos com DP no estágio I da escala de Hoehn Yahr foi de 66, 68 (6,23), no grupo com estágio II $69,80(7,44)$ e no estágio III foi 74,80 $(6,43)$. Já a pontuação média no MEEM nos indivíduos no estágio I foi 26,38 $(2,19)$, 27,47 no estágio II e 26,12 no estágio III da DP. Por fim, a pontuação média na escala GDS-15 nos indivíduos com DP no estágio I foi de 4,13 (1,93), no estágio II a pontuação foi $4,53(2,24)$ e $4,47(2,17)$ no estágio III. 
5.3. Análise da sensibilidade das tarefas funcionais propostas

5.3.1 - Sensibilidade para as alterações decorrentes do envelhecimento

A fim de verificar a sensibilidade do teste proposto para as alterações decorrentes do processo de envelhecimento, foi comparado o desempenho entre adultos jovens e idosos, em cada uma das quatro tarefas funcionais propostas. 
A análise do desempenho de marcha por meio da ANOVA mostrou um efeito significativo de grupo [RM-ANOVA; $\mathrm{F}(1,36)=25,890 ; \mathrm{p}=00001$, poder observado $=$ 0,99] e de condição [RM-ANOVA; $\mathrm{F}(2,72)=40,896 ; \mathrm{p}=0,00000$, poder observado $=0,99$ ], sem interação significativa entre os mesmos, confirmados pelo pos hoc teste de Tukey, que mostrou uma perda significativa de desempenho na condição de DT em comparação a TS, com o desempenho de idosos inferior ao de jovens em todas as condições de teste (Figura-4).

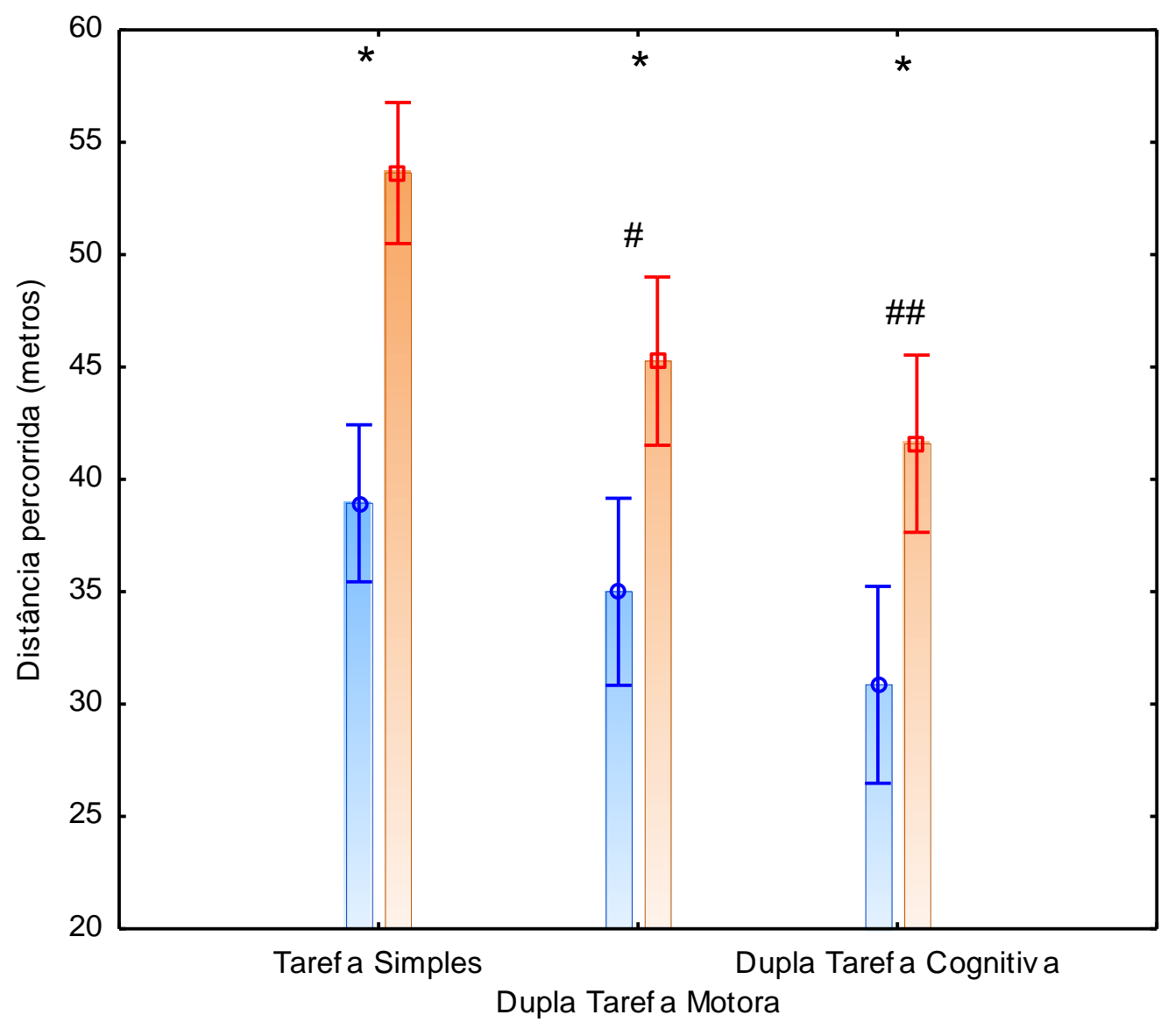

Figura-4. Desempenho da marcha. A distância percorrida no período de 30 segundos em tarefa simples, dupla tarefa motora e dupla tarefa cognitiva, comparando idosos e jovens. $*$ diferença significativa entre grupos no teste de Tukey, $\mathrm{p}<0,05$. \# = diferença significativa em comparação a TS no teste de Tukey, $\mathrm{p}<0,05$, \#\# = diferença significativa em comparação a TS e DTM no teste de Tukey, $\mathrm{p}<0,05$. 
$\mathrm{Na}$ análise do desempenho do controle postural dinâmico, com efeito significativo de grupo [RM-ANOVA; $\mathrm{F}(1,36)=36,553 ; \mathrm{p}=0,0000$, poder observado = $0,99]$ e de condição [RM-ANOVA; $\mathrm{F}(2,72)=34,308 ; \mathrm{p}=0,0000$, poder observado $=$ 0,99], (Figura-5) e para o desempenho do controle manual, efeito significativo de grupo [RM-ANOVA; $\mathrm{F}(1,36)=71,240 ; \mathrm{p}=0,0000$, poder observado $=0,99$ ] e de condição [RM-ANOVA; $\mathrm{F}(2,72)=56,229 ; \mathrm{p}=0,0000$, poder observado $=0,99$ ] (Figura6). Segundo o pos hoc teste de Tukey, os idosos mostraram desempenho inferior em relação aos jovens em ambas as tarefas funcionais em todas as comparações testadas. Analisando especificamente as condições de teste, isto é, diferenças de desempenho entre a TS, DTM e DTC independente do grupo, na tarefa de controle postural dinâmico houve prejuízo significativo na comparação entre a condição de TS para a condição de DTC e entre as tarefas em DT, isto é, DTC e DTM, enquanto que para a tarefa de controle manual houve prejuízo significativo em todas as comparações das condições feitas, TS e DTM, TS e DTC, DTM e DTC. 


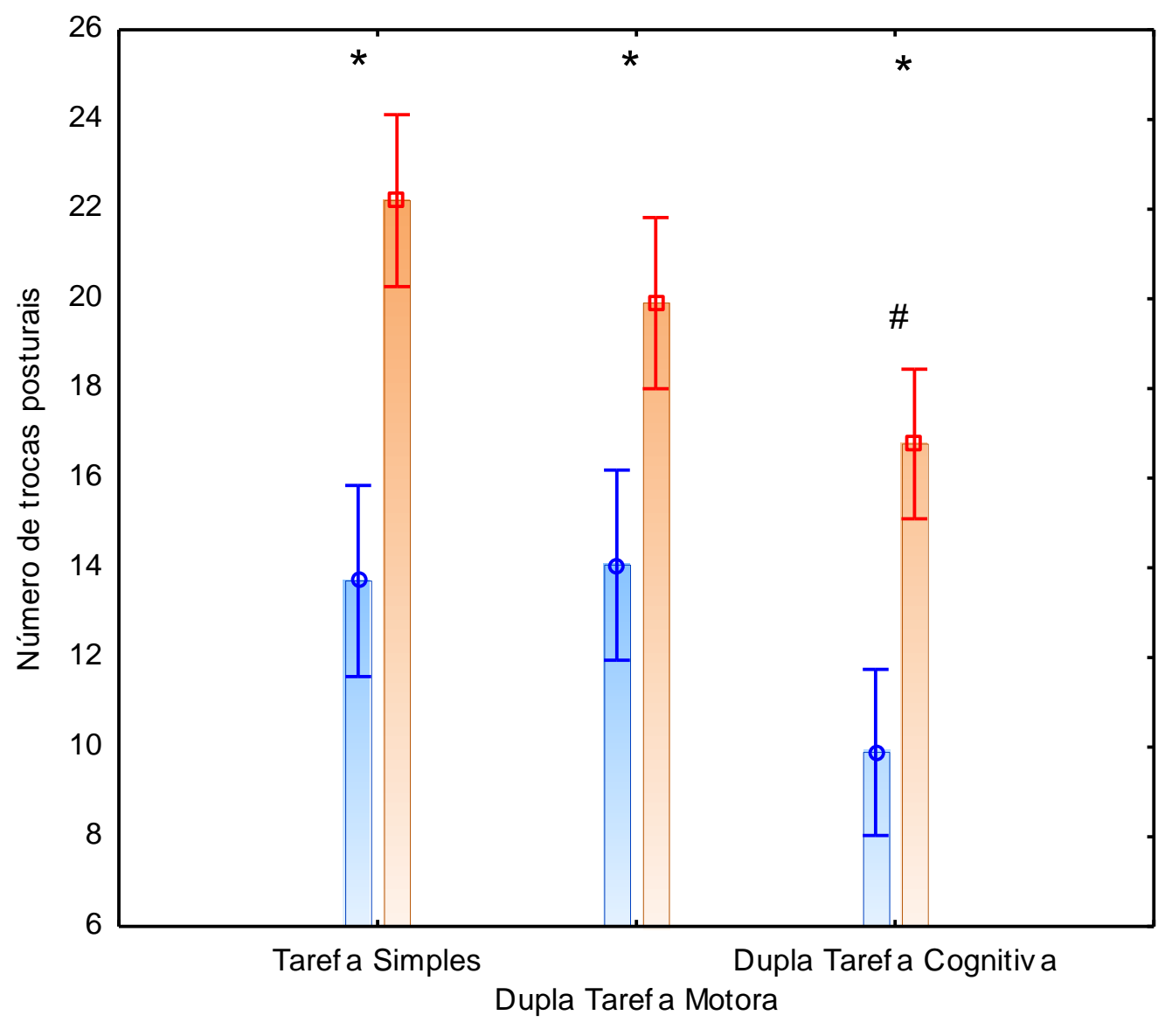

Figura-5. Desempenho do controle postural dinâmico. O número de trocas posturais realizadas em 30 segundos em tarefa simples, dupla tarefa motora e dupla tarefa cognitiva, comparando idosos e jovens. $*$ = diferença significativa entre grupos no teste de Tukey, $\mathrm{p}<0,05 . \#$ = diferença significativa em comparação a TS e a DTM no teste de Tukey, $\mathrm{p}<0,05$. 


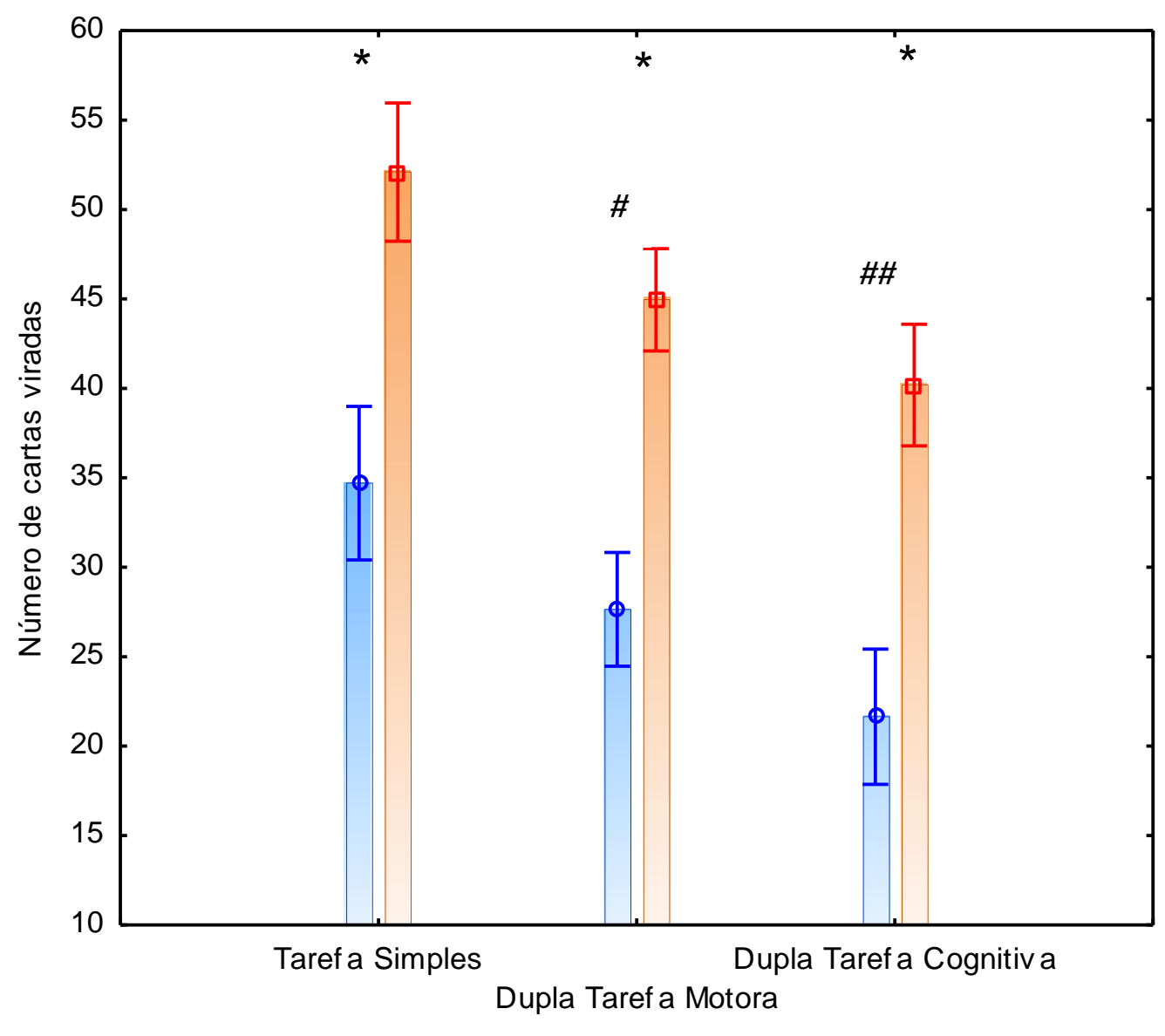

Figura-6. Desempenho do controle manual. Número de cartas viradas em 30 segundos em tarefa simples, dupla tarefa motora e dupla tarefa cognitiva, comparando idosos e jovens. $*$ diferença significativa entre grupos no teste de Tukey, $\mathrm{p}<0,05$. \# = diferença significativa em comparação a TS no teste de Tukey, $\mathrm{p}<0,05$, \#\# = diferença significativa em comparação a TS e DTM no teste de Tukey, $\mathrm{p}<0,05$. 
Já a análise do controle postural estático mostrou efeito significativo apenas para grupo [RM-ANOVA; $\mathrm{F}(1,36)=44,405 ; \mathrm{p}=0,0000$, poder observado $=0,99$ ], confirmado pelo pós-teste que mostrou que idosos tem um desempenho inferior independente da condição de teste. (Figura-7).

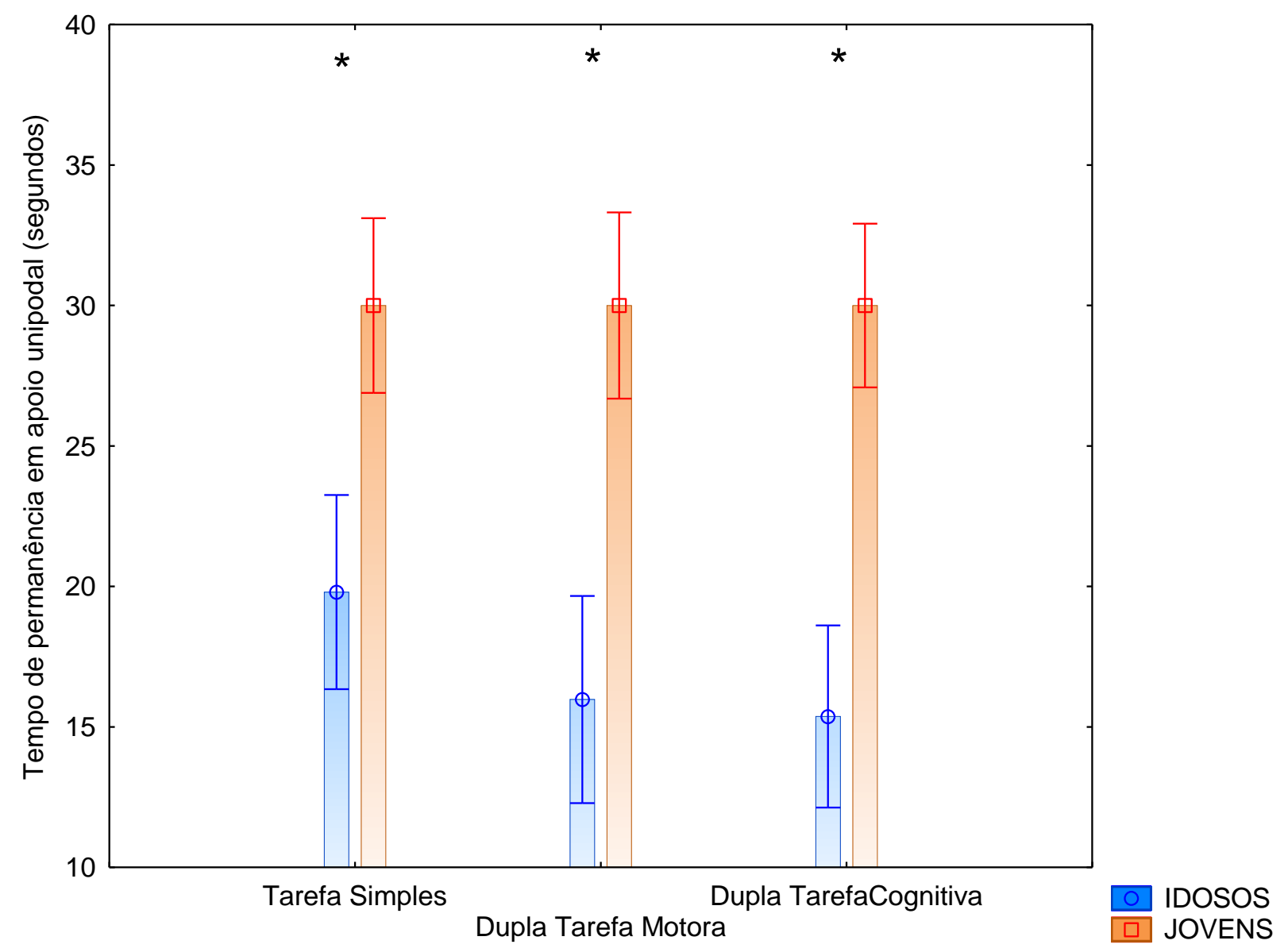

Figura-7. Desempenho do controle postural estático. Tempo de permanência em apoio unipodal em tarefa simples, dupla tarefa motora e dupla tarefa cognitiva, comparando idosos e jovens. $*=$ diferença significativa entre grupos no teste de Tukey, $\mathrm{p}<0,05$. 
Em síntese, as quatro tarefas funcionais propostas pelo teste mostraram-se sensíveis para identificar as diferenças de desempenho entre idosos e jovens, tanto quando avaliadas em isoladamente ou, mais importante, em condições de divisão de atenção seja com outra tarefa motora, seja com uma tarefa cognitiva.

Com relação ao desempenho das tarefas funcionais, estes resultados indicam que os idosos percorreram uma menor distância andando em relação aos jovens, permaneceram menos tempo em apoio unipodal, realizaram menor número de trocas posturais de sedestação para bípede na tarefa de controle postural dinâmico e demonstraram menor velocidade de execução em virar cartas quando estas atividades foram realizadas de maneira isolada. Entretanto, das quatro tarefas propostas, apenas a marcha e a tarefa manual mostraram-se sensíveis para detectar perdas de desempenho associadas à inclusão de outra tarefa, bem como diferenças de desempenho na execução entre uma tarefa motora e cognitiva, sendo o maior impacto na última assim como na tarefa de controle postural dinâmico, que apenas não identificou diferenças entre TS e DTM.

A tarefa de equilíbrio estático apesar de detectar diferenças de desempenho entre os grupos estudados, não foi sensível a inclusão das tarefas específicas. Portanto, todas as tarefas propostas foram sensíveis para identificar prejuízos de desempenho associados ao processo de envelhecimento; analisando as condições propostas, as tarefas da marcha e a tarefa manual foram as mais sensíveis para identificar diferenças resultantes da inclusão de outra tarefa, ou seja, demonstraram que realizar tarefas simultâneas causa custos, sendo estes custos mais "altos" quando houve a introdução de uma tarefa específica cognitiva. 


\subsubsection{Sensibilidade para as alterações decorrentes da DP}

Para a verificação da sensibilidade do teste elaborado para a identificação de alterações decorrentes da DP, foi comparado o desempenho entre idosos e indivíduos com DP em cada uma das quatro tarefas funcionais.

A análise do desempenho da tarefa de marcha por meio da ANOVA mostrou efeito uma interação significativa entre grupo e condição, ou seja, os fatores analisados agem de forma dependente sobre a variável resposta [RM-ANOVA; $F(2,122)=3,8574$; $\mathrm{p}=0,02$, poder observado $=0,70]$. O pos hoc teste de Tukey mostrou perda significativa de desempenho dos indivíduos com DP em relação aos idosos apenas na condição de DTM. Mostrou ainda que para os indivíduos idosos houve prejuízos significativos entre as condições de TS e ambas as DT além de diferenças entre DTM e DTC, enquanto para indivíduos com DP, houve prejuízos significativos apenas entre as condições de TS e DT (Figura-8). 


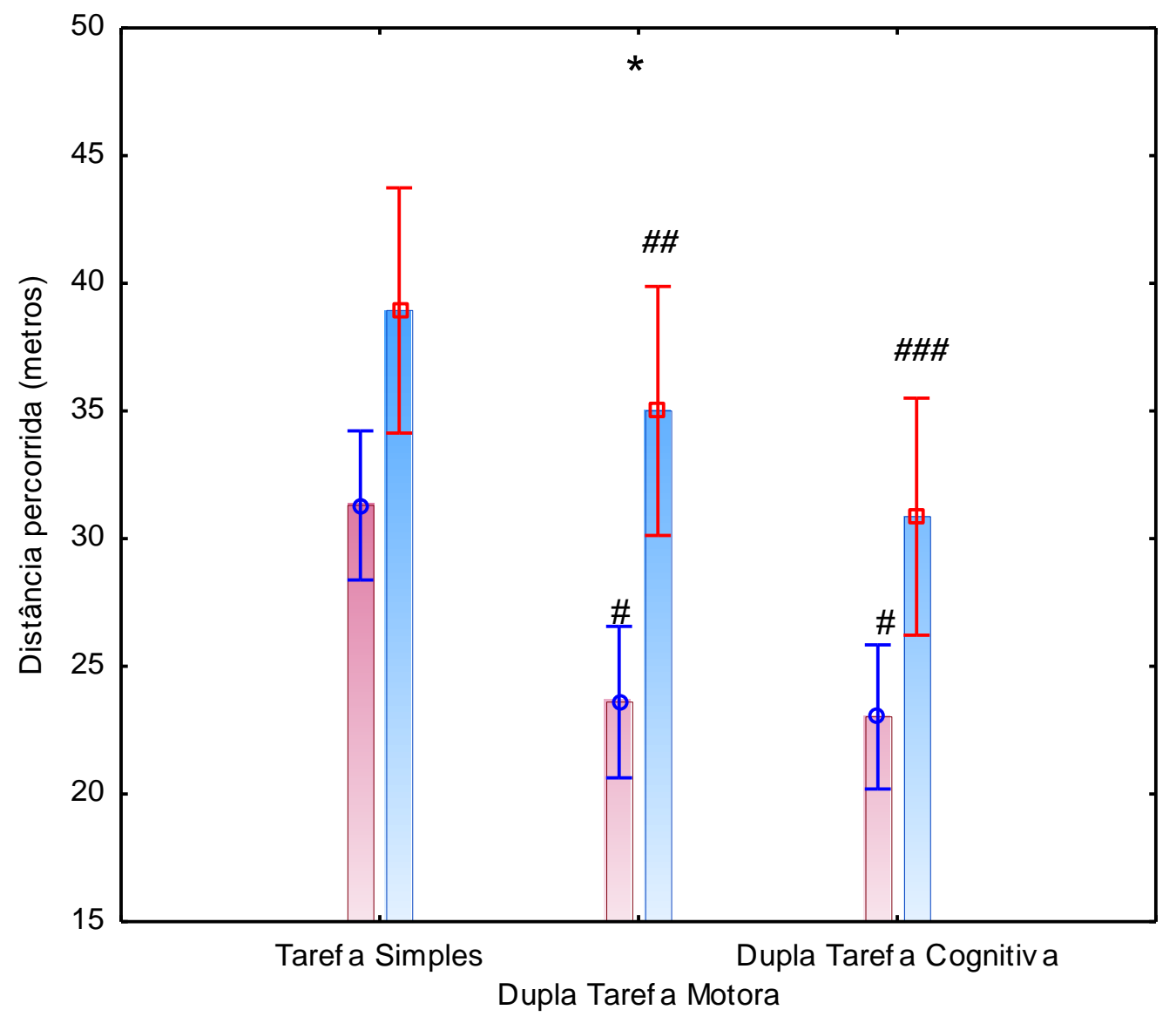

Figura-8. Desempenho da marcha. Distância percorrida no período de 30 segundos em tarefa simples, dupla tarefa motora e dupla tarefa cognitiva, comparando indivíduos com DP e idosos. . * = diferença significativa entre grupos no teste de Tukey, $\mathrm{p}<0,05$. \# = diferença significativa em comparação a TS em indivíduos com DP no teste de Tukey, $\mathrm{p}<0,05$. \#\# = diferença significativa entre TS e DTC em indivíduos idosos. \#\#\# = diferença significativa em comparação a TS em indivíduos idosos no teste de Tukey, $\mathrm{p}<0,05$ 
$\mathrm{Na}$ análise do desempenho do controle postural dinâmico, também houve uma interação significativa entre grupo e condição [RM-ANOVA; $F(2,122)=5,0202$; $\mathrm{p}=0,008$, poder observado $=0,80]$. $\mathrm{O}$ pos hoc teste de Tukey mostrou um prejuízo significativo no desempenho de indivíduos com DP em comparação a idosos novamente apenas na condição de DTM. Mostrou também que para ambos os grupos houve um prejuízo significativo da DTC em comparação a TS e a DTM, mas apenas para indivíduos com DP houve prejuízo significativo da DTM em comparação a TS (Figura9).

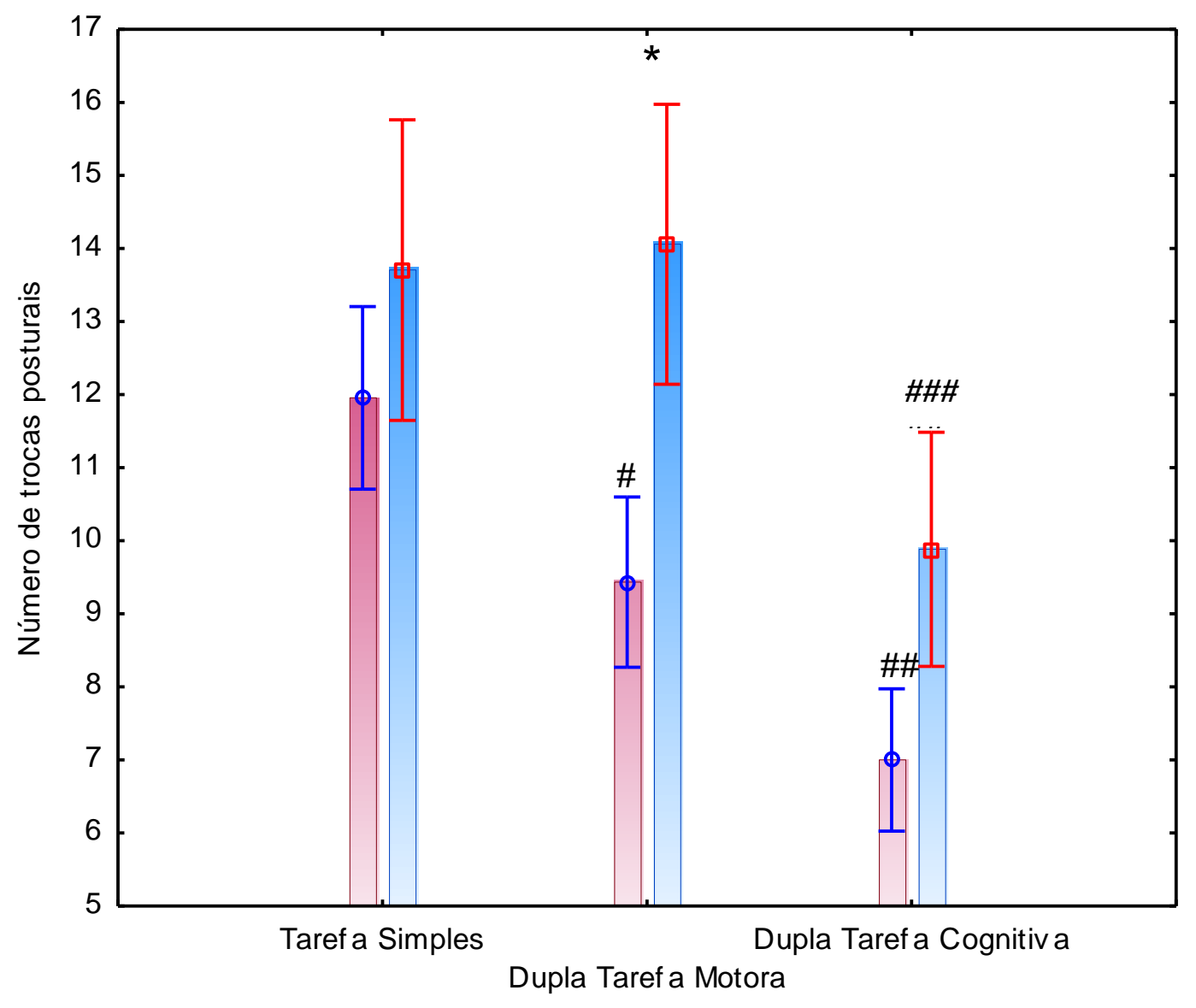

Figura-9. Desempenho no controle postural dinâmico. Número de trocas posturais realizadas em 30 segundos em tarefa simples, dupla tarefa motora e dupla tarefa cognitiva, comparando indivíduos com DP e idosos. * = diferença significativa entre grupos na condição de DTM no teste de Tukey, $\mathrm{p}<0,05$. \# = diferença significativa em comparação a TS em indivíduos com DP no teste de Tukey, $\mathrm{p}<0,05$. \#\# = diferença significativa em comparação da TS e DTM em indivíduos com DP. \#\#\# = diferença significativa entre TS e DTM em indivíduos idosos. 
Na comparação do desempenho do controle manual de idosos e indivíduos com DP houve efeito de grupo [RM-ANOVA; $F(2,43)=12,260 ; \mathrm{p}=0,0000$, poder observado $=0,97$, condição [RM-ANOVA; $F(2,86)=58,257 ; \mathrm{p}=0,0000$, poder observado $=0,99$ ], porém não houve interação. Estes dados foram confirmados pelo pós teste de Tukey, que mostrou um desempenho significativamente inferior de indivíduos com DP em comparação aos idosos em todas as condições. Também houve diferença significativa de desempenho entre todas as condições, independente do grupo (Figura10).

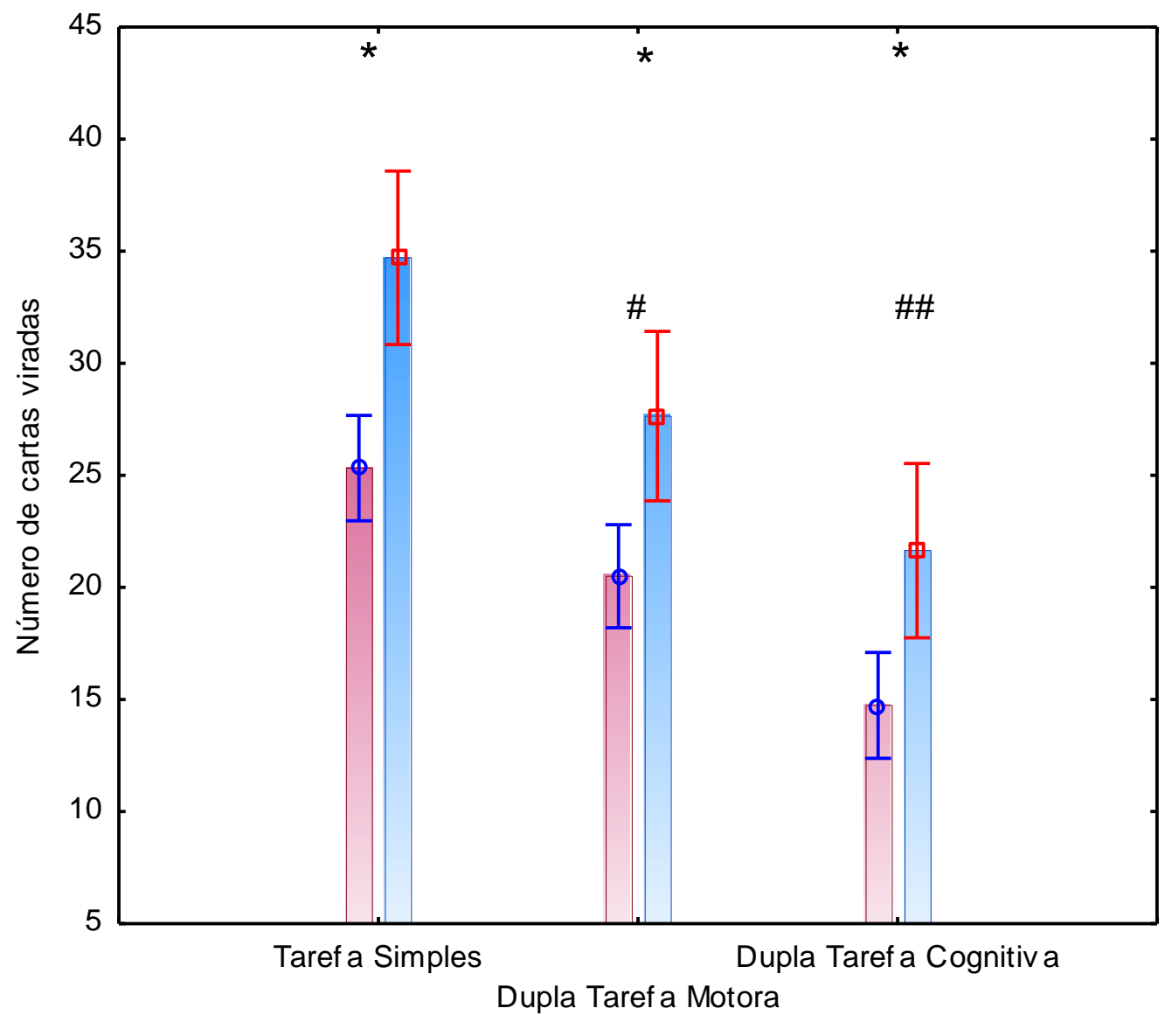

Figura-10. Desempenho do controle manual. Número de cartas viradas em 30 segundos em tarefa simples, dupla tarefa motora e dupla tarefa cognitiva, comparando indivíduos com DP e idosos. * = diferença significativa entre grupos no teste de Tukey, $\mathrm{p}<0,05$. \# = diferença significativa em comparação a TS e no teste de Tukey, p < 0,05, \#\#= diferença significativa em comparação a TS e DTM no teste de Tukey, $\mathrm{p}<0,05$. 
A análise do desempenho do controle postural estático em idosos e indivíduos com DP houve efeito de condição [RM-ANOVA; $F(2,122)=3,2577 ; \mathrm{p}=0,04$, poder observado $=0,70]$, porém o pos hoc teste de Tukey não confirmou esta diferença. Não houve efeito grupo ou interação (Figura-11).

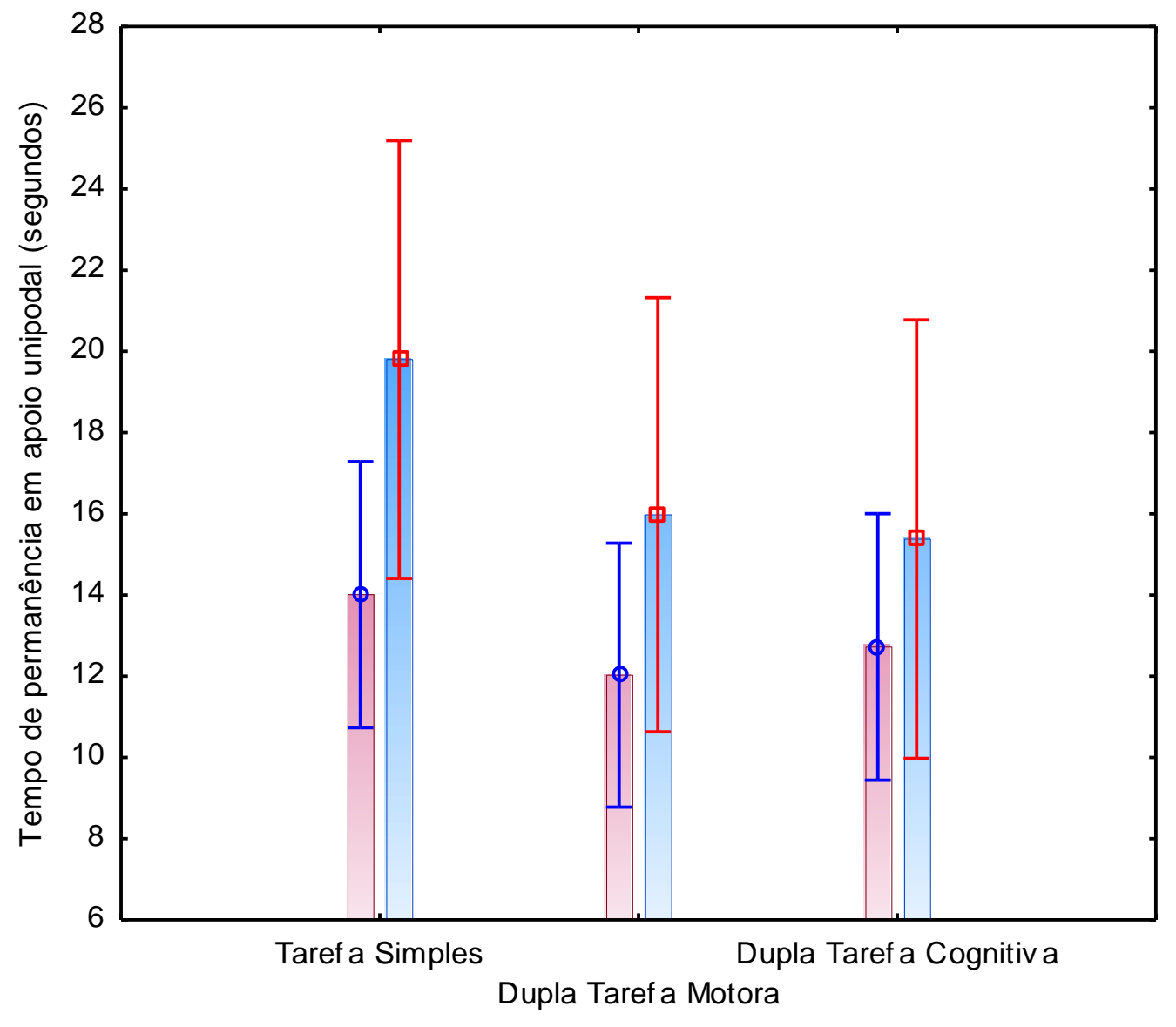

Figura-11. Desempenho do controle postural estático. Tempo de permanência em apoio unipodal em tarefa simples, dupla tarefa motora e dupla tarefa cognitiva, comparando indivíduos com DP e idosos. 
Em conjunto, os resultados mostraram que a tarefa mais sensível para identificar as diferenças de desempenho entre idosos e indivíduos com DP foi a de controle manual, onde os indivíduos com DP apresentaram desempenho inferior aos idosos em todas as comparações. Quanto a análise das condições testadas, ou seja, com e sem divisão de atenção, houve diferença significativa entre TS, DTM e DTC, com pior desempenho da DTC em todas as comparações feitas, independente do grupo. Isto demonstra que executar movimentos manuais em DT causa custos a execução em ambos os grupos, especialmente quando a tarefa acrescentada é uma de característica cognitiva.

Houve interação positiva entre grupo e condição na tarefa de marcha e de controle postural dinâmico, sendo que ambas mostraram-se sensíveis para detectar diferenças no desempenho específicas da DP apenas na condição de DTM, ou seja, nesta condição os indivíduos com DP apresentaram comportamento diferente ao de idosos.

Devido à interação positiva, foi possível analisar diferenças de desempenho dentro de cada grupo nestas duas tarefas funcionais. Na tarefa da marcha, os idosos apresentaram prejuízos na execução de ambas as DT quando comparado a TS e entre a DTM e DTC, com perda mais significativa na DTC na marcha; o mesmo foi verificado no controle postural dinâmico, exceto por não haver diferença estatística entre a DTM e TS.

$\mathrm{Na}$ análise dos indivíduos com DP houve diferença entre todas as condições no controle postural dinâmico, com pior desempenho na DTC, enquanto que na marcha a única comparação sem diferença estatística foi entre DTM e DTC, mostrando que a natureza da tarefa específica acrescentada a marcha não influenciou, mas sim o fato de dividir a atenção em dois focos concorrentes, seja ele motor ou cognitivo.

A tarefa de controle postural estático não identificou qualquer diferença entre os grupos ou condições testadas. Portanto, a tarefa mais sensível para identificar prejuízos no desempenho associados a divisão de atenção foi a de controle manual. Entretanto, as únicas tarefas capazes de identificar prejuízos relacionados especificamente à divisão de atenção em indivíduos com DP e idosos foram a da marcha e o controle postural dinâmico, pois nas mesmas os grupos mostraram comportamentos diferentes de acordo com a natureza da tarefa associada, motora ou cognitiva. 


\subsubsection{Sensibilidade para as alterações decorrentes da progressão da DP}

Com o intuito de verificar a sensibilidade do teste proposto na identificação de alterações decorrentes da progressão da DP, foi feita a comparação entre indivíduos nos estágios iniciais e moderados da doença através da verificação do desempenho de indivíduos com DP nos estágios I, II e III da escala de estadiamento de HY. 
A análise do desempenho da marcha mostrou efeito significativo de grupo [RM-ANOVA; $F(2,43)=22,092 ; \mathrm{p}=0,0000$, poder observado $=0,99]$, condição [RMANOVA; $F(2,86)=84,089 ; \mathrm{p}=0,0000$, poder observado $=0,99]$, porém não houve interação significativa. $\mathrm{O}$ pos hoc teste de Tukey evidenciou diferença significativa de desempenho entre os três grupos de indivíduos, independente da condição e diferença no desempenho global entre as condições de TS e ambas as DT testadas (Figura-12).

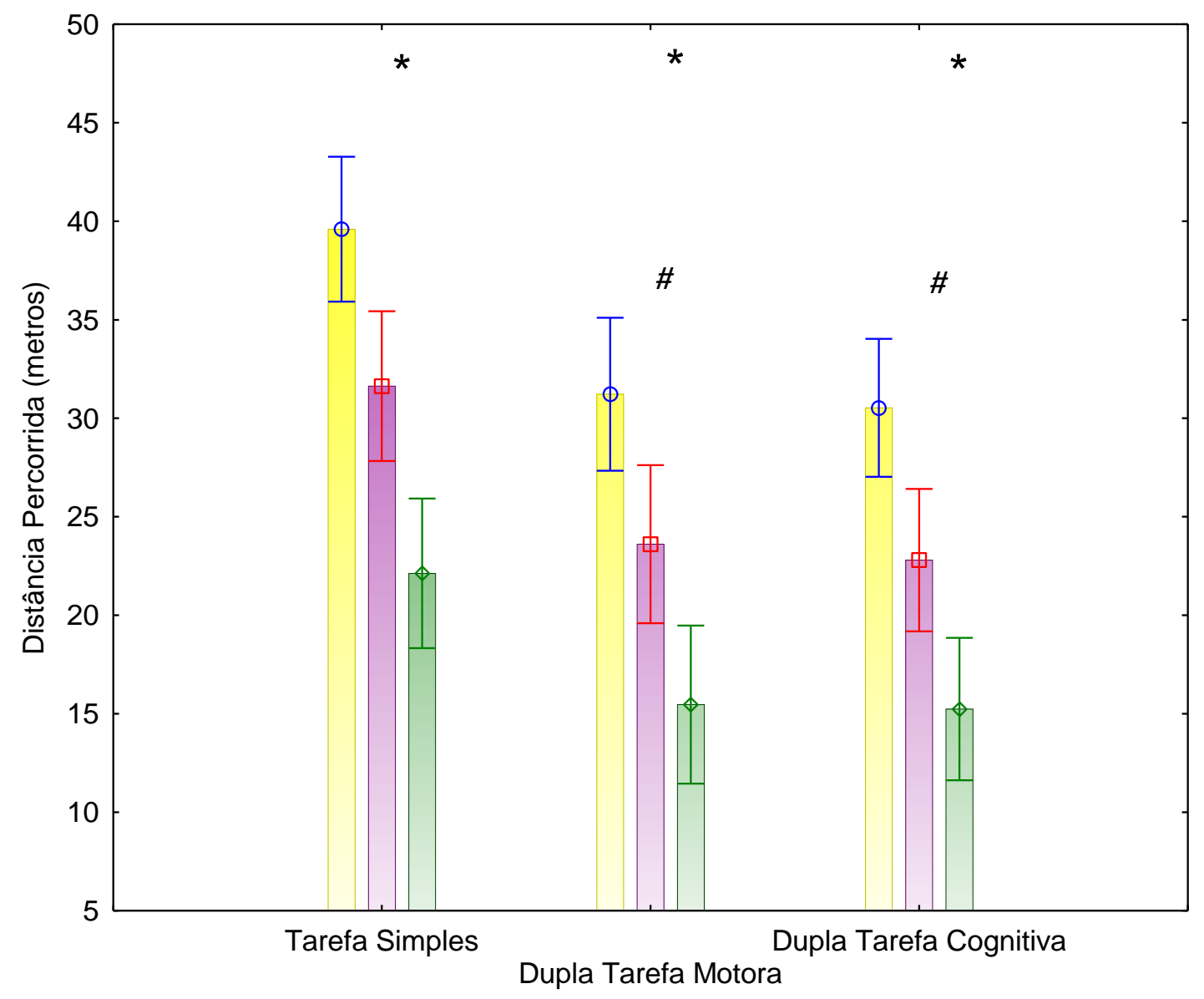

Figura-12. Desempenho da marcha. Distância percorrida no período de 30 segundos em tarefa simples, dupla tarefa motora e dupla tarefa cognitiva, comparando indivíduos com DP nos estágios I, II e III. * = diferença significativa entre grupos no teste de Tukey, $\mathrm{p}<0,05$. \# = diferença significativa em comparação a TS no teste de Tukey, $\mathrm{p}<$ 0,05 . 
$\mathrm{Na}$ análise do desempenho do controle postural dinâmico houve efeito de grupo [RM-ANOVA; $F(2,43)=16,803 ; \mathrm{p}=0,0000$, poder observado $=0,99$ ], condição $[$ RM-ANOVA; $F(2,86)=64,148 ; \mathrm{p}=0,0000$, poder observado $=0,99]$, sem efeito de interação (Figura-13), resultados semelhantes ao desempenho do controle manual, onde não houve interação, porém houve efeito de grupo [RM-ANOVA; $F(2,43)=$ 12,$260 ; \mathrm{p}=0,0000$, poder observado $=0,99$ ] e condição [RM-ANOVA; $F(2,86)=$ 58,257; $\mathrm{p}=0,0000$, poder observado $=0,99$ ] (Figura-14). O pos hoc teste de Tukey confirmou diferenças significativas de desempenho entre as condições (TS em comparação a DTM e DTC, além de diferença entre as condições de DT) para ambas as tarefas funcionais, entretanto, na tarefa de controle postural dinâmico houve diferenças entre os três estágios da doença, enquanto para a de controle manual apenas no estagio III em comparação a I e II, independente da condição. 


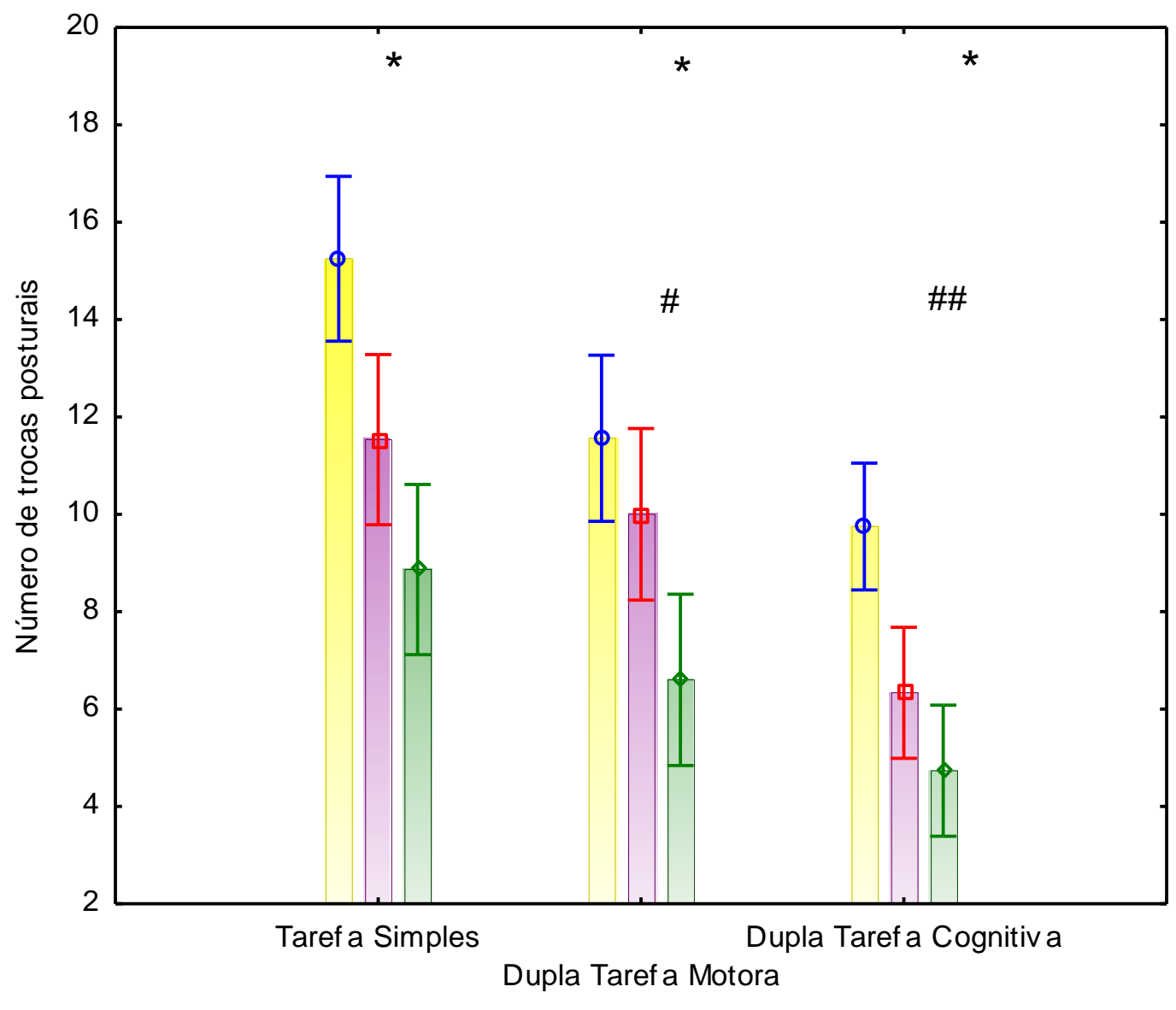

Figura-13. Desempenho do controle postural dinâmico. Número de trocas posturais realizadas em 30 segundos em tarefa simples, dupla tarefa motora e dupla tarefa cognitiva, comparando indivíduos com DP, nos estágios I, II e III. * = diferença significativa entre grupos no teste de Tukey, $\mathrm{p}<0,05$. \# = diferença significativa em comparação a TS no teste de Tukey, $\mathrm{p}<0,05$, \#\# = diferença significativa em comparação a TS e DTM no teste de Tukey, $\mathrm{p}<0,05$. 


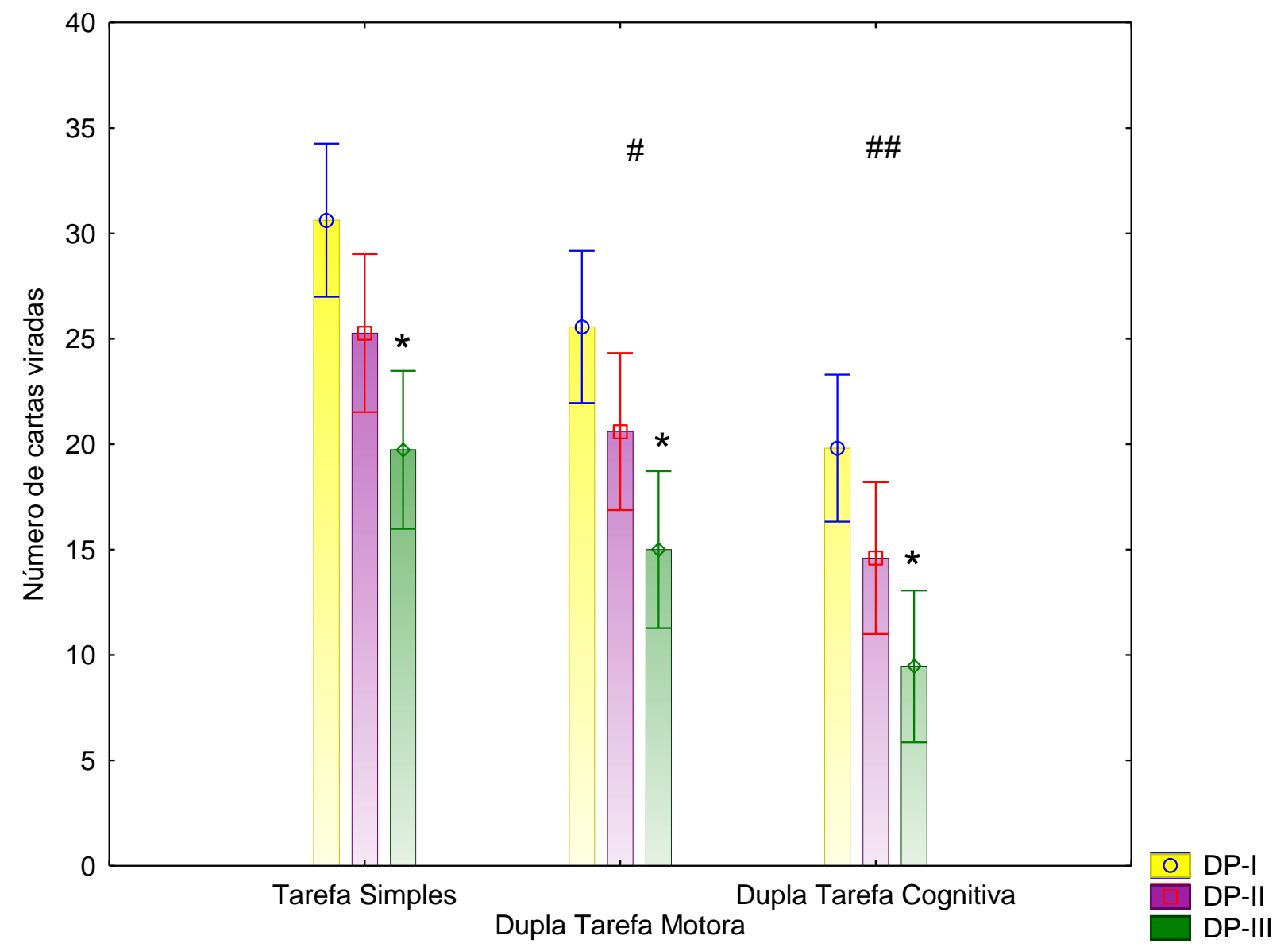

Figura-14. Desempenho do controle manual. Número de cartas viradas em 30 segundos em tarefa simples, dupla tarefa motora e dupla tarefa cognitiva, comparando indivíduos com DP, nos estágios I, II e III. .* = diferença significativa em comparação a DP-I e DP-II no teste de Tukey, $\mathrm{p}<0,05$. \# = diferença significativa em comparação a TS no teste de Tukey, $\mathrm{p}<0,05, \# \#=$ diferença significativa em comparação a TS e DTM no teste de Tukey, $\mathrm{p}<0,05$. 
Por último, na análise do desempenho do controle postural estático entre os indivíduos com DP houve apenas efeito de grupo [RM-ANOVA; $F(2,43)=14,961$; $\mathrm{p}=0,00001$, poder observado $=0,99$ ], confirmado pelo pos hoc teste de Tukey, onde foi encontrada diferença significante entre os grupos independente da condição de teste (Figura-15).

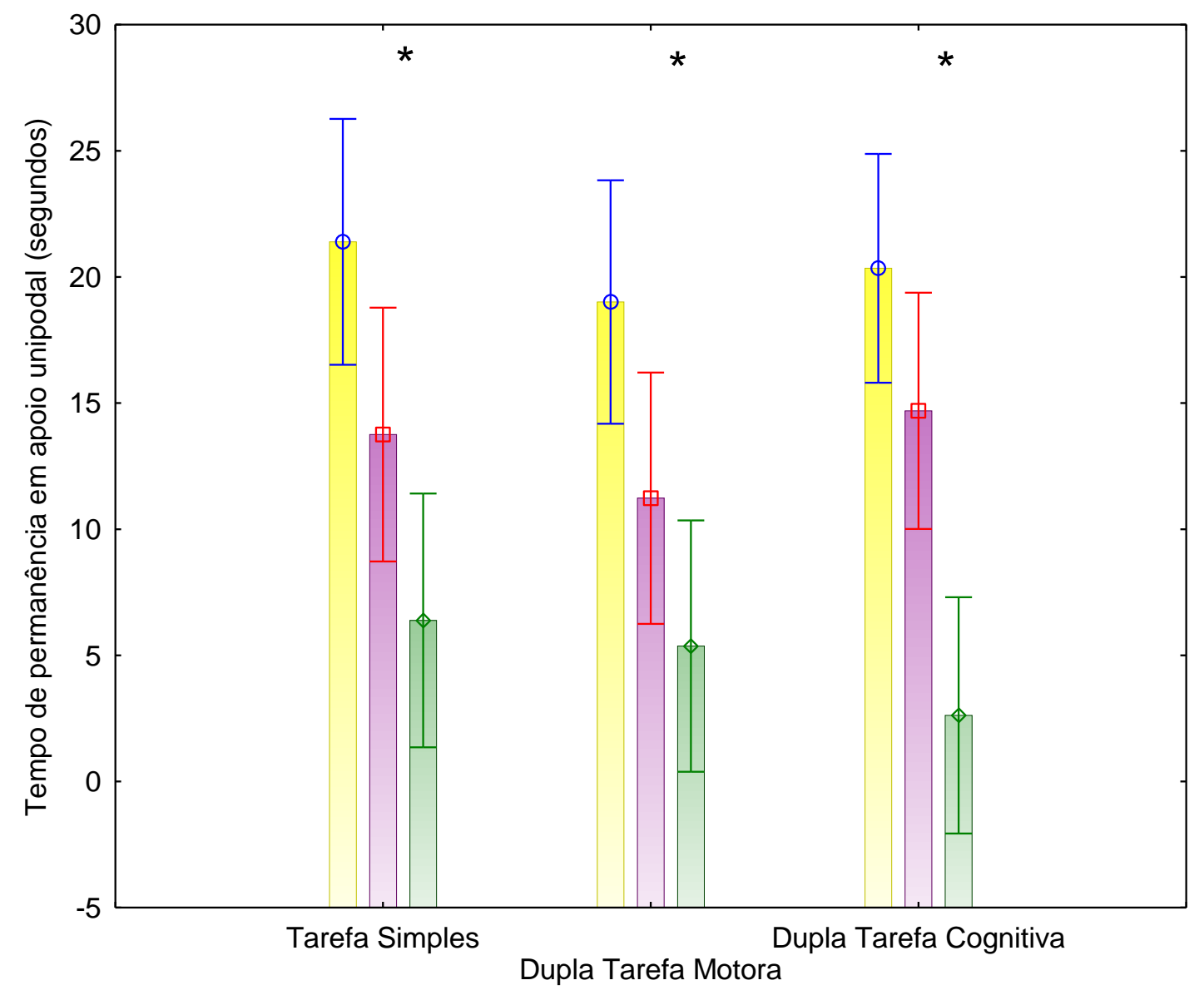

Figura-15. Desempenho com controle postural estático. Tempo de permanência em apoio unipodal em tarefa simples, dupla tarefa motora e dupla tarefa cognitiva, comparando indivíduos com DP, nos estágios I, II e III. .* = diferença significativa entre grupos no teste de Tukey, $\mathrm{p}<0,05$. 
Sintetizando os achados sobre a sensibilidade do teste a progressão da DP, das quatro tarefas propostas, três foram sensíveis para detectar os prejuízos entre cada um dos três estágios da doença. A menos sensível foi a de controle manual, que não foi capaz de identificar prejuízos entre os estágios mais iniciais da doença (I e II).

Dentre as quatro tarefas, apenas o de controle postural estático não foi sensível ao prejuízo de desempenho associado à divisão de atenção. 


\subsection{Análise da sensibilidade das condições propostas}

Além de avaliar a sensibilidade das tarefas funcionais a inclusão de outra tarefa, considerou-se importante avaliar o impacto global da associação de tarefas, analisando não só o prejuízo da tarefa funcional, mas também a soma dos prejuízos da divisão da atenção para a tarefa funcional e a tarefa específica motora e cognitiva. Por exemplo, na marcha, foi calculado o custo da marcha quando associada a uma tarefa concorrente motora e quando associada a uma tarefa concorrente cognitiva. Também foi calculado o custo da tarefa específica motora e da tarefa específica cognitiva associada à marcha. Portando, o custo total motor da marcha representa a soma do custo da marcha em DTM somado ao custo da tarefa específica motora em DTM, enquanto o custo total cognitivo da marcha corresponde a soma do custo cognitivo da marcha em DTC somado ao custo da tarefa específica cognitiva em DTC. 
5.4.1. Análise da sensibilidade das condições propostas para as alterações decorrentes do envelhecimento

Primeiro, o custo total da introdução de uma tarefa concorrente motora (DTM) foi analisado nas quatro tarefas funcionais em indivíduos jovens e idosos (Figura-16). Houve interação significativa entre grupo e condição [RM-ANOVA; $F(3,108)=7,3465$; $\mathrm{p}=0,00016$, poder observado $=0,98]$. Com o pos hoc teste de Tukey foi observado que apenas em idosos houve diferença dos custos totais entre a marcha e o controle postural estático $(\mathrm{p}=0,02)$, onde o maior custo encontrado foi na tarefa de controle postural estático, sendo que também para esta última condição, os idosos apresentaram um custo total maior em comparação aos adultos jovens $(\mathrm{p}=0,0000)$. 


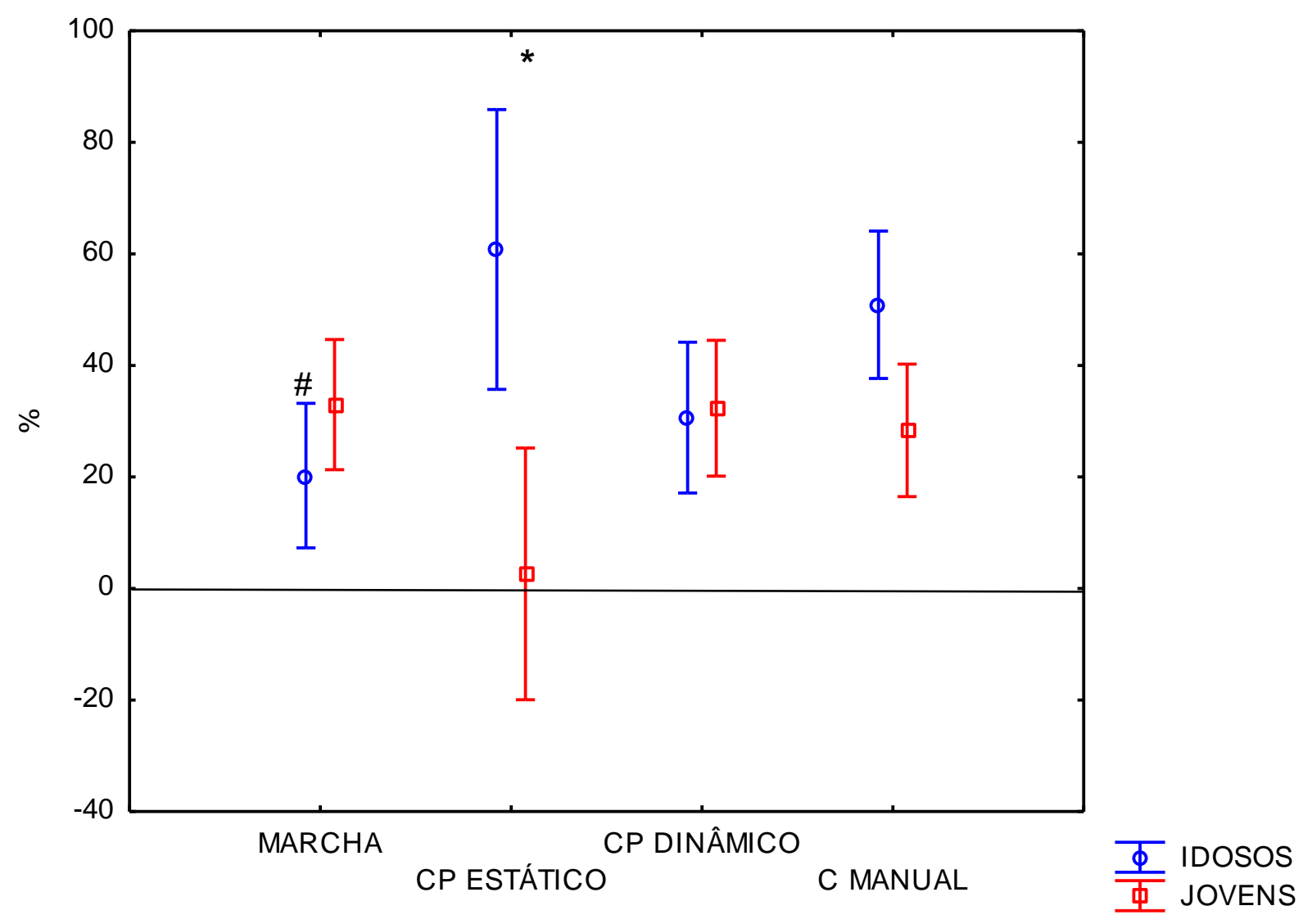

Figura-16. Custo total das duplas tarefas motoras comparando idosos e jovens. Custo total motor das tarefas de marcha (MARCHA), equilíbrio postural estático (CP ESTÁTICO), equilíbrio postural dinâmico (CP DINÂMICO) e controle manual (C MANUAL) em percentual, comparando indivíduos jovens e idosos. As barras verticais representam os valores do intervalo de confiança de 95\%. Os círculos e quadrados centrais presentes nas barras verticais representam as médias. ${ }^{*}=$ diferença significativa entre grupos na tarefa de controle postural estático no teste de Tukey, $\mathrm{p}<0,05$. \# = diferença significativa em comparação ao controle postural estático em idosos no teste de Tukey, $\mathrm{p}<0,05$. 
A seguir, o custo total da introdução de uma tarefa concorrente cognitiva (DTC) nas quatro tarefas funcionais em indivíduos jovens e idosos (Figura-17). Nesta comparação houve efeito significativo de condição [RM-ANOVA; $F(3,108)=5,3829$; $\mathrm{p}=0,001$, poder observado $=0,92] . \mathrm{O}$ post hoc teste de Tukey revelou diferenças entre o custo total do controle postural estático e a marcha $(\mathrm{p}=0,014)$, controle postural estático e controle postural dinâmico $(\mathrm{p}=0,005)$, e o controle postural estático e tarefa de controle manual $(\mathrm{p}=0,007)$, independente de grupo. Ou seja, o custo total cognitivo gerado pela tarefa de controle postural estático foi inferior a todas as outras tarefas.

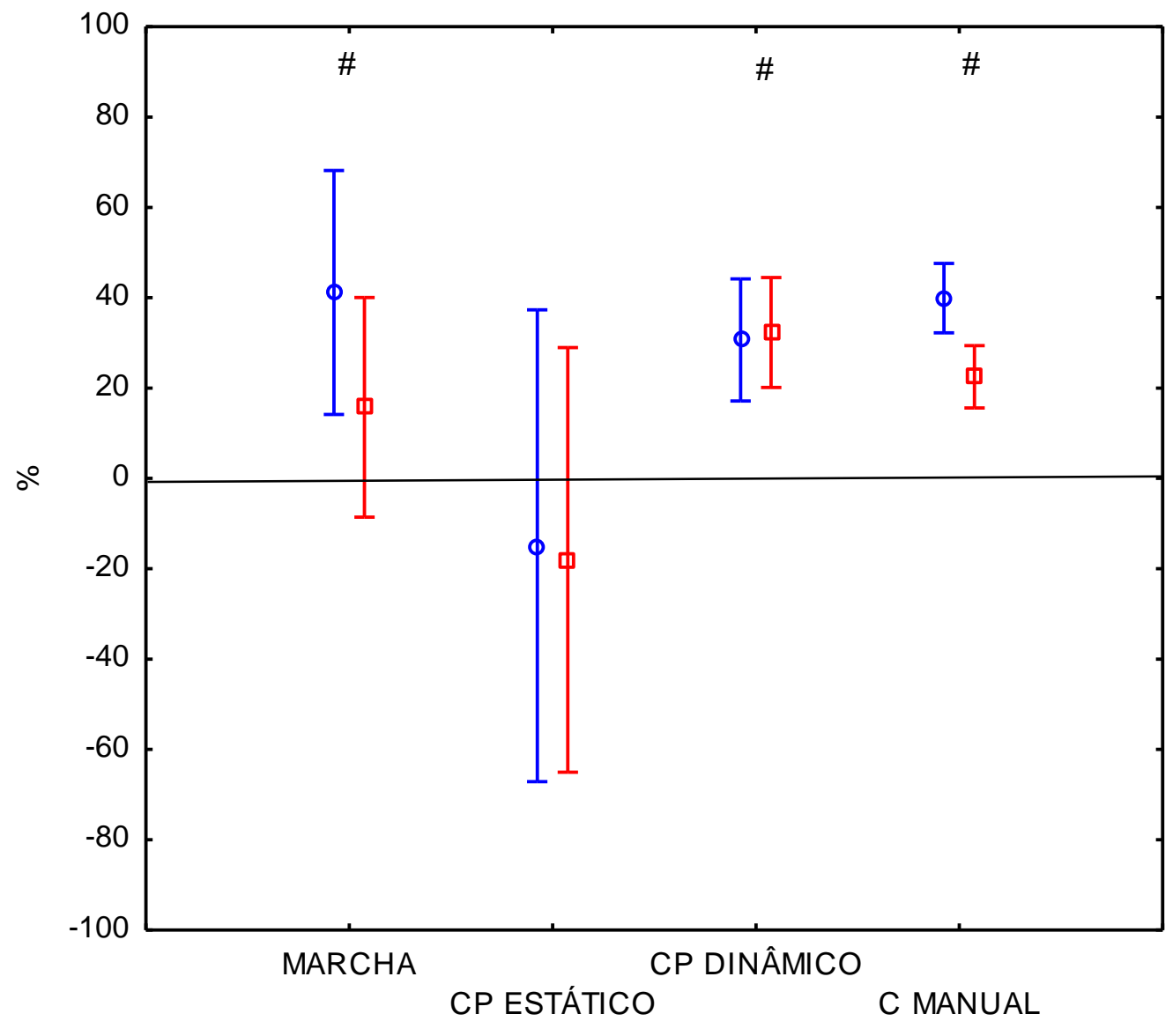

Figura-17. Custo total das duplas tarefas cognitivas comparando idosos e jovens. Custo total cognitivo das tarefas de marcha (MARCHA), equilíbrio postural estático (CP ESTÁTICO), equilíbrio postural dinâmico (CP DINÂMICO) e controle manual (C MANUAL) em percentual, comparando jovens e idosos. As barras verticais representam os valores do intervalo de confiança de 95\%. Os círculos e quadrados centrais presentes nas barras verticais representam as médias. \# = diferença significativa em comparação ao controle postural estático no teste de Tukey, $\mathrm{p}<0,05$. 
Em síntese, a combinação entre uma tarefa funcional e uma tarefa motora foi sensível para identificar diferenças entre os custos apenas entre duas condições (controle postural estático e marcha) em idosos, sendo o maior custo gerado pelo controle postural estático nesta comparação, mas foi sensível para identificar diferença entre idosos e jovens também na condição de controle postural estático. Já a adição de uma tarefa cognitiva às tarefas funcionais foi capaz de identificar diferenças entre as três tarefas funcionais em comparação ao equilíbrio estático, mas não identificou diferenças entre idosos e jovens.

Em conclusão, a combinação entre a tarefa de controle postural estático e uma tarefa motora foi a condição mais sensível para identificar as alterações do processo de envelhecimento na habilidade de dividir a atenção. 
5.4.2 Análise da sensibilidade das condições propostas para as alterações associadas à DP

O custo total motor da introdução de uma tarefa concorrente motora (DTM) nas quatro tarefas funcionais em idosos e indivíduos com DP pode ser observado na Figura 18. Houve efeito de condição [RM-ANOVA; $\mathrm{F}(3,183)=2,8908 ; \mathrm{p}=0,03$, poder observado $=0,68]$. O pos hoc teste de Tukey mostrou diferença significativa entre a tarefa de marcha e de controle postura estático, independente de grupo, ou seja, o maior custo foi do controle postural estático em ambos os grupos. 


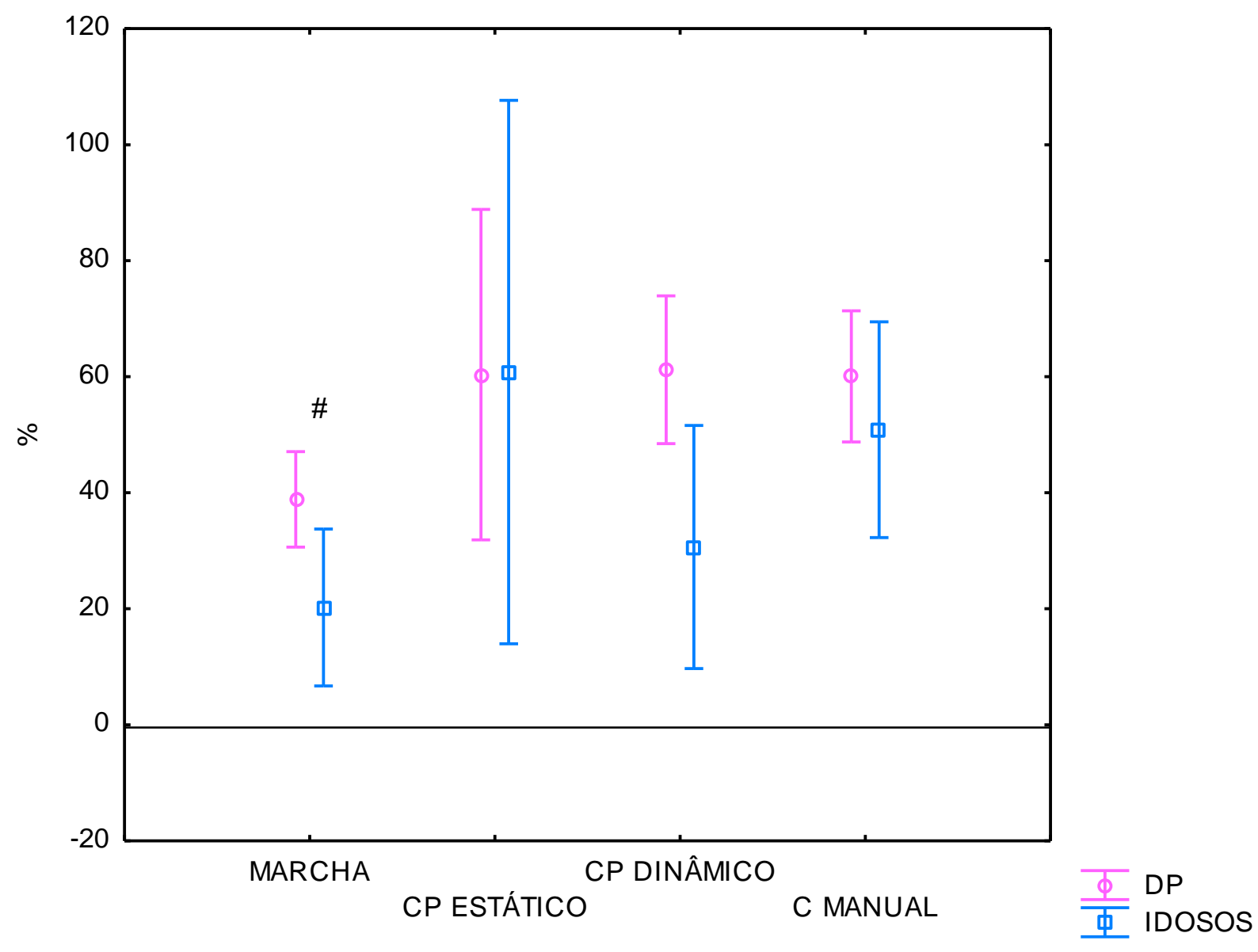

Figura-18. Custo total das duplas tarefas motoras comparando indivíduos com DP e idosos. Custo total motor das tarefas de marcha (MARCHA), equilíbrio postural estático (CP ESTÁTICO), equilíbrio postural dinâmico (CP DINÂMICO) e controle manual (C MANUAL) em percentual, comparando idosos e indivíduos com DP. As barras verticais representam os valores do intervalo de confiança de 95\%. Os círculos e quadrados centrais presentes nas barras verticais representam as médias. \# = diferença significativa em comparação ao controle postural estático no teste de Tukey, $\mathrm{p}<0,05$. 
O custo total da introdução de uma tarefa concorrente cognitiva (DTC) nas quatro tarefas funcionais é observado na Figura 19. Nesta comparação houve efeito significativo de condição [RM - ANOVA; F (3, 183) = 2, 96693; p=0,03, poder observado $=0,69$ ], sendo que o pos hoc teste de Tukey revelou diferença significativa entre as tarefas de controle postural dinâmico e controle postural estático, com custo maior na primeira tarefa, independente do grupo.

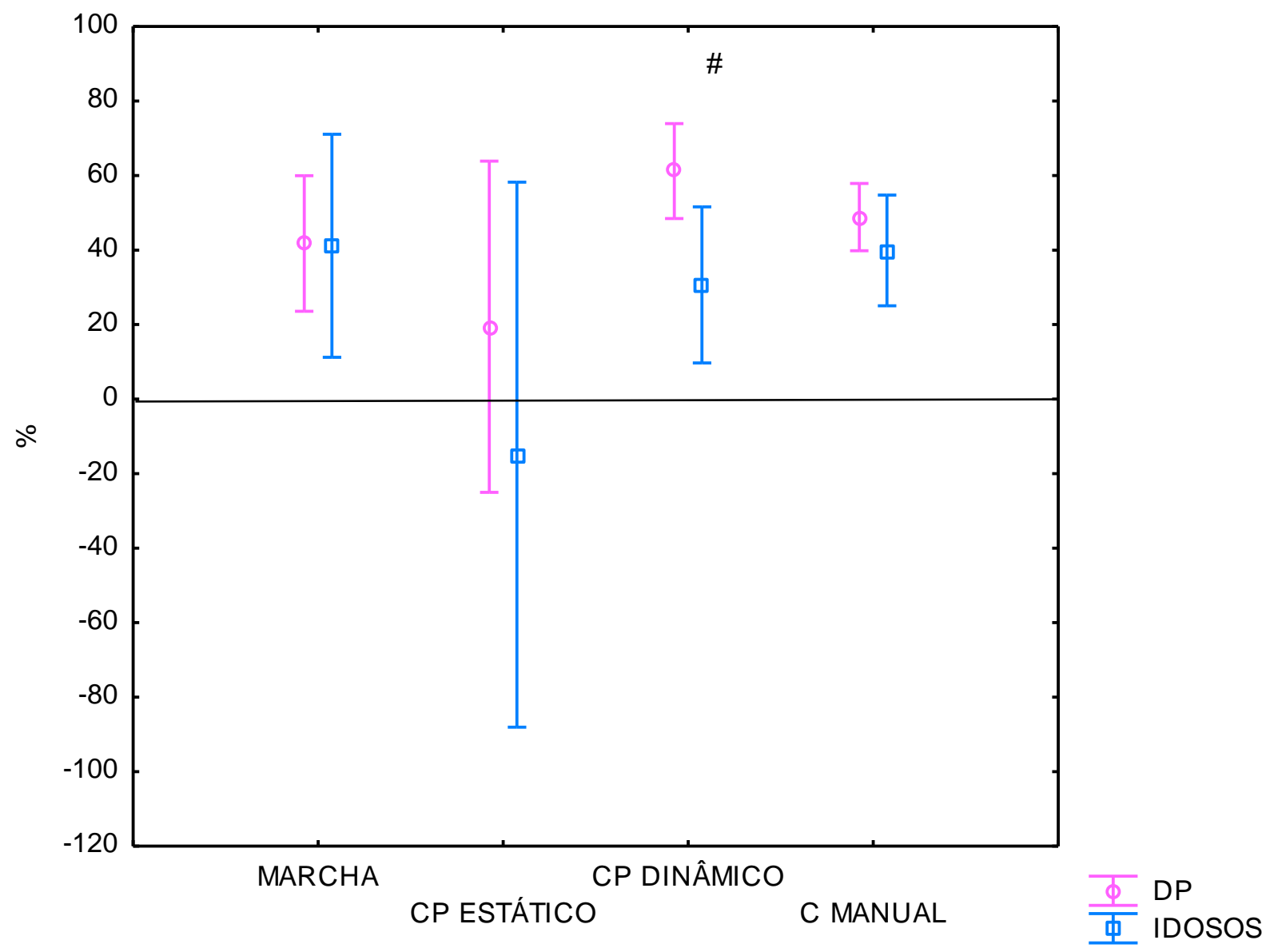

Figura-19. Custo total das duplas tarefas cognitivas comparando indivíduos com DP e idosos. Custo total cognitivo das tarefas de marcha (MARCHA), equilíbrio postural estático (CP ESTÁTICO), equilíbrio postural dinâmico (CP DINÂMICO) e controle manual (C MANUAL) em percentual, comparando idosos e indivíduos com DP. As barras verticais representam os valores do intervalo de confiança de 95\%. Os círculos e quadrados centrais presentes nas barras verticais representam as médias \# = diferença significativa em comparação ao controle postural estático no teste de Tukey, $\mathrm{p}<0,05$. 
Em síntese, a combinação entre uma tarefa funcional e uma tarefa motora foi sensível para identificar diferenças entre os custos apenas entre o controle postural estático e marcha, com maior custo associado à tarefa de controle postural estático; já a adição de uma tarefa cognitiva às tarefas funcionais foi capaz de identificar diferenças entre a tarefa de controle postural estático e controle postural dinâmico, com maior custo no controle postural dinâmico. Entretanto, nenhuma das condições foi capaz de identificar diferenças no custo total da divisão de atenção entre idosos e indivíduos com DP. 
5.4.3 Análise da sensibilidade das condições propostas para as alterações associadas à progressão da DP

O custo total da introdução de uma tarefa concorrente motora (DTM) nas quatro tarefas funcionais em indivíduos em diferentes estágios da DP é apresentado na Figura 20. Houve apenas efeito de grupo [RM-ANOVA; $\mathrm{F}(2,43)=5,3201, \mathrm{p}=0,008$, poder observado $=0,81]$. No pos hoc teste de Tukey, foram observadas diferenças significantes entre os grupos DP-I e DP-II em relação à DP-III, independentemente da condição de teste. 


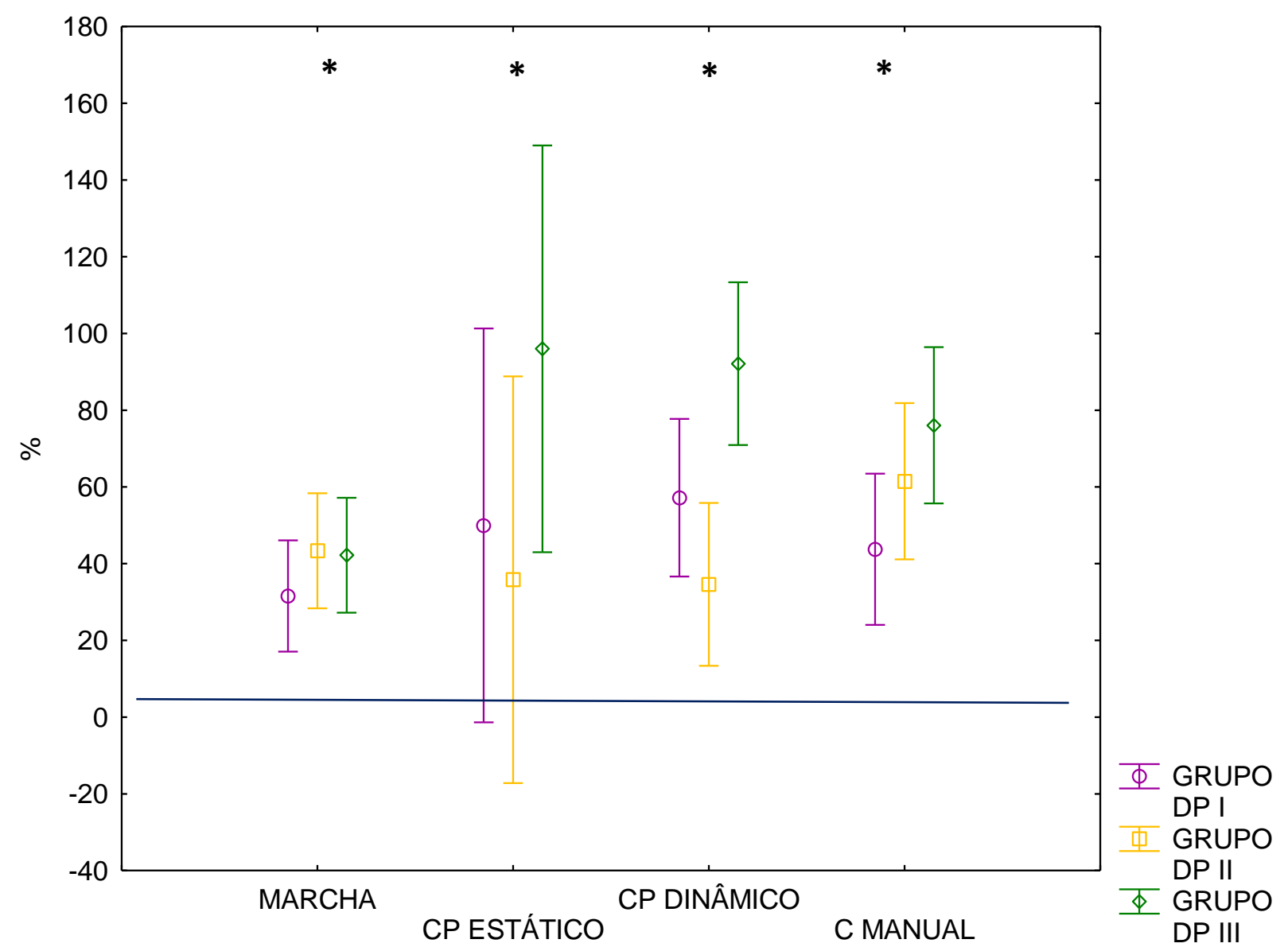

Figura-20. Custo total das duplas tarefas motoras comparando indivíduos nos diferentes estágios da DP. Custo total motor das tarefas de marcha (MARCHA), equilíbrio postural estático (CP ESTÁTICO), equilíbrio postural dinâmico (CP DINÂMICO) e controle manual (C MANUAL) em percentual, comparando indivíduos com DP nos estágios I, II e III. As barras verticais representam os valores do intervalo de confiança de $95 \%$. Os círculos e quadrados centrais presentes nas barras verticais representam as médias. ${ }^{*}=$ diferença significativa em comparando indivíduos do grupo DP-I e DP-II em relação ao grupo DP-III no teste de Tukey, $\mathrm{p}<0,05$. 
A seguir, o custo total da introdução de uma tarefa concorrente cognitiva (DTC) nas quatro tarefas funcionais em indivíduos com diferentes estágios de DP. Houve interação significativa entre grupo e condição [RM-ANOVA; $F(6,129)$ =3,5324, $\mathrm{p}=0,002$, poder observado $=0,94]$. O pos hoc teste de Tukey mostrou que houve um prejuízo significativo no custo total na tarefa de controle postural estático para o estágio III em comparação ao I e II (Figura-21). 


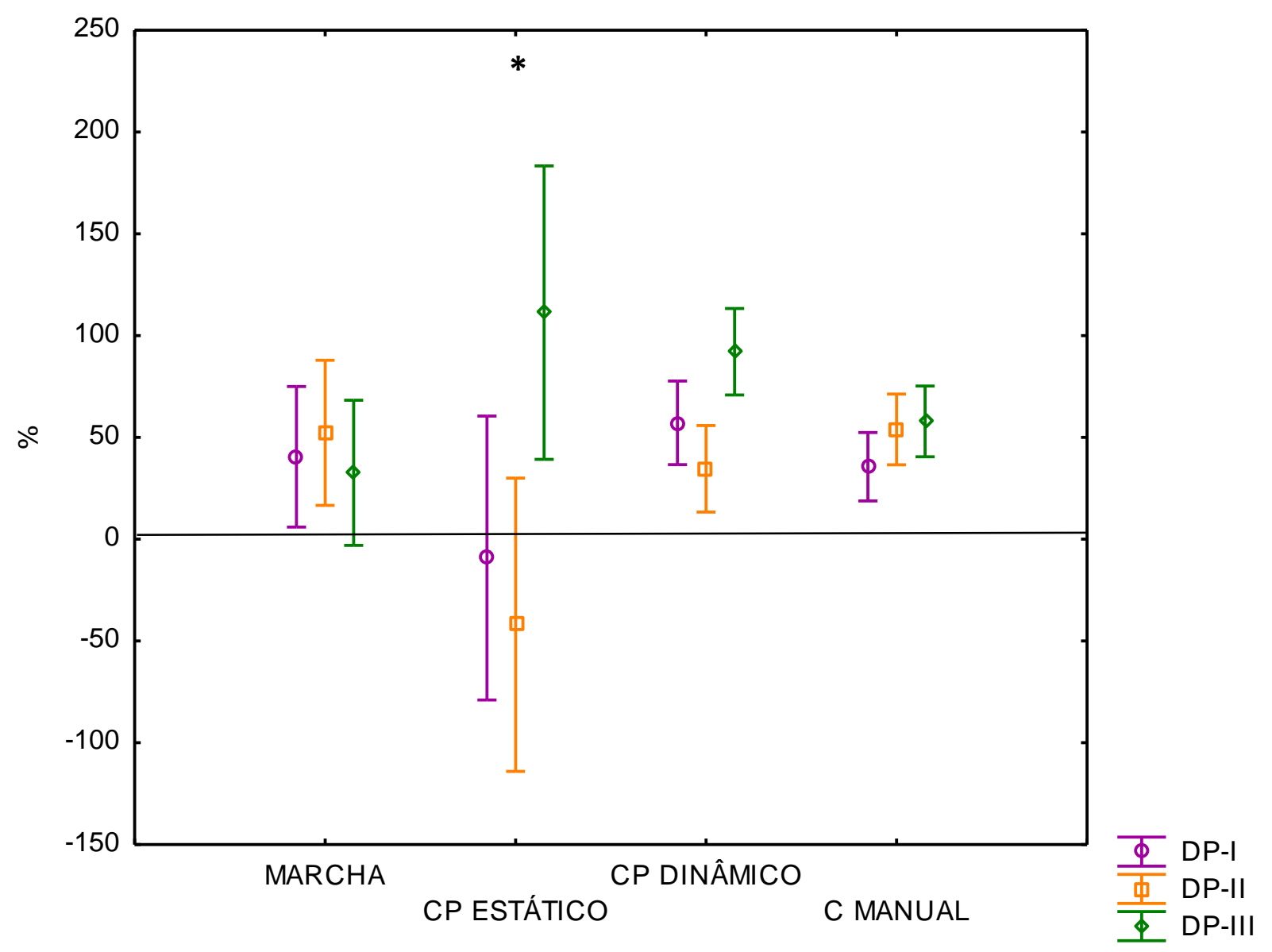

Figura-21. Custo total das duplas tarefas cognitivas comparando indivíduos nos diferentes estágios da DP. Custo total cognitivo das tarefas de marcha (MARCHA), equilíbrio postural estático (CP ESTÁTICO), equilíbrio postural dinâmico (CP DINÂMICO) e controle manual (C MANUAL) em percentual, comparando indivíduos com DP nos estágios I, II e III. As barras verticais representam os valores do intervalo de confiança de $95 \%$. Os círculos e quadrados centrais presentes nas barras verticais representam as médias. $*=$ diferença significativa na tarefa de controle postural estático comparando indivíduos do entre indivíduos do grupo DP-I e DP-II em relação ao grupo DP-III no teste de Tukey, $\mathrm{p}<0,05$. 
Em síntese, o custo da divisão da atenção entre tarefa funcional e uma tarefa motora foi sensível para identificar diferenças tanto entre o estágio inicial (I) e moderado (II) da doença, como entre o moderado e mais avançado (III), para todas as combinações testadas. Já o custo da divisão de atenção entre tarefas funcionais e cognitivas foi sensível para identificar prejuízos entre o estágio mais avançado (III) e inicial e moderado, (I e III), apenas quando a tarefa funcional foi de controle postural estático.

Em resumo, o custo total motor foi sensível para detectar diferenças entre indivíduos com DP no estágio III e os demais grupos (I e II) nas quatro tarefas funcionais. Já o custo da divisão da atenção entre a tarefa de controle postural estático e uma tarefa cognitiva foi a condição mais sensível para identificar as alterações na progressão da DP. 


\section{DISCUSSÃO}

A execução eficiente de atividades funcionais envolve a capacidade individual de compartilhar recursos atentivos, isto é, distribuir a atenção em diferentes focos simultâneos o que permite o ser humano a se adaptar de forma mais eficiente ao ambiente e as demandas da vida moderna, constituindo um pré-requisito para uma vida funcional, independente e segura ((PASHLER, 1994; YOGEV, HAUSDORFF e GILADI, 2008).

Condições que requerem a divisão de atenção são desafiadoras para todos os indivíduos, porém o processo de envelhecimento e a presença de patologias neurológicas exacerbam esta dificuldade, acarretando em impossibilidade de execução, alto risco de quedas e maior predisposição a acidentes nestas situações (DUBOST et al, 2006; PRAKASH et al, 2009; MCCULLOCH et al, 2010).

Assim, instrumentos que avaliem a capacidade de compartilhamento da atenção entre tarefas de diferentes naturezas sensíveis ao envelhecimento e as suas disfunções são importantes para a (1) detecção precoce de riscos; (2) quantificação da eficiência de abordagens terapêuticas e (3) compreensão dos perfis de deficiências o que pode subsidiar a melhor compreensão dos processos envolvidos e fundamentar novas abordagens terapêuticas. Diante disso, o objetivo deste estudo foi elaborar um teste de divisão de atenção envolvendo quatro tarefas funcionais e verificar a sensibilidade deste teste na identificação de alterações decorrentes do processo de envelhecimento por meio da comparação da execução entre jovens e idosos, a sensibilidade a alterações decorrentes da DP, comparando o desempenho de idosos e indivíduos com DP e por último identificar alterações de decorrentes da progressão da DP por meio da comparação entre indivíduos no estágio I, II e III na escala de estadiamento de HY.

A principal hipótese é que o protocolo elaborado permitiria identificar as alterações decorrentes do envelhecimento, da DP e da sua progressão, delineando perfis e identificando as situações mais prejudicadas em cada um dos grupos. Os resultados mostraram que o protocolo proposto foi eficiente para detectar o declínio no compartilhamento da atenção dos idosos em comparação aos jovens nas quatro tarefas funcionais. Mostrou-se também sensível para detectar as alterações decorrentes da DP, 
exceto pela tarefa de controle postural estático, bem como da sua evolução, presentes também nas quatro tarefas funcionais testadas.

Quanto às condições de divisão de atenção testadas, independentemente do grupo, a tarefa funcional mais eficiente para detectar diferentes perfis de perda associados à introdução de uma tarefa simultânea foi a de controle manual, que foi capaz de identificar diferenças de desempenho entre a TS e ambas as DT empregadas, seguida pela tarefa de controle postural dinâmico e pela marcha.

Assim, com base nesses resultados depreende-se importantes evidências:

I) As tarefas funcionais são distintamente afetadas pelo compartilhamento atentivo como outras tarefas. Como os resultados mostraram, os custos da divisão de atenção foram diferentes entre as tarefas funcionais testadas: a tarefa mais afetada foi a manual, seguida pela tarefa de marcha e controle postural dinâmico, sendo a tarefa de controle postural estático demonstrou ser a menos afetada pelas condições de divisão de atenção. Isso provavelmente se deva ao fato das tarefas selecionadas apresentarem diferentes níveis de integração cortical envolvido. Movimentos manuais dependeriam de maior processamento neural realizado por áreas corticais sensório-motoras envolvidas com controle de movimentos distais, feedback somatossensorial e visual, do que por exemplo a marcha, que é regulada por áreas filogeneticamente mais antigas, como tronco encefálico, medula e cerebelo, constituindo um movimento de características mais pré-programadas com menor controle desempenhado pelo córtex (O SHEA, MORRIS, e IANSKE, 2002). Já Morris et al (2000) discutem que o controle da marcha e principalmente dos membros superiores é mediado pelo córtex sensório-motor e áreas pré-motoras, enquanto que o controle postural dependeria de medula, tronco encefálico e cerebelo. O que estes autores argumentam em comum é que tarefas que demandam grande processamento cortical liberariam poucos recursos atentivos para outra atividade simultânea acarretando em maior interferência durante a DT. Portanto, os resultados obtidos por este estudo são coerentes com as evidências da literatura: ações que envolvem maior demanda cortical são mais prejudicadas por condições de divisão de atenção, como ocorreu com a tarefa de controle manual, uma vez que esta maior demanda liberaria poucos recursos corticais para a execução de uma tarefa secundária concorrente. Assim, fica clara a importância de se avaliar a capacidade de compartilhamento atentivo em diferentes tarefas funcionais, sendo esta uma importante 
vantagem deste protocolo que, até onde tenhamos conhecimento, é o primeiro a propor uma avaliação em DT em quatro diferentes tarefas funcionais seguindo o mesmo padrão para a avaliação de desempenho. A maior parte dos estudos sobre DT analisaram apenas o desempenho da marcha em condições de divisão de atenção, o que pelos resultados obtidos neste estudo, não representa como o indivíduo compartilha atenção de uma forma mais abrangente e em diferentes situações funcionais cotidianas.

II) Uma segunda importante evidência é que as tarefas cognitivas são diferentemente afetadas pelas tarefas funcionais. Os resultados mostraram que idosos e jovens analisados conjuntamente apresentaram menor custo total cognitivo na tarefa de controle postural estático em comparação às outras tarefas, ou seja, a tarefa de controle postural estático causou menos interferência que as outras testadas, já que quanto menor o custo total, maior é a capacidade do indivíduo compartilhar recursos atentivos. O mesmo foi verificado em idosos e indivíduos com DP conjuntamente, quando o custo do controle postural estático foi menor do que o encontrado nas outras tarefas, porém com diferença significativa apenas na comparação com a tarefa de controle postural dinâmico. Este padrão de resultados foi oposto ao verificado no custo total motor nas mesmas comparações, mostrando que a natureza da tarefa secundária empregada pode causar uma demanda diferente sobre os processos envolvidos com o compartilhamento da atenção.

Assim, outra importante vantagem do protocolo proposto é que permite investigar os efeitos do compartilhamento atentivo também sobre tarefas cognitivas. Isso é uma importante informação clínica, que pode indicar como e o quanto processos cognitivos envolvidos em tarefas cotidianas podem ser prejudicados pela execução concomitante de tarefas motoras. Com base nessas informações, pacientes podem ser alertados sobre os riscos não só motores, mais explorados, mas também sobre os riscos de um mau desempenho cognitivo que ocorre com a execução de múltiplas tarefas. Que tenhamos conhecimento, este é também o primeiro protocolo que permite essa observação de forma sistemática. Destacamos que um importante aspecto contemplado no desenvolvimento deste protocolo para esse fim foi padronizar os testes pelo tempo de execução e não pelo desempenho, o que permitiu a comparação de diferentes grupos de indivíduos independente do seu desempenho inicial. O tempo proposto também foi importante, pois como o teste envolve controle atentivo e busca reproduzir situações 
mais funcionais, acreditamos que 30 segundos sejam adequados à medida que exigem um compartilhamento de atenção sustentada, mais similar ao exigido na vida cotidiana.

III) Uma terceira evidência é que nem sempre o compartimento atentivo leva a prejuízos no desempenho. Os resultados mostraram que desempenho da tarefa de controle postural estático entre jovens e idosos e de idosos e indivíduos com DP, o custo total cognitivo foi negativo para alguns indivíduos isto é, eles obtiveram um melhor desempenho desta tarefa em DTC do que em TS mostrando a importância da avaliação do custo total e não só o desempenho das tarefas isoladas. A análise dos custos capacita à identificação de como a atenção é compartilhada entre as duas tarefas concorrentes; a verificação apenas da tarefa funcional não mostraria como o desempenho da tarefa específica também sofre interferência. É importante lembrar que na execução da DT ambas as tarefas devem ser levadas em consideração já que o sucesso em dividir a atenção significa a manutenção de desempenho em ambas às atividades executadas simultaneamente, portanto a verificação dos custos capacita uma observação mais global de como cada grupo de indivíduos responde a condições de divisão de atenção mostrando também um diferente padrão de priorização em cada condição.

Assim, a possibilidade de uma análise conjunta dos custos de uma tarefa sobre a outra é uma importante vantagem do presente protocolo.

O fato do protocolo elaborado avaliar o desempenho utilizando duas tarefas concorrentes diferentes favorece o entendimento do processo de compartilhamento e direcionamento de recursos atentivos em um contexto mais ecológico, caracterizando de forma ampla como os indivíduos se comportam em várias situações que são impostas no cotidiano.

Uma última e importante evidência é que os custos do compartilhamento atentivo são distintos entre jovens, idosos saudáveis e com DP. Os resultados mostraram que o protocolo foi sensível para detectar diferentes perfis de custos entre os grupos. Nesta análise, os jovens não demonstraram diferenças de desempenho entre TS e DT nas quatro tarefas funcionais analisadas, já em idosos houve interferência na execução da marcha quando esta foi realizada simultaneamente a uma tarefa motora e a uma cognitiva, assim como entre as DT, com pior desempenho na DTC, enquanto que na tarefa de controle postural dinâmico apenas não houve diferença entre a TS e DTM. Em indivíduos com DP houve perda de desempenho na marcha em DT, independente da 
natureza da tarefa simultânea, e no controle postural dinâmico, onde houve perda de desempenho nas duas DT empregadas além de diferenças de desempenho entre DTM e DTC, com maior prejuízo na última. Na verificação dos diferentes estágios da DP, não foi verificada diferenças de desempenho em DT e TS entre em cada estágio.

Assim, o protocolo foi sensível na detecção de perda de desempenho entre diferentes grupos e condições utilizando instrumentos simples, de baixo custo e de fácil aplicabilidade. Ações que envolvem a divisão de atenção são complexas, porém inerentes ao cotidiano. O reconhecimento precoce de situações de risco e de dependência funcional gerada pela execução da DT é de extrema importância para a elaboração de uma abordagem terapêutica objetiva e eficaz, destinada a cada perfil de indivíduo. Portanto, o presente protocolo é instrumento clínico acessível para que os terapeutas identifiquem com rapidez prejuízos no compartilhamento de recursos atentivos sem a necessidade de grandes aparatos de alto custo.

Tomadas em conjunto essas evidências reforçam a validade do protocolo proposto. Acreditamos que importantes fatores considerados na sua elaboração foram decisivos para esses resultados como a análise de quatro tarefas funcionais que envolvem diferentes segmentos corporais assim como diversos níveis de mobilidade, estabilidade e controle neural envolvido, o uso de tarefas específicas cognitivas e motoras diferentes para cada tarefa funcional com intuito de evitar o processo de aprendizado que poderia interferir diretamente nos resultados, a randomização da sequência de tarefas avaliadas com objetivo de prevenir a fadiga e o aprendizado, utilizar um tempo padronizado de execução para cada tarefa buscando facilitar a análise dos resultados, a verificação do desempenho de todas as tarefas, funcionais $\mathrm{e}$ específicas, isoladamente (em TS) e em DT além da análise dos custos, o que propiciou a observação não só de perfis diferentes em relação aos grupos e condições estudados, mas também possibilitou examinar o processo de priorização.

Uma limitação desse estudo é que apesar da avaliação proposta ser sensível as diferenças associadas a divisão de atenção, ela não possibilita a identificação da causa associada a perda de desempenho: se é devido a um déficit de compartilhamento atentivo propriamente dito ou decorrente da diminuição na quantidade de recursos atentivos disponíveis para a execução da DT. 
As principais direções futuras a partir destes resultados preliminares é testar a reprodutibilidade e validar este protocolo de avaliação em DT inicialmente nos três grupos aqui testados e futuramente em outros perfis de indivíduos e com outras patologias neurológicas. Outro estudo possível seria sobre o processo de priorização durante o compartilhamento de atenção, analisando sua relação com os indivíduos, condições testadas, tarefas, entre outros parâmetros.

Finalizando, acreditamos que o presente estudo tenha fornecido uma contribuição clinica importante e inédita na área da fisioterapia, pois várias evidências mostraram que o instrumento de avaliação elaborado além de ser sensível para os objetivos inicialmente propostos é aplicável em ambiente terapêutico, mas também na área da Neurociências, uma vez que possibilita a verificação de como o sistema nervoso se comporta em situações complexas em que há a necessidade da manipulação de recursos atentivos.

\section{CONCLUSÃO}

O protocolo elaborado foi eficiente para identificar o declínio no compartilhamento da atenção decorrente do processo de envelhecimento, de alterações associadas à DP e de sua progressão, delineando perfis e identificando as situações cotidianas mais prejudicadas em cada um dos grupos. $\mathrm{O}$ protocolo mostrou uma boa aplicabilidade, utilizando instrumentos clínicos simples e de forma rápida. 


\section{REFERÊNCIAS}

ALMEIDA, O.; ALMEIDA, S. Reliability of the Brazilianversion of the geriatric depression scale (GDS) short form. Arq Neuro-Psiquiat, v. 57, P. 421-426, 1999.

ARMIERI, A. et al. Dual task performance in a healthy young adult population: Results from a symmetric manipulation of task complexity and articulation. Gait posture, v.29, n. 2, p. 346-348, 2009.

ASHBURN, A. et al. A community-dwelling sample of people wiyh Parkinson's disease: characteristics of fallers and no-fallers. Age aging, v. 30, p. 47-52, 2001

AZOUVI, P. et al. Divided attention and mental effort after severe traumatic brain injury. Neuropsychologia, v. 42, p. 1260-1268, 2004.

BAKER, K.; ROCHESTER, L.; NIEUWBOER, A. The Immediate Effect of Attentional, Auditory, and a Combined Cue Strategy on Gait During Single and Dual Tasks in Parkinson's Disease. Arch Phys Med Rehabil, v.88, p. 1593-600, 2007.

BAKOS, D.S. et al. Executive functions in the young elderly and oldest old: a preliminary comparasion emphasizing decision making. Psychol. Neurosci, v.1, n. 2, p. 183-189, 2008.

BECIC, E. et al. Driving impairs talking. Psychon B Rev, v. 17, p. 15-21, 2010.

BENECKE, R. et al. Performance of simultaneous movements in patients with Parkinson’s disease. Brain, v. 109, p. 739-757, 1986.

BOCK, O. Dual-task costs while walking increase in old age for some, but not for other tasks: an experimental study of healthy young and elderly persons. J neuroengineering and Rehabil, v, 5, n. 27, p. 1-9, 2008.

BLOEM B. R. et al. The multiple tasks test. Strategies in Parkinson's disease. Exp Brain Res, v. 137, p. 478-486, 2001.

BOND, J.; MORN'S. Goal-directed secondary motor tasks: their effects on gait in subjects with Parkinson disease. Arch Phys Med Rehabil, v. 81, p. 110-116, 2000. 
BRAUER, S.G. et al. Simplest tasks have greatest dual task interference with balance in brain injured adults. Hum Movement Sci, v. 23, p. 489-502, 2004.

BROWN, R. G.; JAHANSHAHI, M. An unusual enhancement of motor performance during bimanual movement in Parkinson's disease. J Neurol Neurosurg Psychiatry, v. 64, p. 813-816, 1998.

BROWN, A. Talking whilst driving: A discussion of the difficulties of dual task performance . STARR, v. 38, 2010.

BROWN, L. A. et al. Novel challenges to gait in Parkinson's disease: the effect of concurrent music in single and dual task contexts. Arch Phys Med Rehabil, v. 90, n. 9, p. $1578-83,2009$.

CAMERON, I.G.M., et al. Role of the basal ganglia in switching a planned response. Euro J Neuro, v. 29, n. 12, p. 2413-2425, 2009.

CAMERON, I.G.M., et al. Executive impairment in Parkinson's disease: response automaticity and task switching. Neuropsychologia, v.48, p. 1948-1957, 2010.

CAMPBELL, C.M. et al. The effect of cognitive demand on Timed up and Go performance in older adults with and without Parkinson disease. Neurol Report, v.27, n.1, p. 2-7, 2003.

CANNING, C.G. The effect of directing attention during walking under dual-task conditions in Parkinson’s disease. Parkinsonism Relate D, v. 11, p. 95-99, 2005.

COPPIN, A. K. et al. Association of executive function and performance of dual-task physical tests among older adults: analyses from the In Chianti study. Age Ageing, v. 35, n. 6, p. 619-624, 2006.

DAULT, M.C.; FRANK, J.C.; ALLARD, F. Influence of a visuo-spatial, verbal and central executive working memory task on postural control. Gait Posture, v. 14, n. 2, p.110-116,2001.

DRAG, L.L., et al Source memory and frontal functioning in Parkinson's disease. J Int Neuropsychol Soc, v.15, n. 3, p. 399-406, 2009.

DELONG, M.; WICHMANN, T. Update on models of basal ganglia function and dysfunction. Parkinsonism Relat D, v. 15, p. 237-240, 2009. 
DUBOST, V. et al. Relationships between dual-task related changes in stride velocity and stride time variability in healthy older adults. Hum Mov Sci, v. 25, p. 372-382, 2006.

FOLSTEIN, M.F.; FOLSTEIN, S.E.; MCHUGH, P.R. Mini-mental state - practical method for grading cognitive state of patients for clinician'. J Psychiat Res, v. 12, p. 189-198, 1975

FRASER, S.A.; LI, K.Z.H.; PENHUNE, V.B. Dual task performance reveals increased involvement of executive control in fine motor sequencing in healthy aging. J Gerontol Psychol Sci, v.18, p. 1-9, 2010.

FUSTER, J.M. Synopsis of function and dysfunction of the frontal lobe. Acta Psychiatr Scan, v.99, p. 51-57, 1999.

GALLETLY, R; BRAUER, S. G. Does the type of concurrent task affect preferred and cued gait in people with Parkinson's disease? Aust J Physiother, v. 51, p. 175-180, 2005.

GELB, D.J; OLIVER, E; GILMAN, S. Diagnostic Criteria for Parkinson Disease. Arch Neurol, v. 56, p. 33-39, 1999.

GOTHE, K.; OBERAUER, K.; KLIEGL, R. Age differences in dual-task performance after practice. Psychol Aging, Vol. 22, N.3, P. 596-606, 2007

HACKNEY, M. E.; EARHART, G. M. The effects of a secondary task on forward and backward walking in Parkinson's disease. Neurorehabil Neural Repair, 2009; 1-14 doi:10.1177/1545968309341061.

HELENE, A.F.; XAVIER, G.F. A construção da atenção a partir da memória. Rev Bras Psiquiatr, v.25, p. 12-20, 2003

HIKOSAKA, $\mathrm{O}$ et al. Central mechanisms of motor skill learning. Curr opin neurobiol, v. 12, p. 217-222, 2002.

HIRAGA, C. Y. et al Dual task interference: attentional and neurophysiological influences. Behav Brain Res, v. 205, p. 10-18, 2009.

HOEHN, M.M.; YAHR, M.D. Parkinsonism: onset, progression and mortality. Neurology, v.17, n. 5, p. 427-442, 1967. 
HOLMES, J.D. Dual-task interference: the effects of verbal cognitive tasks on upright postural stability in Parkinson’s disease. Parkinson's Disease; 2010: 1-5.

HORSTINK, H. J., et al. Bimanual simultaneous motor performance and impaired ability to shift attention in Parkinson's disease. J Neurol Neurosurg Psychiatry, v. 53, p. 685-690, 1990.

HOU, J.G.; LAI, E. C. Non-motor symptoms of Parkinson's disease. J Gerontol, v. 1, n. 2, p. 53-64, 2007.

HUXHOLD, O.; LI, S.C.; SCHMIEDEK, F.; LINDENBERGER, U. Dual-tasking postural control: aging and the effects of cognitive demand in conjunction with focus of attention. Brain Res Bull, v. 69, P. 294-305, 2006.

JOHNSON, A.M.; HOLMES, J.D.; WOOD, K.W.; JEKINS, M.E. The Hidden Cost of Cognition: Examining the Link Between Dual-Task Interference and Falls. J Curr Clin Care, v. 2, 2012.

JANKOVIC, J. Parkinson's disease: clinical features and diagnosis. J Neurol Neurosurg Psychiatry, v. 79, p. 368-376, 2008.

JUEPTNER, et al. Anatomy of Motor Learning I. Frontal cortex and attention to action. J Neurophysiol, v. 77, p. 1313-1324, 1997.

JUEPTNER, M. et al. Anatomy of Motor Learning. II. Subcortical Structures and Learning by Trial and Error. J Neurophysiol, v. 77, p. 1325-1337, 1997.

KELLY, V.E.; EUSTERBROCK A.J.; SHUMWAY-COOK, A. A review of dual-task walking deficits in people with Parkinson's disease: motor and cognitive contributions, mechanisms, and clinical implications. Parkinson's Disease, v 2012, doi:10.1155/2012/918719.

KIZONY, R. et al. Cognitive Load and Dual-Task Performance During Locomotion Poststroke: A Feasibility Study Using a Functional Virtual Environment. Phys Ther, v. 90, p.252-260, 2010.

KOERTS, J. et al. Executive Functioning in Daily Life in Parkinson's Disease: Initiative, Planning and Multi-Task Performance. PLoS ONE, v. 6, n. 12, 2011.

LAJOIE, Y.; GALLAGHER, S.P. Prediciting falls within the elderly community: comparision of postural sway, reaction time, the Berg balance scale and the Activitiesspecific Balance Confidence (ABC) scale for comparing fallers and non-fallers. Arch Gerontol Geriatr, v. 38, p. 11-26, 2004. 
LEES, A. J.; HARDY, J.; REVESZ, T. Parkinson’s disease. Lancet, v. 373, p. 205566, 2009.

LEHERECY, $S$ et al. Distinct basal ganglia territories are engaged in early and advanced motor sequence learning. PNAS, v. 102, p. 12566-12571, 2005.

MARCHESE, R.; Bove, M. A. Effect of cognitive and motor tasks on postural stability in Parkinson's disease: a posturographic study. Mov Disord, v. 18, p. 652-658, 2003.

MCCULLOCH, K. L. Attention and dual-task conditions: physical therapy implications for individuals with acquired brain injury. JNPT, v. 31, p. 104-118, 2007.

MCCULLOCH, K. L. et al. Balance, attention, and dual-task performance during walking after brain injury: associations with falls history. J Head Trauma Rehabil, v.25, n. 3, p. 155-163, 2010.

MCDOWD, J. M. An Overview of Attention: Behavior and Brain. JNPT , v. 31, p. 98103, 2007.

MCKINLAY, A. et al. Characteristics of executive function impairment in Parkinson's disease patients without dementia. JINS, v.16, p. 268-277, 2009.

MORRIS, M. et al. Postural instability in Parkinson's disease: a comparison with and without a concurrent task. Gait Posture, v. 12, p. 205-216, 2000.

MOURÃO, C.A.; MELO, L.B.R. Integração de Três Conceitos: Função Executiva,Memória de Trabalho e Aprendizado. Psic.: Teor. e Pesq, V.27, P. 309-314, 2011.

MULDER, T.; ZIJLSTRA, W.; GEURTS, A. Assessment of motor recovery and decline. Gait Posture, v.16, p. 198-210, 2002.

NEWMAN, S.D.; KELLER, T.A.; JUST, M.A. Volitional control of attention and brain activation in dual task performance. Hum Brain Mapp, v.28, p. 109-117, 2007.

OBESO, J. A., et al. The basal ganglia and disorders of movement: pathophysiological mechanisms. Physiol Sci, v. 17, n. 2, p. 51-55, 2002

O’SHEA S.; MORRIS, M.E.; IANSEK, R. Dual task interference during gait in people with Parkinson disease: effects of motor versus cognitive secondary tasks. Phys Ther, v.82, n. 9, p.888-897, 2002.

OWEN, A.M. Cognitive Dysfunction in Parkinson's Disease: The Role of Frontostriatal Circuitry. Neuroscientist, v. 10, n.6, p. 525-537, 2004. 
PASHLER, H. Dual task interference in simple tasks: data and Theory. Psychol Bull, v. 116, p. 220-244, 1994

PASSINGHAM, M et al. Attention to action anatomy of motor learning. I. Frontal cortex and attention to action. J Neurophysiol, v. 77, p. 1313-1324, 1997.

PLOTNIK, M. et al. Postural instability and fall risk in Parkinson's disease: impaired dual tasking, pacing, and bilateral coordination of gait during the $\mathrm{ON}$ medication state. Exp Brain Res, v. 210, p. 529-538, 2010.

PLOTNIK, M.; GILADI, N.; HAUSDORF, J.M. Bilateral coordination of gait and Parkinson's disease: the effects of dual tasking. J Neurol Neurosurg Psychiatry, v 80, p. 347-350, 2009.

PRADLAM, S.D. et al. Assessment of fine motor control in individuals with Parkinson's disease using force tracking with a secondary cognitive task. JNPT, v. 34, p. 32-40, 210.

PRAKASH, R.S. et al. Age-related differences in the involvement of the prefrontal cortex in attentional control. Brain and Cognition, v. 71, p. 328-335, 2008.

PROUD, E. L.; Morris, M. E. Skilled hand dexterity in Parkinson’s Disease: effects of adding a concurrent task. Arch Phys Med Rehabil, v. 91. P. 794-799, 2010.

ROCHESTER, L. D et al. Attending to the task: interference effects of functional tasks on walking in Parkinson's disease and the roles of cognition, depression, fatigue, and balance. Arch Phys Med Rehabil, v. 85, p. 1578-1585, 2004.

ROCHESTER, L., et al. The effect of external rhythmic cues (auditory and visual) on walking during a functional task in homes of people with Parkinson's disease. Arch Phys Med Rehab, v.86, p. 999-1006, 2005.

ROCHESTER, L. et al. Walking speed during single and dual tasks in Parkinson's disease: which characteristics are important? Mov Disord, v. 23, p. 2312-2318, 2008.

RODRIGUEZ-OROZ M. C. et al. Initial clinical manifestations of Parkinson's disease: features and pathophysiological mechanisms. Lancet Neurol, v. 8, p. 1128-39, 2009.

SAVICA, R.; ROCCA, W. A.; AHLSKOG, J. E.When Does Parkinson Disease Start? Arch Neurol, v.67, n.7, p.798-801, 2010.

SPRINGER, S. et al. Dual-Tasking Effects on Gait Variability: The Role of Aging, Falls, and Executive Function. Mov Disord, v. 21, n. 7,p. 950-957, 2006. 
SCHMIDT, A.R.; WRISBERG, C.A. Aprendizagem e performance motora- Uma abordagem da aprendizagem baseada no problema. $2^{\circ}$ ed. Porto Alegre: Artmed Editora, 2001.

SHUMWAY-COOK, A.; BRAUER, S.; WOLLACOTT, M. Predicting the probability for falls in community-dwelling older adults using Timed Up \& Go test. Phys Ther, v. 80, n. 9, p. 896-903, 2000.

STUDER, M. Rehabilitation of Executive Function: To Err is Human, To Be Aware Divine, JNPT, v. 31, p. 128-134, 2007.

STUSS, D.T.; ALEXANDER, M.P. Executive functions and the frontal lobes: a conceptual view. Psychol Res, v. 63, p. 289-298, 2000.

SZAMEITAT, A.J. et al. Localization of executive functions in dual-task performance with fMRI. J Cog Neuroscience, v.14, p. 1184-1199, 2002.

VAN IERSEL, M.B. et al. Executive functions are associated with gait and balance in community-living elderly people. J Gerontol, v. 63A, n. 12, p. 1344-1349, 2008.

TEIXEIRA, N. B.; ALOUCHE, S. R. O desempenho da dupla tarefa na doença de Parkinson. Rev bras fisioter, v. 11, n. 2, p. 127-132, 2007.

VERGHESE, J. et al. Walking while talking: effect of task priorization in the elderly. Arh Phys Med Rehabil, v. 88, n. 1, p. 50-53, 2007.

WICHMANN, T.; DOSTROVSKY, J.O. Pathological basal ganglia activity in movement disorders. Neuroscience, v. 198, p. 232-244, 2011.

WYLIE, S.A. et al. The effect of Parkinson's disease on interference control during action selection. Neuropsychologia, v. 47, p. 145-157, 2009.

WOOLLACOTT, M.; SHUMWAY-COOK, A. Attention and the control of posture and gait: a review of an emerging area of research. Gait Posture, v. 16, p. 1-14, 2002.

WU, T.; HALLET, M. Neural correlates of dual task performance in patients with Parkinson's disease. J Neurol Neurosurg Psychiatry, v. 79, p. 760-766, 2008

WU, T.; HALlETT, M. Dual task interference in Parkinson's disease. Eur Neurol Rev, v, 4, p.34-37, 2009. 
YANAGISAWA, N. Natural history of Parkinson's disease: From dopamine to multiple system involvement. Parkinsonism Relat D, v. 12, S40-S46, 2006.

YOGEV, G. et al. Dual tasking, gait rhythmicity, and Parkinson's disease: which aspects of gait are attention demanding? Eur J of Neurosci, v. 22, p. 1248-1256, 2005.

YOGEV, G.; HAUSDORFF, J.M.; GILADI, N. The role of executive function and attention in gait. Mov Disord, v. 15, p. 329-472, 2008.

YOGEV, G., et al. How does explicit prioritization alter walking during dual-task performance? Effects of age and sex on gait speed and variability. Phys Ther, v. 90, p. 177-186, 2010.

ZGALJARDIC D. J. et al. A review of the cognitive and behavioral sequelae of Parkinson's disease: relationship to Frontoestriatal circuitry. Cog Behav Neurol, v. 16, p. 193-210, 2003.

ZGALJARDIC, D.J. et al. An Examination of executive dysfunction Associated with frontostriatal circuitry in Parkinson's Disease. J Clin Exp Neuropsyc, v. 28, p. 11271144, 2006.

ZILSTRA, A. et al. Do dual tasks have an added value over single tasks for balance assessment in fall prevention programs? A mini-review. Gerontology, v. 54, p.40-49, 2008. 
ANEXO A - APROVAÇÃO DO PROJETO PELO COMITÊ DE ÉTICA

\begin{tabular}{|c|c|c|c|c|c|c|c|c|}
\hline \multicolumn{9}{|c|}{ [o Andamento do projeto - CAAE - 0368.0.251.000-11] } \\
\hline \multicolumn{9}{|c|}{$\begin{array}{l}\text { Título do Projeto de Pesquisa } \\
\text { Avaliação do desempenho de pacientes com Doença de Parkinson em situações de dupla tarefa }\end{array}$} \\
\hline Situação & \multicolumn{2}{|c|}{ Data Inicial no CEP } & \multicolumn{2}{|c|}{ Data Final no CEP } & \multicolumn{2}{|c|}{ Data Inicial na CONEP } & \multicolumn{2}{|c|}{ Data Final na } \\
\hline Aprovado no CEP & \multicolumn{2}{|c|}{$30 / 05 / 201111: 22: 48$} & \multicolumn{4}{|c|}{ 10/06/2011 11:41:12 } & & \\
\hline \multicolumn{2}{|l|}{ Descrição } & \multicolumn{2}{|c|}{ Data } & \multicolumn{2}{|c|}{ Documento } & No do Doc & & c \\
\hline \multicolumn{2}{|c|}{1 - Envio da Folha de Rosto pela Internet } & \multicolumn{2}{|c|}{ 18/05/2011 21:37:09 } & \multicolumn{2}{|c|}{ Folha de Rosto } & FR429754 & & F \\
\hline \multicolumn{2}{|c|}{2 - Recebimento de Protocolo pelo CEP (Check-List) } & \multicolumn{2}{|c|}{$30 / 05 / 201111: 22: 48$} & \multicolumn{2}{|c|}{ Folha de Rosto } & 0368.0 .251 .0 & $00-11$ & c \\
\hline \multicolumn{2}{|c|}{3 - Protocolo Aprovado no CEP } & \multicolumn{2}{|c|}{ 10/06/2011 11:41:12 } & \multicolumn{2}{|c|}{ Folha de Rosto } & $334 / 11$ & & $c$ \\
\hline
\end{tabular}




\section{ANEXO B - MINI EXAME DO ESTADO MENTAL - MMSE}

(Folstein, Folstein \& McHugh, 1975)

Paciente:

Idade: Escolaridade (em anos):

Data da Avaliação: Avaliador:

\section{ORIENTAÇÃO - 10 pontos}

Dia da semana (1 ponto)

Dia do mês (1 ponto)

Mês (1 ponto)

Ano (1 ponto)

Hora aproximada (1 ponto)

Local específico (andar ou setor) (1 ponto)

Instituição (residência, hospital, clínica) (1 ponto)

Bairro ou rua próxima (1 ponto)

Cidade (1 ponto)

Estado (1 ponto)

\section{MEMÓRIA IMEDIATA (RETENÇÃO) - 3 pontos}

Fale 3 palavras não relacionadas. Posteriormente pergunte ao paciente pelas 3 palavras. Dê 1

ponto para cada resposta correta:

VASO, CARRO, JANELA

Depois repita as palavras e certifique-se de que o paciente as aprendeu, pois mais adiante você irá

perguntá-las novamente.

\section{ATENÇÃO E CÁLCULO - 5 pontos}

$\square$ Calcular a subtração (100-7) 5 vezes sucessivamente (1 ponto para cada cálculo correto $\square$ Alternativamente, soletrar MUNDO de trás para frente.

\section{EVOCAÇÃO (MEMÓRIA) - 3 pontos}

Pergunte pelas 3 palavras ditas anteriormente (1 ponto por palavra)

\section{LINGUAGEM - 9 pontos}

Nomear um relógio e uma caneta (2 pontos)

Repetir "nem aqui, nem ali, nem lá" (1 ponto)

Comando: "pegue este papel com a mão direita, dobre ao meio e coloque no chão" (3 pontos)

Ler e obedecer: "feche os olhos" (1 ponto)

Escrever uma frase (1 ponto)

Copiar um desenho (1 ponto)

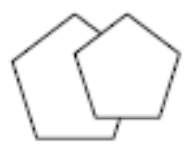




\section{ANEXO C - ESCALA DE ESTADIAMENTO DE HOEHN \& YAHR}

- Estágio 0 = Nenhum sinal da doença;

- Estágio 1 = Doença unilateral;

- Estágio 2 = Doença bilateral sem comprometer o equilíbrio;

- Estágio 3 = Doença bilateral de leve a moderada; alguma instabilidade

- postural; fisicamente independente;

- $\quad$ Estágio 4 = Incapacidade grave; ainda capaz de andar e ficar ereto sem

- ajuda;

_ Estágio 5 = Preso a cadeira de rodas ou ao leito; necessita de ajuda 


\section{ANEXO D - ESCALA DE DEPRESSÃO GERIÁTRICA - GDS 15}

(Almeida \&, Almeida, 1999)

1. Está satisfeito (a) com sua vida? (não $=1)(\operatorname{sim}=0)$

2. Diminuiu a maior parte de suas atividades e interesses? $(\operatorname{sim}=1)($ não $=0)$

3. Sente que a vida está vazia? $(\operatorname{sim}=1)($ não $=0)$

4. Aborrece-se com frequiência? $(\operatorname{sim}=1)($ não $=0)$

5. Sente-se de bem com a vida na maior parte do tempo? $($ não=1) $(\operatorname{sim}=0)$

6. Teme que algo ruim possa lhe acontecer? $(\operatorname{sim}=1)($ não $=0)$

7. Sente-se feliz a maior parte do tempo? $($ não=1) $(\operatorname{sim}=0)$

8. Sente-se freqüentemente desamparado $(a)$ ? $(\operatorname{sim}=1)($ não $=0)$

9. Prefere ficar em casa a sair e fazer coisas novas? $(\operatorname{sim}=1)($ não $=0)$

10. Acha que tem mais problemas de memória que a maioria? $(\operatorname{sim}=1)($ não $=0)$

11. Acha que é maravilhoso estar vivo agora? $($ não=1) $(\operatorname{sim}=0)$

12. Vale a pena viver como vive agora? $($ não $=1)(\operatorname{sim}=0)$

13. Sente-se cheio(a) de energia? (não=1) $(\operatorname{sim}=0)$

14. Acha que sua situação tem solução? $($ não=1) $(\operatorname{sim}=0)$

15. Acha que tem muita gente em situação melhor? $(\operatorname{sim}=1)($ não $=0)$

Avaliação:

$0=$ Quando a resposta for diferente do exemplo entre parênteses.

$1=$ Quando a resposta for igual ao exemplo entre parênteses.

Total $>\mathbf{5}=$ suspeita de depressão

Yesavage 